\title{
Los mapuchismos en el DRAE
}

\author{
Gilberto Sánchez Cabezas* \\ Universidad de Chile
}

\begin{abstract}
Resumen
Este artículo trata del léxico proveniente del idioma mapuche (mapudungun(n) contenido en la última edición (vigésimo segunda) del Diccionario de la Real Academia Española (DRAE). Se propone la voz mapuchismo(s) para dicho léxico, así como ya existe guaranismo, mayismo, nahuatlismo o aztequismo y quechuismo para el que procede de las correspondientes lenguas amerindias. Desde que se produjo el contacto entre el pueblo mapuche y los conquistadores españoles (1540), comenzó a incorporarse en la lengua de estos últimos léxico referido al medio ambiente natural local, y a la cultura autóctona. Por ello, una parte importante del léxico del español de Chile que se refiere a la flora (boldo, canchalagüa, luma, mañío, peumo, etc.), a la fauna (chuncho, coipo, loica, peuco, tiuque, etc.), a la alimentación (cancato, curanto, pirco, ulpo, etc.), al cuerpo humano (guata, charcha, trutro o tuto), al origen geográfico de los habitantes (colchagüino, curicano, penquista, rancagüino, talquino, etc.) es de origen indígena. Tal léxico no solo se ha empleado en la lengua coloquial y familiar, sino también en la culta formal escrita: en las crónicas coloniales, en los tratados de historia, en tratados científicos de botánica, zoología, geografía, en obras literarias (desde La Araucana hasta el presente), en textos
\end{abstract}

\footnotetext{
*Para correspondencia dirigirse a: Gilberto Sánchez C. (gsanchez@uchile.cl), Departamento de Lingüística, Facultad de Filosofía y Humanidades, Universidad de Chile, Av. Ignacio Carrera Pinto 1025, tercer piso, Ñuñoa, Santiago, Chile.
} 
escolares, etc., y actualmente en los medios de comunicación. La lengua mapuche pervive igualmente en la abundante toponimia del país (desde la IV ${ }^{\mathrm{a}}$ hasta la XI ${ }^{\mathrm{a}}$ Regiones) e, incluso, en la antroponimia (con nombres como Caupolicán, Guacolda, Lautaro, Millaray, Tucapel). En el artículo se trata de recuperar, en la medida de lo posible, la forma original del léxico, la cual aparece ya alterada en los escritos coloniales, hecho que se constata también en la actualidad. Para ello se ha recurrido a los léxicos de la lengua vernácula, tanto del pasado como del presente.

Palabras clave: léxico de origen mapuche (mapuchismo), fitonimia, zoonimia autóctonas, cultura mapuche.

\title{
MAPUCHISMS IN DRAE
}

\begin{abstract}
This article deals with lexical items coming from Mapuche (Mapudungun(n) present in the latest edition (twenty second) of Diccionario de la Real Academia Española (DRAE). The expression mapuchismo(s) is proposed to refer to them, following the already existing forms guaranismo, mayismo, nahuatlismo and quechuismo to refer to words coming from the corresponding Amerindian languages. Since contact was made between the Mapuche people and the Spanish conquistadores (1540), lexical items referring to the local natural environment and the indigenous culture were incorporated into Spanish. Because of this, an important part of the Spanish lexicon referring to flora (boldo, canchalagua, luma, mañío, peumo), fauna (chuncho, coipo, loica, peuco, tiuque, etc.), food (cancato, curanto, pirco, ulpo, etc.), the human body (charcha, guata, trutro o tuto), the geographical origin of inhabitants (colchagüino, curicano, penquista, rancagüino, temucano, etc.) is of indigenous origin. This lexicon has been used not only in the colloquial and domestic language, but also in the written educated formal variety: in colonial chronicles, in historical treatise, in scientific treatises (botanical, zoological, geographical), in literary works (from La Araucana up to now), in school textbooks, etc., and at present in mass media. The vernacular survives in the rich toponymy of the country (from the IV to the XI Regions) and even in anthroponymy (with names such as Caupolicán, Guacolda, Lautaro, Millaray, Tucapel). As far as it is possible, in this article, we intend to recover the original form of the lexical item, which is already altered in colonial writings, a fact that is also frequently
\end{abstract}


observed at present. With this purpose in mind, vernacular language lexicons from the past and the present have been resorted to.

Key words: mapuchisms in Spanish, autochthonous phytonymy and zoonymy, Mapuche culture

Recibido: 30/08/10. Aceptado: 30/09/10.

\section{INTRODUCCIÓN}

En Chile, como en otros países de América, han sido habladas lenguas originarias, diez amerindias y una polinésica. La mayoría de ellas ya se ha extinguido y algunas están, actualmente, por extinguirse. Las que aún están vigentes son el aimara (chileno), el mapuche (mapudungu(n) -llamado tradicionalmente araucano- y el rapa nui (pascuense), hablado en la Isla de Pascua. La más hablada, en el pasado y todavía en el presente, es el mapuche (mapudungu(n). Según el censo de población del año 2002, los mapuches son 604.349 (87.81 \% de la población indígena chilena), cifra que coincidiría con la existente al iniciarse la conquista de Chile, a fines de 1540. Los mapuches ocupaban la mayor parte del país, desde Coquimbo (500 $\mathrm{km}$ al norte de Santiago) hasta Chiloé (unos $1200 \mathrm{~km}$ al sur de Santiago) y, por consiguiente, contribuyeron en una alta proporción a la formación de la nacionalidad chilena. Desde que se produjo el contacto entre mapuches y españoles - poco amistoso, pues hubo una guerra interminable- las voces aborígenes fueron incorporándose al español. Ya se encuentran en las Cartas del conquistador de Chile Pedro de Valdivia que dirigió al emperador Carlos V y también en las Crónicas, desde la primera escrita por Gerónimo de Vivar, en 1558. Los nombres de los grandes toquis (generales en jefe) -Caupolicán, Lautaro, Pelantaro, etc.- fueron conocidos a través de la obra del soldado y poeta Alonso de Ercilla y Zúñiga, La Araucana, cuya primera parte apareció, en Madrid, en 1559. Las crónicas posteriores a la de Vivar abundan en antropónimos, topónimos, léxico de la organización social, de la vestimenta, de las prácticas bélicas, de la flora y de la fauna. Dado que los mapuches permanecieron independientes hasta fines del siglo XIX, conservaron también sus nombres vernáculos, usados actualmente como apellidos (Huenumán, Catrileo, Nahuelpan, Quilapán, etc.). Se ha sostenido que el léxico mapuche solo ocurre en el español oral, coloquial e, incluso, vulgar; ello no es así, pues -como ya he dicho-se registra desde 
antiguo en las crónicas, en obras históricas de la época republicana, en obras literarias, en tratados de zoología, botánica, geografía, etc. Y, en la actualidad, y con mayor frecuencia que antes, en los medios de comunicación (en la prensa escrita, por ejemplo). Hay léxico mapuche que ha sido empleado en gran parte del país (por ejemplo, cahuín, chalcha $\sim$ charcha, curiche, guata) y otro que ocurre en la zona centro sur, donde el contacto con los mapuches ha sido continuo (por ejemplo, ayecahue, meucar, percán). Ambos quedaron registrados en las obras de los lexicógrafos chilenos del siglo XIX y, sobre todo, en la gran obra del sabio alemán -radicado en Chile- Dr. Rodolfo Lenz, Diccionario etimológico de las voces chilenas derivadas de lenguas indígenas americanas (Santiago, 1905-1910); también en obras posteriores, como por ejemplo, en el Diccionario ejemplificado de chilenismos y de otros usos diferenciales del español de Chile, del profesor Félix Morales Pettorino y colaboradores (cinco volúmenes publicados en Valparaíso, entre los años 1984 y 1998. Fue reeditado en 2006, en tres volúmenes, con un total de 3382 páginas).

\section{MAPUCHISMOS QUE INCLUYE LA ÚLTIMA EDICIÓN DEL DRAE (2001)}

En primer lugar, consideramos oportuno explicar por qué empleamos en este trabajo el término mapuchismo, el cual no aparece consignado en el $\boldsymbol{D R} \boldsymbol{A E}$. Tradicionalmente la lengua de los mapuches ha sido denominada araucano. Esta es una denominación impropia, por dos razones: 1. los mapuches no se denominaron nunca así, sino che 'gente'; reche 'gente pura' y mapuche 'gente de la tierra', y su lengua fue llamada -en una primera época- chilidüngu, chillidüngu 'lengua de Chile' y, luego, mapudungu 'lengua de la tierra', mapudungun 'hablar, habla de la tierra'; el gentilicio araucano fue acuñado, sin duda, por los conquistadores españoles (a partir del topónimo Arauco, compuesto de la preposición española a y los términos mapuches rag 'greda' y ko 'agua(s)', a cuya difusión contribuyó, sin duda, Alonso de Ercilla y Zúñiga. Además, la denominación solo se refería a un grupo de mapuches, a aquellos que, según el mismo Ercilla, ocupaban un territorio de apenas veinte leguas de longitud por siete de ancho, y que se caracterizaron por su gran belicosidad para defender su tierra y su libertad. Por ello la denominación mapuche es más general y comprende a los diversos grupos que han constituido -y constituyen todavía- el pueblo mapuche. Por lo anterior, se puede - estimamos- emplear mapuchismo 
para referirse a "préstamo lingüístico de origen mapuche introducido en el español" o "vocablo o giro de origen mapuche empleado al hablar o escribir en español", etc., de acuerdo cómo el $\boldsymbol{D} \boldsymbol{R} \boldsymbol{A} \boldsymbol{E}$ define los préstamos que provienen de algunas lenguas indígenas americanas: "guaranismo. m. Préstamo lingüístico de origen guaraní introducido en el castellano" (DRAE: 791), "mayismo. m. Vocablo o giro de origen maya empleado al hablar o escribir en español" (DRAE: 997), nahuatlismo. m. Giro o modo de hablar propio y privativo de la lengua nahua // 2. Vocablo, giro o elemento fonético de esta lengua empleado en otra" (DRAE: 1060) y quechuismo. m. Palabra o giro de la lengua quechua empleado en otra lengua" (DRAE: 1271).

La última edición del $\boldsymbol{D R} \boldsymbol{A} \boldsymbol{E}$ consigna 302 voces de origen mapuche, pertenecientes a diversos campos semánticos. Es una cifra importante, dado que el mapuche nunca tuvo la relevancia, por ejemplo, del quechua, del nahuatl o del maya (quiché). Las voces son sustantivos, adjetivos (sobre todo gentilicios) y verbos. La mayor proporción de sustantivos la constituyen los fitónimos (37.41\%); luego siguen los zoónimos (23.50\%); los sustantivos incorporados en español (con derivados) -que no son ni fitónimos ni zoónimos- $(12.58 \%)$; los adjetivos gentilicios $(11.25 \%)$; los sustantivos que se refieren a elementos de la cultura mapuche $(7.61 \%)$; verbos derivados $(4.30 \%)$, adjetivos $(2.97 \%)$ y solo una interjección $(0.33 \%)$.

\section{TRANSCRIPCIÓN DEL LÉXICO}

Tradicionalmente el léxico de origen mapuche no ha sido transcrito de manera adecuada. Los nombres suelen presentarse con alteraciones -incluso deformaciones- que no se condicen con la realidad fonológica de la lengua. Los errores que contienen las crónicas coloniales continúan repitiéndose. Ellos resultan comprensibles, pues sus autores no eran ni gramáticos ni lingüistas. Quienes representaron más adecuadamente el léxico -en comparación- fueron los misioneros que compusieron Artes de las lenguas indígenas, obras que no solo contenían información sobre la estructura de las mismas, sino también doctrina católica. A este respecto, contenían oraciones, confesionarios, coplas y pláticas; también vocabularios, dos de ellos bastante extensos. Los autores coloniales de Artes sobre el mapuche lo representaron naturalmente con el alfabeto español, con algunas modificaciones, a fin de dar cuenta de las 'letras', es decir, fonemas, que eran característicos de la lengua. Así, para representar la sexta vocal /i/ (alta cerrada posterior no redondeada) emplearon ú ('u de bastardillo con 
virgulita', Valdivia), ù (Febrés y Havestadt); la realización semivocálica [ə] de /ï/ fue generalmente omitida. Tocante a los fonemas consonánticos, $/ \mathbf{t}^{\mathrm{r}} /$ (africado ápicoalveolar retroflejo áfono) fue transcrito con $\overline{\mathbf{t}}$ (Valdivia), th (Febrés) y $\mathbf{t}$ gótica (Havestadt); /y/ (resonante nasal velar sonoro), con $\overline{\mathbf{g}}$ (Valdivia), $\mathbf{g}$ (Febrés) y g gótica (Havestadt); / $/$ (fricativo velar sonoro) con ù (Valdivia), gh (Febrés) y û (u cum circumflexo, Havestadt). Sin embargo, las palabras aparecen, en muchos casos, sin las 'virgulitas', con lo cual se desvirtúa la realidad fonológica del mapuche. Los autores coloniales no emplearon una grafía especial para el fonema/./. / fricativo alveocacuminal retroflejo sonoro) y mantuvieron la grafía $\mathbf{r}$, pues, según su percepción, el sonido mapuche se asemejaba a la /r/ del español, pero 'más suave' ${ }^{\text {. Los }}$ textos presentan la grafía $\mathbf{v}$, la cual representaba probablemente un fonema labiodental fricativo sonoro, que todavía ocurre en sectores del país mapuche (por ejemplo, en el Alto Bío-Bío). También se registra la grafía b, la cual no representaba un fonema $/ \mathbf{b} /$, sino a $/ \mathbf{v} /$ (posiblemente con realizaciones [b] y [\$] , sobre todo en mapuches bilingües). Se carece de data como para dar una descripción exacta. Actualmente se registra/f/ en algunos sectores, pero debe tratarse de un desarrollo posterior, pues los misioneros advierten que la lengua no poseía /f/ (pero algunas palabras aparecen transcritas con f en la obra del P. Luis de Valdivia, lo cual indicaría un cambio fonológico en curso). Se puede afirmar, en todo caso, que los préstamos adoptados de inmediato por el español evidencian la fonología del mapuche cuando se produjo el contacto entre las dos lenguas.

Para recuperar la forma original del léxico hemos empleado, en primer lugar, los vocabularios contenidos en las obras de los misioneros jesuitas PP. Luis de Valdivia (1606), Andrés Febrés (1765) y Bernardo Havestadt (1777). También utilizamos el vocabulario contenido en el diario de viaje del capitán holandés Elías Herckman, el cual data de 1642, o sea, es el segundo más antiguo y, aunque algunas voces presentan alteraciones, son reconocibles como mapuches. Es interesante, pues contiene algunas que el Vocabulario del P. Valdivia no consigna, como, por ejemplo, ülmen y machi $^{2}$. Luego utilizamos el Diccionario Chileno Hispano del misionero

1 De la descripción del misionero A. Febrés se podría inferir que el sonido era retroflejo: "La R la pronuncian en el principio, medio, y fin de las palabras, no tan duro como nosotros en èstas Rayo, Parra; ni tan suave como èstas Para, María, Mar, sino en un medio, doblando algo la punta de la lengua arriba, o a un lado" (Arte, \# 4, p. 5).

2 Publicado por Rodolfo R. Schuller, con el título de El Vocabulario Araucano de 16421643, en Santiago (1907). En la segunda parte, el editor escribió: “Autor del Vocabulario [...] fue el oficial holandés Elías Herckmann que durante el dominio de lso Nassau en el Brasil ocupaba el puesto de gobernador de Parahyba; i que en 1642 fué agregado en calidad de 
Franciscano Antonio Hernández i Calzada, publicado en 1846. Se trata de una reproducción del léxico del misionero Andrés Febrés, pero con omisiones $\mathrm{y}$ adiciones que informan sobre el uso en la primera mitad del siglo XIX. Hemos recurrido también a léxicos modernos, como los del estudioso del mapuche Alejandro Cañas Pinochet (1911), del sacerdote chilote Francisco Javier Cavada (1914, 1921), del misionero capuchino Fray Félix José de Augusta (1916), de las Memorias de un cacique mapuche (Pascual Coña, 1930) y de los profesores mapuches Martín Alonqueo $(1985,1989)$ y María Catrileo (1995). Hemos tenido a la vista igualmente el Diccionario etimolójico de las voces chilenas de lenguas indíjenas americanas, del Dr. Rodolfo Lenz. Respecto de esa importante obra, hemos podido comprobar que su autor no revisó con detención -por alguna razón que ignoramos-el Chilidúǵu de Havestadt, obra que contiene abundante léxico perteneciente a diversos campos semánticos; tampoco pudo revisar, al parecer, el Vocabulario Chileno-Hispano de Febrés. Hemos consultado el extenso artículo del profesor Hugo Gunckel Nombres indígenas relacionados con la flora chilena (1959) y el libro del misionero capuchino P. Ernesto Wilhelm de Moesbach Botánica indígena de Chile (1999), por tratar de las plantas mapuches con sus correspondientes nombres. Para informarnos de los nombres científicos de la flora y fauna hemos consultados obras especializadas que proporcionan un conocimiento actual sobre la materia (Vid. Referencias bibliográficas) Por último, nos ha sido de utilidad nuestro propio conocimiento del léxico vernáculo, adquirido en numerosas permanencias en el país mapuche ${ }^{3}$.

vicealmirante i capitán del buque Vlissingen a la escuadra de Hendrick Brouwer, en la cual éste iba a conquistar las tierras australes. De allí, en vez del soñado oro, trajo este diccionario araucano, que fue publicado cuarenta i un años después de la gramática del P.Luis de Valdivia (primer documento sobre el mapuche) i que, por consiguiente, constituye el segundo diccionario impreso en este lengua.

Fue el inspirado vate i escitor flamenco don Gaspar van Baerle, quien, encargado de escribir los sucesos ocurridos en el Brasil durante el dominio de los Batavos en ese país, insertó los "Vocablos chilenos" en su magnífica obra: Casparis Barlaei/Rerum per octennium/in/Brasilia/ Et alibi nuper gestarum, sub Praefectura illustrissimi.Comitis I.Mavritii, /Nassoviae (sic), \&c. Comitis, /nunc Vesaliae Gubernatoris \& Equitatus Foederatorum/Belgii Ordd. sub Avriaco Doctoris. /Historia./ Grabado en madera con esta leyenda): indefessus/Amstelodami, /ex Typographeio Joannis Blaev, /MDCXLVII//"' (Schul: 67-68).

3 Abreviaturas de los nombres de autores y sus obras que contienen léxico mapuche: Vald.: Luis de Valdivia (Voc.: Vocabulario, Confes.: Confessonario, Serms.: Sermones); Herck.: Elías Herckmann; F.: Andrés Febrés (Cal:: Calepino Chileno-Hispano, Voc.: Vocabulario Hispano-Chileno, Dic.Brev.: Diccionario Breve); H.: Bernardo Havestadt (Chil.I: tomo I del Chilidúǵ $\boldsymbol{u}$, Chil.II: tomo II del Chilidúǵ $\boldsymbol{u}$ ); F.-Hern.: Andrés Febrés y Antonio Hernández i Calzada (I: primera parte mapuche-español del Diccionario Chileno Hispano, II: segunda 
Hemos consignado también el léxico mapuche que contienen las crónicas coloniales y las obras del abate Juan Ignacio Molina ${ }^{4}$, el cual aparece adaptado a la fonología y morfología del español. En las palabras fueron alterados mayomente los fonemas característicos del vernáculo; los nombres aparecen ya pluralizados en español. Las transcripciones evidencian la ausencia de algún fonema del mapuche actual como, por ejemplo, /f/. Respecto de las obras, hemos considerado el año en que los manuscritos de las mismas fueron terminados y publicados (cuando ello ocurrió), a saber: Gerónimo de Vivar (1558), Alonso González de Nájera (1614), Luis Tribaldos de Toledo (1634), Alonso Ovalle (1646), Francisco Núñez de Pineda y Bascuñán (1673), Diego de Rosales (1674), Miguel de Olivares (1782), Juan Ignacio Molina (1782, 1787), Felipe Gómez de Vidaurre (1789), Vicente Carvallo y Goyeneche (1796), Juan Pérez García (1810) .

Reproducimos textualmente las definiciones del $\boldsymbol{D} \boldsymbol{R} \boldsymbol{A} \boldsymbol{E}$, algunas de las cuales difieren de las contenidas, por ejemplo, en obras de botánica y zoología de Chile. Por nuestra parte, hemos consultado obras especializadas y consignamos los nombres científicos de plantas y animales. Sin embargo, el objetivo primario del presente trabajo es recuperar la forma más exacta posible de las voces de origen mapuche contenidas en el $\boldsymbol{D R} \boldsymbol{A E}$.

parte de la misma obra); Schul: Rodolfo R. Schuller; Cañ: Alejandro Cañas Pinochet; Cav.: Francisco J.Cavada; Aug.: Félix José de Augusta; Val.: Pedro Armengol Valenzuela; Coñ.: Pascual Coña; Gu.: Hugo Gunckel; Alon.: Martín Alonqueo; Wilh.: Ernesto Wilhelm de Moesbach; Catr.: María Catrileo. Además: L.: Lenz (DE.: Diccionario Etimológico); Rom.: Manuel Antonio Román; GH.: Diego González Holguín; Midd.: E.W. Middendorf; Sol.-A.: Francisco Solano Asta-buruaga y Cienfuegos.

${ }^{4}$ El Abate empleó las grafías del P. Febrés. Por ello, por ejemplo, el dígrafo th corresponde a tr del español: Cuthalcura [cùtralcura], Thaca=Traca, Lithi= Litri, Thili=Trili, etc.; $g$ equivalente a ng: Rugi=Rungi [Rùngi], Huigan=Huingan. Los Saggi -como es sabidofueron escritos originalmente en italiano, de acuerdo con la ortografía de esa lengua. En ella el dígrafo gn, que equivale a $\tilde{\mathbf{n}}$ del español, se mantuvo en la traducción a esta lengua; por

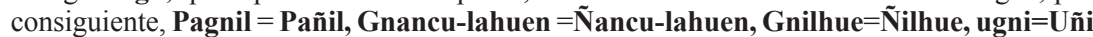
[Ùñi]. En varios nombres, en vez de ù se encuentra $\mathbf{u}$, cambio que quizá ocurrió en la imprenta.

5 Abreviaturas de los nombres de los autores coloniales: Viv: Gerónimo de Vivar; G. de Naj.: Alonso González de Nájera; Trib. de T.: Luis Tribaldos de Toledo; Ov.: Alonso Ovalle; Nuñ. de P.: Francisco Nuñez de Pineda y Bascuñán; Ros.: Diego de Rosales (I: tomo I de la Historia General del Reyno de Chile, III: tomo III de la misma obra); Oliv.: Miguel de Olivares; Mol.: Juan Ignacio Molina (I: Compendio sobre la historia natural del Reyno de Chile, II: Compendio sobre la historia civil del Reyno de Chile); Vid.: Felipe Gómez de Vidaurre; Carv. y G.: Vicente Carvallo y Goyeneche; JPG.: José Antonio Pérez García. No consignamos la Historia de todas las cosas que han acaecido en el Reino de Chile y de los que lo han gobernado (1536-1575), de Alonso de Góngora Marmolejo, y la Crónica del Reino de Chile, escrita por el capitán Pedro Mariño de Lobera, porque contienen exclusivamente antropónimos y topónimos de su época. 
En el presente trabajo representamos el léxico mapuche, del cual provienen los préstamos, con el Alfabeto Mapuche Unificado - uno de los que se emplea para escribir la lengua-, e incluimos también una transcripción fonológica exacta. No señalamos el acento de las palabras, pues, en general, no es fijo, y no es pertinente o fonológicamente relevante. Se puede afirmar que, transcurridos ya más de cuatro siglos, el mapuche ha conservado con muy pocos cambios su estructura fonológica, como también la de su morfología y sintaxis.

Respecto de la etimología de los nombres vernáculos, solo la consignamos afirmativamente cuando es verosímil. Dado que el mapuche es una lengua tardíamente documentada, no es posible recuperar, en la mayoría de los casos, el significado original de las voces. Ello se ha intentado, sin embargo, con el riesgo de entregar una interpretación falsa, ya sea de antropónimos, topónimos, fitónimos, zoónimos, etc., realizándose segmentaciones arbitrarias de los significantes de los nombres ${ }^{6}$. Al respecto, tampoco es siempre factible en una lengua como el español, cuyo antecedente histórico, el latín, es conocido desde hace más de dos milenios.

Algunas voces mapuches proceden del quechua, pero fueron incorporadas en el mapuche seguramente en tiempos precolombinos y, por ello, los hablantes ya no las sienten como extranjeras. Por consiguiente, forman parte de su acervo léxico permanente.

Respecto del léxico de origen indígena contenido en el $\boldsymbol{D R} \boldsymbol{A E}$ referido a Chile, hemos considerado las voces que pueden proceder del mapuche, aunque no estén documentadas, o la documentación es limitada; no hemos considerado unas pocas que tendrían otro origen, difícil -eso sí- de probar, por no disponerse de antecedentes lingüísticos (por ejemplo, el insecto tabolango, o el gentilicio talagantino, na, etc.).

6 La obra de Fray Pedro Armengol Valenzuela, Glosario Etimológico [...], contiene 10.445 nombres de personas, etc., con sus respectivas etimologías; muchas son fidedignas, pero también muchas, inverosímiles. También la Botánica mapuche, del misionero capuchino ErnestoWilhem de Moesbach entrega etimologías erradas; además, la trancripción mapuche de los nombres de plantas mapuches es inadecuada. No ocurre así, sin embargo, en las Memorias de Pascual Coña, recopiladas por la misma persona, y publicadas originalmente como libro con el título de Vida y costumbres de los indígenas araucanos en la segunda mitad del siglo $\boldsymbol{X I X}$, Santiago, 1930. En el prólogo y prefacio del mismo se consigna que el texto fue revisado previamente por el Dr. Lenz y Fray Félix José de Augusta, grandes conocedores de la lengua vernácula. Vid. Referencias bibliográficas. 


\section{FITÓNIMOS}

Araucaria, boldo, bollén, boqui, cachanlagua canchalagua, calchacura, callecalle, caucha, caucháu, changle, chapico, chépica, chequén, chilco, chinchín, clonqui, cóguil, coihué, coirón, coligüe colihue, colliguay, copihue, corcolén, coyán, coyocho, culén, culle, daudá, dengue, dicha, dihueñe dihueñi, doca, gargal, gualputa, guanta, guañil, guaucho, guayo, huévil, huilte, huingán, huira, huiro, lingue, litre, llaulláu, lleivún, luche, luma, maitén, mañío, maqui, nalca, natri, notro, nuño, ñipe, ñire, ñocha, palhuén, palpallén, palpi, palqui, pangue, panul, pañil, patagua, pehuén, pellín, pelú, petra, peumo, pichi, pichoa, pilapila, pillopillo, pilo, pilpil, pingopingo, pircún, pitao, piune, póquil, puya, quelenquelén, queule, quiaca, quila, quillay, quilmay, quilo, quilquil, quinchamalí, quinchihue, quintral, radal, raulí, rimu, sandialahuén, temu, tenío, tepú, tiaca, tique, tralhuén, trebo, trique, trun, tupa, uñi, uñoperquén, votri, yáquil.

“araucaria. (De Arauco, región de Chile). f. Árbol de la familia de las Abietáceas, que crece hasta $50 \mathrm{~m}$ de altura, con ramas horizontales cubiertas de hojas verticiladas, rígidas, siempre verdes, que foman una copa cónica y espesa, flores dioicas poco visibles y fruto drupáceo, con una almendra dulce muy alimenticia. Es originario de América donde forma extensos bosques [...]" (DRAE: 131).

De $\mathbf{~ r a g} / \mathbf{d a}$ /, raw /.sau / 'greda' ko/ko/ 'agua(s)': 'agua gredosa'. "Raú, barro para jarros, y con q se labã los cabellos" (Vald., Voc.); "Ragh - greda comun [...]: raghco- agua de greda, y lugar del Fuerte, que los Españoles han corrompido en Arauco" (F., Cal.: 617); "Rau, creta.rauco, aqua cretosa. Inde Arauco: nam Hispani interroganti quo vadis? respondebant hispanice $\boldsymbol{a}$ Rauco" (H., Chil. II: 768); "raq, s., la greda" (Aug. I: 194). Ko se encuentra en los diferentes léxicos y significa 'agua'.

Araucaria araucana

Araucaniaceae

"boldo. (Voz mapuche). m. Arbusto de la familia de las Monimáceas, originario de Chile, de hojas siempre verdes, flores blancas en racimos cortos y fruto comestible. La infusión de sus hojas es muy aromática y de uso medicinal" (DRAE: 225).

De voldu /volðu/, boldo /boldo/. "BOLDO, árbol. Boldo" (F.-Hern. II: 15); Boldo (Cañ.: 252); fol·o, s., el boldo [... ]" (Aug. I: 50); fol·o, el boldo (Coñ.: 88); fol'o (Gu.: 218); Foló: el boldo (Alon., 1985: 140, 1989: 121); Folo (Wilh.: 80); "folo [fo' $\underline{l} \boldsymbol{l}]$ ]: Boldo (árbol y sus frutos)" (Catr.: 112). 
En cronistas y J. I. Molina: voldu (Ros.I: 119), Boldu (Ros. I: 227); boldo (Oliv.: 38); Peumus boldus (Mol. I: 178, 200); boldo (Vid.: 159); boldu (Carv. y G.: 12).

El nombre no aparece consignado en los léxicos del mapuche de los siglos XVII y XVIII. La denominación original de la planta debe haber tenido /v/; $/ \mathbf{b} /$ se debe seguramente a influencia del español. Los nombres mapuches con /f/ representan una evolución fonética y fonológica más reciente.

\section{Peumus boldus \\ Monimiaceae}

"bollén. m. Árbol chileno, de la familia de las Rosáceas, cuya madera, que es muy dura, se emplea para hacer mangos y en la construcción de casas. Sus hojas son febrífugas // 2. Madera de este árbol" (DRAE: 226).

Probablemente de wayun /wajun/, wayen /wajen/ 'espina', 'espino'. "Huayun, espinos" (Vald., Voc.); "Huayun - el espino, y espina" (F., Cal.: 504), "Espina - huayun, caveñ " (F., Voc.: 347); "Rhamnus, rubus. Chacai, huayun" (H., Chil. I: 229), "Huaiun, sentis, spina, vepres" (H., Chil. II: 669; "HUAYUÑ . Espino, espina" (F.-Hern. I: 27); Bollen (Cañ.: 252); huayo [...] se llama también vollén (Gu.: 222, 296); "Bollen (follen), vollen, además Ниауи (Huallo) [...]" (Wilh.: 82). El nombre debe haber sido influido tempranamente por la fonología del español.

En cronistas y J. I. Molina: Bollen [...] (Ros. I: 242, III: 502, "para purgar por todas partes"); Bollén: vomitivo y purgante (Mol. I: 190); bollen (Vid.: 151, 154).

\section{Kageneckia oblonga}

Rosaceae

"boqui. m. Especie de enredadera de Chile, de la familia de las Vitáceas, cuyo tallo, que es muy resistente, se emplea en la fabricación de cestos y canastos" (DRAE: 230).

De voki /voki/, boki /boki/. "[...] thùncùl voqui - los rollos del voqui”" (F., Cal.: 652); "Boquis varios- Voqui, coghùll, nùpu, pùllpùll (F., Voc.: 317); "Boqui, copin, coull [coùll] [...] nomina erbarum quae instar polipodii arbores subeunt, iisque adhaerent, et quibus utuntur funium loco. Harum erbarum volumen. tencúl, v.g. tencul voqui, \&." (H., Chil.I: 230); "BOQUIS varios: Voqui bueno para amarrar" (F.-Hern. I: 15); Boqui (Cañ.: 252), "Voqui, s.- Las guías de ciertos galaripsos o enredaderas que crecen en lo bosques, que son fibrosas o filamentosas y por eso buenas para amarrar" (Cañ.: 329); voqui (Cav., 1914: 47,194); "foki, s., cualquiera enredadera, el boqui" (Aug. I: 50); kuduñfoki, el voqui parilla (Coñ.: 92); voqui (Gu.: 296); "foki la enredadera, el voqui" (Alon., 1989: 121); voqui ofoki (Wilh.: 76, 91, 102, 107); "foki [fo'ki] Enredadera que crece en los bosques" (Catr.: 62 ; también en 117). 
En cronistas y J. I. Molina: “Boqui $[\ldots]$ unas sogas naturales [...] largas y delgadas, flexibles y de mucha fortaleza y duración en el agua [...]" (Ros. I: 172); Voqui: liana, bejucos (Mol. I: 165, 166); Voqui (Vid.: 138); voqui: especies de yedra (Carv. y G.: 12).

\section{Cissus striata}

\section{Vitaceae}

"calchacura. (Del mapuche calcha y cura, pelo o barba de la piedra). f. Chile. Líquen semejante al islándico y de aplicación igual en medicina" (DRAE: 269).

De kalcha /kalča/ 'pelos interiores' y kura /ku.sa/ 'piedra'. "Calcha, pili interiores hominis" (Vald., Voc.); "Calcha -pelos interiores" (F., Cal.: 436); "Pilus, pili subalares, pectoris, \& caeteri interiores, calcha" (H., Chil. I: 287), "Calcha -pili interiores" (H., Chil. II: 616); "kalcha, s., el pelo de las partes pudendas" (Aug. I: 74); calchakura, líquenes (Coñ.: 107); kalčaku.ıa (Gu.: 228); Calcha-cura: pelusa de la piedra (Wilh.: 52); “kalcha ['kalča]: Pelo púbico" (Catr.: 186).

En cronista: "Calchacura es una yerbezuela que se cría entre las peñas" (Ros. I: 242, III: 502, "para llagas e hinchazones de las vías").

\section{Parmelia caperata Parmeliaceae}

"callecalle. amb. Chile. Planta medicinal de flores blancas, de la familia de las Iridáceas" (DRAE: 273).

De kallekalle /kaKekaKe/. "kallekalle, s., cierta planta de flor blanca [...]" (Aug. I: 75); "trëke callecalle, trique o callecalle (Coñ.: 94); callecalle (Gu.: 203); callecalle o trhëke (Alon.: 137); Calle-Calle (Wilh.: 69).

No está consignado en los léxicos coloniales. Podría ser que el nombre proceda de kalla $/ \mathbf{k a K a} /$ ' $m a t a '$, 'brote' o 'renuevo', reduplicado, significando 'abundancia de matas, etc.' (F., Cal.: 436 - 437).

\section{Libertia chilensis Iridaceae}

"cachanlagua. (Del mapuche cachanlahuén). f. canchalagua" (DRAE: 259). "canchalagua. (Del mapuche cachanlagua, hierba contra el dolor de costado).f. Planta anual americana, de la familia de las Gencianáceas, muy semejante a la centaura menor, pero con los tallos más delgados y las hojas más estrechas. Se usa en medicina" (DRAE: 285).

De kachan /kačan/ 'dolor de costado' y lawen /lawen/ 'remedio' " "Cachan, dolor de costado" (Vald., Voc.); "Cachan - dolor de costado: Cachan lahuen - la Centaurea, hierba conocida, amarga y fresca" (F., Cal.: 433), "Lahuenqualquiera hierbas medicinales, ò cualquiera remedio, ò medicina [...]" (F., Cal.: 528); "Simplicia ampiñ lahuen [...] Centauria minor, cachanlahuen [...] (H., Chil. I: 236-237), "Cachan, pleuritis, cachanlahuen, centauria 
minor" (H., Chil. II: 614); "kachánl·awen, s. c., yerba centaurea (muy amarga), conocida con el nombre de cachanlahue [...]" (Aug. I: 71); kachanl·awen, el cachanlahue (Coñ.: 100); cachanlahua, cachanlahuén (Gu.: 202); "Kachanlawen el cachanlahue" (Alon., 1989: 129); el Cachanlahuen (Cachanlagua) (Wilh.: 101).

En cronistas y J. I. Molina: Cachalaguen [cachalagüen] (Ros. I: 235, III: 502, "para dolor de costado"); Cachanlahuen, canchalagua: "yerba contra el dolor de costado" (Mol. I: 155); canchalagua (Oliv.: 38); cachanlahuen: "yerba contra el mal de puntada" (Vid.: 123); canchalagua: centaura menor (JPG.: 18). El P. Havestadt tradujo kachan por 'pleuritis', voz que en latín significa 'inflamación de la pleura' y también 'dolor de costado'.

\section{Centaurium cachanlahuen Gentianaceae}

"caucha. f. Chile. Especie de cardo de hojas lanceoladas, de $20 \mathrm{~cm}$ de longitud. Se usa como antídoto de la picadura de la araña venenosa" (DRAE: 327).

Probablemente de kawchu /kauču/ 'mucho', 'demasiado'. "Cauchu -mucho con exceso, demasiado [...]" (F., Cal.: 440): "Cauchu, multus.Cauchun, esse multos" (H., Chil. II: 619); "CAUCHU. Mucho con exceso o demasiado" (F.-Hern. I: 7); "Cauchu, s.-Planta de los campos que florece en forma de pirámide" (Cañ.: 254); kauchu, el cauchu (Coñ.: 96); kawča (Gu.: 230); "caucha: la voz cauchu alude a solitario y soberbio" [...] (Wilh.: 99). Kawchu significa también 'soltero, ra'.

\section{Eryngium rostratum Umbelliferae}

"caucháu. m. Chile. Fruto de la luma, semejante en la forma y gusto a la murtilla" (DRAE: 327)

De kawchawe /kaučawe/, kawchaw /kaứčuu/. "Cauchao, s.-, El fruto del árbol llamado luma" (Cañ.: 258); Cauchahue (s.m.). Fruto comestible del myrtus luma [...]" (Cav. 1914: 310); "ka mëlei luma [...] kauchawe pinei ñi fən [...] la luma, cuyo fruto es el cauchau" (Coñ.: 88); kawčawe, cauchao, cauchau: Nombre map. del fruto de la luma (Gu.: 230).

En cronista: "El cauchau es el fruto de la luma" (Oliv.: 37).

Amomyrtus luma

Myrtaceae

"changle. m. Planta parásita, especie de hongo que crece en algunos árboles. Es comestible" (DRAE: 350).

De changdu /čanðu/, changdi /čanði/. "Chagdu-unos hongos que nacen en los robles como manitas" (F., Cal.: 442); "CHAGDU CHANGHLE. Hongos que nacen en la tierra, no en los árboles" (F.-Hern. I: 8); chaydi, el changle (Coñ.: 106); "chaydi, s., ciertos hongos comestibles, conocidos 
con el nombre de chandi. Termina en muchos dedos en lugar del sombrero" (Aug. I: 16): chaydi, el changle (Coñ.: 106); changle (Gu: 208); “Changdi (Changle): dedo, un hongo codiciado de exquisito sabor [...]" (Wilh.: 52). Podría relacionarse con changüll /čajï $\mathbf{K} /$ 'dedo(s)', o bien provenir del verbo changün /čanïn/ "haber partes, ò ramitos, ser ramoso, ò copioso [...] (F., Cal.: 442).
Clavaria sp.
Clavariaceae

“chapico. m. Chile. Arbusto solanáceo, siempre verde, con hojas espinosas que se usan para teñir de amarillo" (DRAE: 351).

$\mathrm{Al}$ parecer, de trapi / $\mathbf{t}^{\mathrm{r}} \mathbf{a p i}$ / 'ají' y ko /ko/ 'agua': 'agua de ají', por su savia amarga y picante. Se denomina también taique, michai blanco y trautrau (Gu.: 208, 312); los mismos nombres en Wilh. (101).

Desfontainia spinosa Desfontainiaceae

"chépica. f. Chile. grama (// planta gramínea)" (DRAE: 355).

De chedpika/čeðpika/, chepika/čepika/. "Chedpica - la grama hierba" (F., Cal.: 446), "Grama-chepidca" (F., Voc.: 354); "Agrestes herbae. Relahuen [.... ] sagmen, chepica" (H., Chil. I: 239), "Chepica, gramen" (H., Chil. II: 623); chépica (Cav., 1914: 49); "chepika, s., la grama o chépica (pasto)" (Aug. I: 20); “chepidca v. walom raki”' (Gu.: 209); chedpica (Wilh.: 62).

En cronistas: chepica (Ros. I: 240, III: 501, 502, "para apostemas"); "chepica" (Oliv.: 38).

\section{Paspalum vaginatum Gramineae}

"chequén. (Del mapuche chequeñ). m. Chile. Especie de arrayán, de hojas elípticas, de igual color por ambas caras y con puntitos en la interna" (DRAE: 355).

De chekeñ /čeken/, cheken /čeken/. "chequeñ, arrayan" (Vald., Voc.); "Chequeñ-arrayan blanco, mirtus" (F., Cal.: 447); "[...] ruscus, chequeñ " (H., Chil. I: 229); "Chequen, s. Arbusto de los campos del sur. También se llama chequeñ" (Cañ.: 267); "chekeñ, s., cierto arbusto mirtáceo [...]" (Aug. I, suplemento: 4); chekeñ, el chequén (Coñ.: 91); chequén (Gu.: 209); chequén (Wilh.: 95). Ha sido llamado también arrayán blanco.

Luma chequen

Myrtaceae

"chilco. (Del mapuche chillco). m. Chile. Fucsia silvestre" (DRAE: 357). De chillko/čiKko/, chilko/čilko/ 'acuoso', 'aguachento'. "Chilcon-estar aguanoso" (F., Cal.: 448); "Chilcon, aquosum esse" (H., Chil. II: 624); "CHILLCO. Yierba fresca medicinal y sirve para teñir sus mantas" (F.-Hern. I: 10); "chillko, s., fucsia (arbusto)" (Aug. I: 23); chillko, el chilco (Coñ.: 
91); "chilko= el chilco, medicinal" (Alon., 1985:139), "chillko aguanoso, insípido, lleno de agua" (Alon., 1989: 28); chilco (Gu.: 210); "Chillco: aguachento (el fruto) [...] el chilco, o la "fucsia", arbusto arborescente de gran dispersión geográfica [...]” (Wilh.: 97); “chillko [čiK'ko] : [...] Arbusto conocido con el nombre de fucsia o chilco" (Catr.:117).

En cronistas y J. I. Molina: chilco: "para el mal de orina es la mejor medicina que se halla" (Ros. I: 230,); Thilco, arbusto: sirve para teñir de negro (Mol. I: 168); chilco "que los españoles llaman jazmín encarnado" (Carv. y G.: 12).

\section{Fuchsia magellanica}

Onagraceae

"chinchín' ${ }^{1}$ m. Chile. Arbusto siempre verde de la familia de las Poligaláceas, de hojas mellizas y de dos bayas, flores en espigas de color amarillo, a veces olorosas" (DRAE: 359).

De chinchin /činčin/, chinchiñ /činčij/. "Puchinchin, arboleda de vnos arboles que llaman chinchin" (Vald., Voc.); Chinchin [...] (Cañ.: 268); "Chinchin - Es remedio emenagogo" (Cav., 1914: 190, tb. 46; 1921:42); "chiñchíñ, s., arbusto conocido con este mismo nombre [...]" (Aug. I: 23); chinchín (arbusto), el chinchín (Coñ.: 90); chiñ-chin (Gu.: 211); chiñchiñ (Wilh.: 93).

\section{Azara microphylla}

Flacourtiaceae

"clonqui. m. Chile. Planta muy común semejante a la arzolla" (DRAE: 386).

De konkül /konkïl/, konküll /konkïK/. "Concùll- sepa cavallo hierba" (F., Cal.: 460); "Simplicia. ampiñ lahuen [...] concll" (H., Chil. I: 236-237), "Concùll. herb" (H., Chil. II: 633); conquil (Cañ.: 261); Conquil (Cav., 1914: 315, 1921: 30); koykëlli, el conquil (Coñ.: 103); Clonqui (Gu.: 204); "Concüll (Conquëli), el Clonqui, "abrochillo" o "cepacaballo", molesta maleza de los cultivos, con delgadas espinas tricúspides a cada lado de las hojas" (Wilh.: 111).

\section{Xanthium spinosum Compositae}

"cóguil. (Del mapuche coghull). m. Chile. Fruto comestible del boqui" (DRAE: 393).

De koül /koïl/, kowüll /kowïß/. "Coghùll - cierto boqui muy bueno, y una fruta como pepinos, que da, y se come" (F., Cal.: 457); "coull" [coùll] (H., Chil. I: 230); "Coùll, herb.” (H., Chil. II: 634); "COGHÙLL. Cierto boqui, y su fruta como pepinos que se comen" (F.-Hern. I: 13); Coguil (Cañ.: 259); "kowall, s., la fruta del nüpufoki, los cóguiles" (Aug. I: 96), "cóguil, m. (del araucano; fruto de nüpu foki) kowüll, kowall, koül' (Aug. 
II: 73); Coguil, enredadera de los bosques, que da flores moradas y un fruto conocido" (Cañ.: 259); kowüll, los cóguiles (Coñ.: 92); cóguil (Gu.: 204); "[...] el voqui cogüil o la "cogüilera"; cogüil (coile) es además designación del fruto comestible [...]" (Wilh.: 78); “kowüll [ko'wic]: Cóguil o fruto del boqui o voqui" (Catr.: 121).

En cronistas y J. I. Molina: $\operatorname{cogùl}$ (Mol.: 165); $\boldsymbol{c o g u l}$ (es voqui) (Vid.: 138); coguill, verde todo el año (Carv. y G.: 12).

\section{Lardizabala biternata Lardizabalaceae}

“coguilera.f. Chile. boqui'” (DRAE: 393). Vid. supra.

"coihué, (De or. mapuche).m. Arg. y Chile. Árbol de la familia de las Fagáceas, de gran porte y amplia copa ovoide, con hojas coriáceas y persistentes" (DRAE: 394). Tb. coihue (DRAE: ibíd).

De koywe /koi we/. "Coyhue - otro árbol como roble" (F. Cal.: 458); "Robur [...] coyue" (H., Chil. I: 229), “Coyue, arb.” (H., Chil. II: 632); “COYHUE. Arbol como roble" (F.-Hern. I: 13); coihue (Cav., 1914: 47); "koiwe, s., el coigüe, coihue (árbol) [...]" (Aug. I: 91); Coihue (Cañ.: 260); koiwe, el coigüe (Coñ.: 87); coihue (Gu.: 205); "koiwe = el coigüe" (Alon., 1985: 140); Coihue (Wilh.: 72). En Chile no se llama coihué.

Nothofagus dombeyi Fagaceae

“coirón. m. O. Arg. y Chile. Planta xerofila, de la familia de las Gramíneas, que alcanza los $50 \mathrm{~cm}$ de altura, de hojas duras y punzantes, de color verde amarillento. Se emplea para techar chozas y constituye un importante recurso forrajero" (DRAE: 394).

De koyron /koi..ın/. "Gùtan - la hierba, aplicanlo especialmente al coiron" (F., Cal.: 502); "Coyron - gùtan" (Feb., Voc.: 330); "Agrestes herbae. Relahuen [...] gramen, coiron, gùtan" (H., Chil. I: 239); coirón (Cav., 1914: 47); Coiron (Wilh.: 62).

En cronista: "El coiron es muy conocido por ser tan semejante al Exparto [...]" (Ros. I: 243; III: 502, "para la hinchazón del liti”).

Quizá originalmente el nombre no es mapuche. Actualmente parece ser más común el nombre ngütan /nïtan/.

Festuca spp.

Gramineae

“coligüe. (Del mapuche coliu). m. Arg. y Chile. colihue" (DRAE: 398). "colihue.m. Arg. Planta de la familia de las Gramíneas, cuyas cañas son rectas, de corteza lisa y muy resistente. Con ellas se hacían lanzas, y tienen hoy un cierto uso en la fabricación de muebles" (DRAE: 398). 
De kuliw/kuliu/, kolew/koleu/. "Culiu, coleo, cañas brauas" (Vald., Voc.); "Culiu - cañas bravas gruesas, como las de Buenos Ayres; las llamadas colehues, son rùgi" (F., Cal.: 464); "Arundo, calamus, canna, coleu, rgi, rùgi, rugl [rùgl]" (H., Chil. I: 230); culeu (Cañ.: 262); colihue (Cav., 1914: 46); rëyi kuliu, el colihue (Coñ.: 92); colihue; variantes regionales: Colihue, colehue, coleu, coleo (Gu.: 205); Rëngi, coliu (Wilh.: 64).

En cronistas y J. I. Molina: "[...] unas cañas que llaman trabas o coleos, de que abundan sus montes [...]" (G. de Náj.: 28, 95); coleo: cañas bravas (Nuñ. de P.: 521); culeu: cañas bravas (Ros. I: 175, 198); coligües: cañas para pescar; cañaveral de caña brava (Oliv.: 35, 259); coliu: caña sólida; se usa para pescar (Mol. I: 163,243); coliu: caña brava (Vid.: 137); coliu: cañas (Carv. y G.: 11).

\section{Chusquea culeou}

Gramineae

"colliguay. (De or. mapuche). m. Chile. Arbusto euforbiáceo cuya leña, al quemarse, exhala un olor agradable. Tiene hojas alternas, lanceoladas, aserradas, coriáceas y pecioladas. Su altura total es de un metro, y el jugo de su raíz venenoso" (DRAE: 399).

De kolliwayu /kohiwayu/, kolï/koli/, koli/koli/, kollü /koSï/, kolli /kohi/ 'colorado'; 'pardo', 'castaño' y wayun /wajun/ 'espino', 'espina', 'espino colorado' " Colli-colorado, v. colù, ò colli-color bermejo, colorado: aplicanlo al color pardo, y al castaño de los cavallos [...]" (F., Cal.: 459); "Colù, color heluus, ravus" (H., Chil. II: 632), "Huayun -el espino, y espina" (F., Cal.: 504), "Espino-huayun, caveñ " (F., Voc. Br.: 347); "Huaiun, sentis, spina, vepres" (H., Chil. II: 669); “wayun, s., la espina (vegetal), el espino" (Aug. I: 246); coliguay (Gu.: 205); Colliguayu (Wilh.: 88).

En cronistas y J. I. Molina: Coliguai: "su raíz produce una leche muy venenosa" (Ros. I: 118, 239, 243, III: 502: "veneno para las flechas"); colliguai (Oliv.: 38); Colliguay (Mol. I: 168,169).

\section{Collihuaja integerrima}

Euphorbiaceae

"copihue. (Del mapuche copiu). m. Planta ornamental de tallo voluble, de la familia de las Liliáceas, que da una flor roja, a veces blanca, y una baya parecida al ají antes de madurar. Es originaria de la zona austral de América Meridional" (DRAE: 440).

De kopiw /kopiun/, kopiwe/kopiwe/. "Copiu, vna yerua de comer" (Vald., Voc.); "Copiu - una fruta como agí" (F., Cal.: 461); "COPIU. Pepinos, fruta como el ají verde" (F.-Hern. I: 14); "kopiu, kopiwe, s., la fruta de kolkópiu" (Aug. I: 95); kolkopiu, el copihue (Coñ.: 92); Copihue [...] del map. kopiu, nombre de la planta y del fruto" (Gu.: 206); "Kopíu= el fruto del copihue" (Alon., 1985: 139); “Сopiu, copihue [...] El vocablo copiu 
alude más precisamente al fruto, una baya gruesa, alargada, de pulpa dulce y comestible, vulgarmente llamada "pepino [...]" (Wilh.: 68).

En crónicas y J. I. Molina: Copiu (Mol. I: 165); сорiu (Vid.: 138); сорiu (Carv y G.:12).

Es la flor nacional de Chile.

\section{Lapageria rosea}

Philesiaceae

"corcolén. m. Chile. Arbusto siempre verde, de la familia de las Bixáceas, parecido al aromo por sus flores, aunque menos oloroso" (DRAE: 443).

De korkolen /ko.kolen/. "korkolen, s., cierto arbusto de flores amarillas [...]" (Aug. I: 95); corcolen (Gu.: 206); "Pëdwe o korkolen" (Alon., 1989: 141); Corcolén (Wilh.: 93). Se llama también püdwe/pïðwe/ (Aug. I: 173). Azara spp.

Flacourtiaceae

"coyán. m. Chile. Especie de haya" (DRAE: 458).

De koyam /kojam/ 'roble'. "Coyam - el roble" (F., Cal.: 457), "Roble - coyam [...]" (F., Voc.: 396); "Robur, coyam" (H, Chil. I: 229), "Coiam, robur arb." (H., Chil. II: 631); “COYAM. Roble, o pellín” (F.-Hern. I: 12); “koyam, s., el roble chileno" (Aug. I: 96); koyam, el roble (Coñ.: 87); koyam; variante regional: coyán (Gu.: 232); "Koyam = el roble" (Alon., 1985: 140, 1989: 95); "Coyam [...] vulgarmente roble chileno, aunque tal designación no es muy acertada. Roble significa Quercus, no Fagus, encina, no haya [...]" (Wilh.: 72); "koyam [ko'yam]: [...] Roble" (Catr.: 112).

\section{Nothofagus obliqua}

Fagaceae

“coyocho. m. Chile. nabo (// planta crucífera). // 2. Chile. Raíz de esta planta" (DRAE: 458).

De koyocho /kojočo/ 'la raíz del nabo'. "Coyocho - raíz de nabo" (F., Cal.: 458); "Radix raparum, coyocho" (H., Chil. I: 236), "Coyocho, napi, raparum radices” (H., Chil. II: 634); “COYOCHO. Nabos” (F.-Hern. I: 13); “koyotro, s., (probablemente, no es palabra indígena) el coyocho, bulbo de yuyo" (Aug. I: 96). Según Lenz, es imposible que provenga del quechua (DE.: 216).

"culén (De or. mapuche). m. albahaquilla de Chile" (DRAE: 481).

De kulen /kulen/. "Culen - el culen, ò albaquilla" (F., Cal.: 464); "Simplicia ampiñ lahuen [...] Culen [...]" (H., Chil. I: 237), "culen, herb" (H., Chil. II: 636); “CULEN. Arbusto así llamado" (F.-Hern. I: 14); "Culén, s.- Arbusto muy útil en la medicina casera [...]" (Cañ.: 262); "kulen, s., el culén o albaquilla [...]" (Aug. I: 98); kulen, la albaquilla o culén (Coñ: 90); culén (Gu.: 206); "kulen = culén medicinal y estomacal" (Alon., 1985: 139); "Culen [...] reconocida y aprovechada ya en tiempo colonial como 
hierba medicinal por excelencia, ha conservado esta fama hasta nuestros días [...]" (Wilh.: 85).

En crónicas y J. I. Molina: culen: albahaquilla (Ov.: 22); “[...] porque estaba sembrado de espesos arbolillos de culenes, que nosotros llamamos "albahaquillas del campo" (Nuñ. de P.: 343 - 344); culen (albaquilla) "es provechosísimo para muchos remedios" (Ros. I: 235, III: 502, "para heridas y almorranas"); culén: "árbol pequeño" (Oliv.: 38); Culén (Mol. I: 173, 174, 175); culen (Vid.: 142); culén: contra obstrucciones (JPG.: 20).

\section{Psoralea glandulosa Papilionaceae}

"culle. m. Chile. Hierba oxalídea, cuyo zumo se usa como bebida refrescante" (DRAE: 481).

De kulli /kußii/, kulle /kuie/ 'vinagrillo'. "Culle - vinagrillo hierba" (F., Cal.: 464), "Vinagrillo - culle" (F., Voc.: 412); "acetosa, culle" (H., Chil. I: 237), "Culle, herb."(H., Chil. II: 636); “CULLE. Vinagrillo, yierba” (F.Hern. I: 14); "Culli, s.- Planta anual, pequeña, cuyo zumo es muy ácido, pero agradable [...]" (Cañ.: 263); "El culli para teñir de rojo" (Cav., 1914: 48); "kulle, s., la yerba vinagrilla. Restregada con orines se toma en enfermedades del estómago y vientre; también se prepara con ella el hilo antes de teñirlo colorado" (Aug. I: 98); kulle, el culle rosado (Coñ.: 98); "culle colorado [...] Se llama, además, culli [...]" .Tb. vinagrillo (Gu.: 206 - 207);"Kulle = el vinagrillo o culle. Medicinal" (Alon., 1985: 137); Culle (Wilh.: 86).

En cronistas y J. I. Molina: Culle roxo: "excelente para los tintes, y buen específico contra las fiebres ardientes" (Mol. I: 138, 159); culli (Vid.: 131); culli: vinagrillo (Carv. y G.: 10).

\section{Oxalis rosea \\ Oxalidaceae}

"daudá. (Del mapuche daldal). Chile. contrahierba (//planta morácea)" (DRAE: 493).

De daldal /ðalðal/, dalal/ðalal/, dawda /ðaữa/. dal·al, la daudá o matagusanos (Coñ.: 104); daldal, daudá (Gu.: 214); "Daudá, dalal, dasdaqui [...] llamada vulgarmente "matagusanos"' (Wilh.: 112).

En cronista: "Daldal es una yerba conocida de todas las mujeres porque para teñir hilados la buscan" (Ros. I: 243).

\section{Flaveria contrayerba}

Compositae

“dengue 2 . m. Chile. Planta herbácea, ramosa, de hojas opuestas, ovaladas y carnosas, y flores inodoras, rojas, amarillas o blancas, pedunculadas en hacecillos terminales que se marchitan al menor contacto. // 2. Chile. Flor de esta planta" (DRAE: 505).

¿De dengüll//ðeyïß/ 'poroto'? “Degùll - porotos, frixoles” (F. Cal.: 476); 
"Degll [degùll], phaseolus" (H., Chil. II: 647); “Degüll, s. Arbusto venenoso usado por los brujos para envenenar" (Cañ.: 271);"Dengue: [...] según Gay, planta originaria del Perú, crece espontáneamente en el centro del país y produce flores rojas, sencillas [...]" (Wilh.: 76).

\section{Mirabilis jalapa}

Nyctaginaceae

"dicha². (Del mapuche dichon, dar estocada). f. Nombre vulgar de varias hierbas con hojas o frutos punzantes, que se crían en Chile" (DRAE: 553).

De dicha /ðiča/, dücha /ðiča/ 'abrojo'. "Dicha, abrojo" (Vald., Voc.); "dëcha/kachu, s.c., yerba que crece en los trigos y hiere mucho los pies [...]" (Aug. I: 31); dëcha kachu, la cizaña (Coñ.: 103); dicha (Gu.: 214); Dëcha, dëcha-cachu (Wilh.: 112). El nombre puede tener relación con el verbo dichon/ðičon/, düchon/ðï̌on/, el cual según Febrés significa “ensartar como con chuzo, ò lanza, dar estocada" (F., Cal.: 477).

En cronista: dichalaquen [dichalagüen], dichalaguen [dichalagüen] (Ros. I: 241, III: 502).

\section{Soliva sessilis \\ Compositae}

“dihueñe o dihueñi. (Del mapuche dihueñ). m. Chile. Nombre vulgar de varios hongos comestibles que crecen en algunos robles, y de los cuales, haciéndolos fermentar, obtienen los indios una especie de chicha" (DRAE: 557).

De diweñ /ðiwej/. "Dihueñ-compañero, y la fruta de los robles" (F., Cal.: 477-478); "DIHUEN. Compañero, la fruta del roble" (F.-Hern.: 19); "Dihuen, s. El fruto esponjoso del roble [...]" (Cañ.: 271); "diweñ/, s., unos hongos que crecen en los robles" (Aug. I: 33); diweñ, el dihueñe (Coñ: 106); dihueñe (Gu.: 215); "diweñ el dihuen, hongos que crecen en los robles" (Alon., 1989: 108); "Dihueñ, (Dihueñe), Pëna, Pinatra, Curacucha: llamados todos "frutos del roble o ñirre [...]" (Wilh.: 52); “diweñ [oi'wen]: Hongos comestibles que crecen en los robles" (Catr.: 121].

En cronistas y J. I. Molina: Diguen [digüen] (fruto del roble) (Ros. I: 229); dihueñes (Vid.: 148).

Cyttaria spp.

Citaraceae

“doca. (De or. mapuche). f. Planta rastrera de de Chile, de la familia de las Aizoáceas, de flores grandes y rosadas, y fruto comestible, un tanto purgante" (DRAE: 570).

De doka /doka/. "Doca, s.- Una planta rastrera que crece en las playas del mar y el fruto de la misma [...]" (Cañ.: 271); "doka+, s., la doca, una planta con las hojas gruesas, que crece por el suelo y tiene frutos comestibles y 
sabrosas, llamadas "frutillas del mar" (Aug. I: 33); doka, la doca (Coñ: 98); "doca [...] Se llama también frutilla del mar; doquilla [...]" (Gu.: 216); "Doca [...] Planta de la inmediaciones del mar, que cubre con largas guías las arenas movedizas de las dunas [...]" (Wilh.: 76).

\section{Carpobrotus aequilaterus \\ Aizoraceae}

"gargal. m. Chile. Agalla del roble" (DRAE: 758).

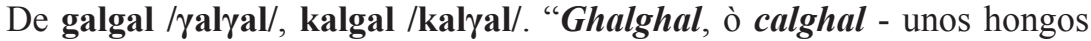
que nacen en los robles" (F. Cal.: 489), "Hongos-ghalghal" (F., Voc.: 357); "Fungus, quales annosa quercus vel robur producit, calgal" (H., Chil. I: 231), "Calgal. - fungi, qui nascuntur in arboribus, praesertim in robore" (H., Chil. II: 616); "GHAL GHAL . Hongos que nacen en los robles como manitas" (F.Hern. I: 22); "Calghal. Dan este nombre al poliporus senex de los botánicos, especie de yesca u orejas que nacen en los palos podridos de los bosques" (Cañ.: 254); "kalqal, s., (cierta clase de) hongos que nacen en los robles" (Aug. I: 75); $\boldsymbol{k a l} \cdot \boldsymbol{k a l}$, el galgal (Coñ.: 106); galgal, gargal (Gu.: 218-219); "[...] Calgal (Cargal) [...] solo este último suele comerse, ora hervido, ora asado. Son excrecencias en los troncos, de formas semiesféricas"(Wilh.: 52). Ramaria spp. Gomphaceae

"gualputa.f. Planta americana parecida al trébol" (DRAE: 789).

De walputa /walputa/, wallpütra /walpïtra/. hualputa (Cav., 1914: 49);“"allfid, allfida*, s., la arveja. /- $\boldsymbol{k a c h} \boldsymbol{u}^{*}$ s.c. la gualputra yerba (o hualputa [...])" (Aug. I: 7); wallpütra, la hualputa (Coñ.: 96); hualputa, galputra, huarputra (Gu: 220); Huallpütra (Wilh.: 85).

En crónicas y J. I. Molina: Gualputhe: trébol vulgar (Mol. I: 130); gualputa: trifolio o trébol (Vid.: 134); gualputhe: trébol (Carv. y G.: 8).

\section{Medicago spp. Leguminosae}

"guanta ${ }^{3}$ f. Chile. Planta solanácea forrajera" (DRAE: 790).

¿De wente 'la parte superior', 'sobre', 'arriba de', 'encima de', por ser planta cordillerana? "Huanta, de huente: altura [...], planta cordillerana de hojas pina-tífido-laciniadas en roseta y flores violáceas, solitarias" (Wilh.: 105). Trechonaetes laciniata

Solanacea

"guañil. m. Arbusto americano de la familia de las Compuestas, con hojas lanceoladas y flores en panoja" (DRAE: 790).

Posiblemente de wangilkülen /wanilkïlen/, wangülün /wajillïn/ 'abundar cosas agudas, paradas' (Aug. I: 243). "huañil, s.- Árbol muy conocido en el Sur" (Cañ.: 278); huañil, huiñal variante regional (Gu.: 221-222); "Huañil: nombre de varias especies medicinales [...] arbusto de hojas membranosas y 
mucronadas, las ramitas secundarias, portadoras de las cabezuelas, terminan en un fuerte punzón [...]" (Wilh.: 115). Quizá el nombre original fue wiñal /winal/ (Cf. "Huyñal - una yerba llamada assi" (F., Cal.: 518).

Proustia sp.

Compositae

"guaucho.m. Arbusto americano, de hoja menuda y gruesa, que arde aun cuando esté verde, por ser resinoso" (DRAE: 794).

De wawtru /waunt ${ }^{\mathrm{r}} \mathbf{u} /$, wawcho/waunčo/. "HUAUTHU. El romerillo cuya corteza suave sirve para lavarse la cabeza i ropa los indios" (F.-Hern. I: 27); "wautru, s., cierto arbusto [...]" (Aug. I: 246); wautru, el huaultro (Coñ: 91); wautro; variantes regionales gualtro; uautro; guaucho; vautro (Gu.: 298); "wawtro El guautro, planta medicinal" (Alon., 1989: 205); "Huautru (vautru), guaultro, Puauchu [...]" (Wilh.: 110).

En cronista: Guaucho (Ros. I: 246).

Baccharis concava

Compositae

guayo $^{1}$ (Voz mapuche). m. Chile. Árbol de la familia de las Rosáceas, de madera dura y colorada" (DRAE: 794).

De wayu /wayu/, wayun /wayun/ 'espino', 'espina'. "Huayu - un arbolito sin fruto" (F., Cal.: 504); "Arbores non fructiferae [...] hиауи [...]" (H., Chil. I: 229); "HUAYU. Un arbusto sin fruto" (F.-Hern. I: 27); "Hиауu, s. - Árbol de corteza tintórea del Sur, conocido con el nombre huayo" (Cañ.: 278); huayo (Gu.: 222). Según Wilhelm, es el mismo Bollen (follen), vollen (Wilh.: 82); también según Gunckel (ibíd).

\section{Kanegeckia oblonga}

Rosaceae

"huévil. m. Planta de Chile, de la familia de las Solanáceas, de unos $80 \mathrm{~cm}$ de altura, lampiña y de olor fétido. De su palo y hojas se extrae un tinte amarillo, y la infusión de ellos se emplea contra la disentería" (DRAE: 838). ¿De üvir /ïvis/, üvirkun /ïvi.skun/? "ùvir, herba.uvircùn, traho, attraho: plantae ex terra succum trahunt, quo aluntur" (H., Chil. II: 799); "Huévil.s.Una planta de las solanáceas, que es febrífuga" (Cañ.: 283); "Ivircún (s.m.) Yerba medicinal usada por los curanderos", (Cav., 1914: 358); "ifëlkoñ, s., el huévil (planta [...]"). (Aug. I: 65); ifëlkoñ, el huévil (Coñ.: 90); huévil (Gu.: 223); “wüfülkon El huévill” (Alon., 1989: 244); "Huévil, Ifelcón, Echuelcún [...] planta de olor fétido y de sabor muy amargo [...]" (Wilh.: 105).

En cronistas: guebul [güebul]: "para calenturas" (Ros. III: 502); huevil (Vid.:144).

Es más probable que el nombre proceda de /ïvi.s/, transformado en /wïvir/, /wévir/y, finalmente, en la forma españolizada huévil /wébil/.

Vestia foetida

Solanacea 
"huilte. m. Chile. Tallo o tronco del cochayuyo, principalmente cuando está creciendo y antes de ramificarse. Es comestible" (DRAE: 838).

¿De wülte /wilte/? Voz escasamente documentada. Huilte, tronco comestible del cochayuyo (Wilh.: 51). De las obras coloniales, se encuentra en Ovalle como ulteu, que es el tronco de raíces como la muñeca que se crían junto al luche. De esas raíces nacen los cochayuyos (60). Según Lenz, "Es evidentemente mapuche, probablemente una forma uülte o qüilte; no está en los diccionarios"( DE.: 401). El nombre mapuche actual es lümfü /lïmfï/(Aug. I: 114; Coñ: 105).

"huingán. (Voz mapuche). m. Arbusto chileno de la familia de las Anacardiáceas, de flores blancas y pequeñas en racimos axilares, y frutos negruzcos, de unos cuatro milímetros de diámetro" (DRAE: 838 - 839).

De wingan /winan/. "Huingan, s.- Árbol que da un fruto parecido a la pimienta, de que hacen una chicha" (Cañ.: 284); wëgan, el huingán (Coñ.: 89); huingán (Gu.: 225); "Huingán [...] arbusto arborescente de vasta distribución geográfica [...]" (Wilh.: 89). Es llamado también borocoi, boroco (Hoff., 1998: 56); "wingan [wi'yan]: [...] Árbol de hojas pequeñas y ramas en forma de palmera" (Catr.: 114).

En cronistas y J. I. Molina: huigan (Ov.: 78), Quigan [¿Q por G?]: "es alto y copado" (Ros. I: 229); guingan (Oliv.: 38); “Huigan" (Mol. I: 181); güinghan (árbol) (Carv. y G.: 12).

\section{Schinus polygamus}

Anacardiaceae

"huira. f. Chile. Corteza del maqui que, sola o torcida en forma de soga, sirve para atar" (DRAE: 839).

¿De wiran /wi.ıan/ 'desollar', 'descuerar', 'quitar la corteza'? "Huyran, hender" (Vald., Voc.); "Scindere, findere ligna, rian, huiran" (H., Chil. I: 518), "Huiran, scindere, findere" (H, Chil. II: 683); "Huiran, v. Desollar, descuerar, quitar la piel a los animales muertos" (Cañ.: 284).

"huiro'. m. Nombre común a varias algas marinas muy abundantes en las costas de Chile" (DRAE: 839).

De wildu /wilðu/, widu /wiðu/, wiru /wi.su/. "widu +, s., cierta alga incomestible que el mar bota en grandes cantidades" (Aug. I: 260); widu, el macrocisto gigante (Coñ.: 105); huiro (Gu.: 225); "wirrú = el huiro" (Alon., 1985: 138), "widu la alga marina comestible" (Alon., 1989: 223); "Huildu, Huiru [...] inmensa alga marina, talvez el vegetal más largo del globo [...]" (Wilh.: 51). Podría ser de origen quechua ("viru. Caña de maiz, o caña dulce" (GH.: 353); "huiru, s. el tallo, la caña de las plantas monocotiledones, la caña brava, la caña del maíz" (Midd.: 465).

Macrocystis spp.

Lessoniaceae 
"lingue (Del mapuche line). m. Árbol chileno, de la familia de las Lauráceas, alto, frondoso y de corteza lisa y cenicienta. Su madera flexible, fibrosa y de mucha duración, se emplea para vigas, yugos y muebles, y su corteza es muy usada para curtir el cuero. // 2. Corteza de este árbol" (DRAE: 937).

Del linge /line/. "Lige-un Arbol" (F., Cal.: 532); "Arbores non fructiferae [...] Lige" (H., Chil. I: 229); "Liñe, s.- El conocido lingue, que tiene bonita madera y su cáscara sirve para curtir pieles" (Cañ.: 291); "line, s., el árbol lingue [...]" (Aug. I: 115); liye, el lingue (Coñ.: 88); lingue (Gu.: 238); linge el lingue (Alon., 1989: 140); Linge o lingue (Wilh.: 79).

En cronista: Lige (Ros. I: 228).

\section{Persea lingue Lauraceae}

"litre. (Del mapuche lithe, árbol de mala sombra). m. Árbol chileno, de la familia de las Anacardiáceas, de hojas enterísimas, flores amarillas en panoja, y frutos pequeños y dulces, de los cuales se hace chicha. Su madera es tan dura, que se emplea en dientes de ruedas hidráulicas y ejes de carretas. Su sombra y el contacto de sus ramas producen sarpullido, especialmente a las mujeres y a los niños. // 2. coloq. Chile. Enfermedad producida por la sombra de este árbol" (DRAE: 940-941).

De litri /lit' ${ }^{\mathbf{1}}$ /. "Lithi - un arbol de mala sombra" (F., Cal.: 534); "Litrri, s. -El litre, árbol muy conocido" (Cañ.: 291); litri, el litre (Coñ.: 89); litre (Gu.: 239); "Litre = el litre" (Alon., 1985: 139); "Litre [...] arbusto y árbol xerófito del centro y norte [...]" (Wilh.: 89).

En cronistas y J. I. Molina: Litre: "de tan maligna sombra" (Ros. I: 227); "liti [sic]" (Oliv.: 8); Lithi (Mol. I: 186, 188); litre (Vid.: 151,153); litre (JPG.: 20).

\section{Lithraea caustica}

Anacardiaceae

"llaulláu. (Voz mapuche). m. Hongo chileno que se cría en los árboles. Es comestible y se emplea también en la fabricación de cierta especie de chicha" (DRAE: 942).

De lawlaw /laulau/, Ilawllaw / KauKau/. "Laulau, ò llaullau - fruta que da el coyhue" (F., Cal.: 530); "Laulau, llaullau, fructus coihue arboris" (H., Chil II: 693); "LLAULLAU. Fruta que da el coihue i roble" (F.-Hern. I: 40); "Llaullau (s.m.) - Hongo parásito del roble o coihue [...]" (Cav., 1914: 363); "llaullau, s., la fruta del roble coigüe [...]" (Aug. I: 121); "Ileulleu + s., la fruta del roble = llaullau" (Aug. I: 123.); lleulleu, la fruta del coihue (Coñ.: 106); llau-llau, lleu-lleu (Gu.: 242); "Ilaullau el fruto del coigüe" (Alon., 1989: 146); "[...] el Llau-Llau o Lleu-Lleu es el el "fruto" del coihue [...]" (Wilh.: 52).

Cyttaria harioti

Cytaraceae 
"Ileivún. m. Planta chilena de la familia de las Ciperáceas, que crece en terrenos húmedos y cuyos tallos se emplean para hacer lazos, atar sarmientos, plantas de jardines, etc." (DRAE: 943).

¿De lleyvun /Keivun/, lleyfun /Keifun/? lleivun, leivún (Coñ: 95-96); "Ileivun [...] El nombre tiene variantes regionales: reivun, deivún, veivun, yeigún [...]” (Gu.: 242-243); “[...] Lleifun, Ühuén, Nocha [...]” (Wilh.: $65)$.

\section{Cyperus sp.}

Cyperaceae

"luche 2 . (Voz mapuche). m. Alga marina de Chile. Es comestible" (DRAE: 949).

De luche /luče/, lluche / Kuče/. "Luche, lluche - hierba del mar, que se come" (F., Cal.: 535); "Herbae marinae, luche, lluche" (H., Chil. I: 303), "Luche, herba marina bona et comestibilis" (H., Chil. II: 698); "Luchi, s. - Musgo ó liquen que tapiza las rocas del mar [...] Es comestible" (Cañ.: 292); "luche, s., el luche, cierta alga comestible (ulva lactuca)" (Aug. I: 117); luche, el luche (Coñ.: 106); "luche [...] variante regional: luchi" (Gu.: 240); Luche o liwa = el luche (Alon., 1985: 138, 1989: 142); "Luche [...] alga clorofílica de este nombre mapuche y vulgar [...]" (Wilh.: 51-52).

En cronistas: luche: yerba a manera de escarolas (Ov.: 59); luche (Carv. y G.: 22).

\section{Porphyra columbina}

Bangiaceae

"Iuma. (Voz mapuche). f. Árbol chileno de la familia de las Mirtáceas, que crece hasta $20 \mathrm{~m}$ de altura. // 2. Madera de este árbol, dura, pesada y resistente" (DRAE: 951).

De luma /luma/. "Luma - una madera muy dura [...]" (F., Cal.: 536); "arbores non fructiferae [...] luma [...]" (H, Chil. I: 229), "Luma, arbor, cujus ligna sunt oppido gravia \& dura [...]" (H., Chil. II: 699); "LUMA A Árbol de madera muy dura" (F.-Hern. I: 39); "Luma, s. - Árbol de la familia mirtácea que da una madera fibrosa i muy fuerte; llaman lumas los instrumentos con que remueven la tierra para sembrar" (Cañ.: 292); luma (Cav., 1914: 47, 191); "Iuma, s., la luma (árbol [...])" (Aug. I: 118); luma, la luma (Coñ.: 88); luma (Gu.: 240); "Luma $[\ldots]$ = la luma; palo muy duro y medicinal [...]" (Alon., 1985: 141); luma (Gu.: 240); "Iuma [...] un arbolito del continente [...] muy estimado por su madera pesada y extraordinariamente dura. Su baya negra, llamada chauchau, fue aprovechada antiguamente en la elaboración de chicha $[\ldots]$... (Wilh.: 95).

En cronistas y J. I. Molina: Luma (Ros. I: 119, 227); la luma (Oliv.: 38); Luma (Mol.I: 180, 185); luma (árbol) (Carv. y G.: 12); luma (JPG.: 20) Amomyrtus luma

Myrtaceae 
“maitén (Del mapuche maghtén). m. Árbol chileno, de la familia de las Celastráceas, que crece hasta ocho metros de altura, de hojas dentadas, muy apetecidas por el ganado vacuno, flores monopétalas, en forma de campanilla y de color purpúreo, y de madera dura, de color anaranjado"(DRAE: 962).

De magtün /maytïn/, mayten /maiten/. "Maghtùn - el mayten arbol" (F., Cal.: 544); "Arbores non fructiferae, maiten, maùtun [maùtùn] [...]" (Chil. I: 229), "Maùtún, maiten, arb." (Chil. II: 713); “maiten, s., el árbol maitén [...] Sus hojas se refriegan y se hace con ellas una infusión fría la cual se toma con clara de huevo batida. La espuma se aplica a la cabeza" (Aug. I: 129); maiten, el maitén (Coñ.: 88); maitén (Gu.: 245 - 246); "Maiten = el maitén; es medicinal" (Alon., 1985: 141); "Maitén [...] elegante árbol de ramaje delgado y hojas finas, flores monoicas, verdosas y rosadas, y semillas aceitosas [...]" (Wilh.: 90).

En cronistas y J. I. Molina: “[...] maitenes, que son a manera de laur[e]les [...]" (Ov.: 39); Maiten (Ros. I: 224); maiten (Oliv.: 38); Mayten (Mol.I: 186, 190, 191); maiten (Vid.: 151); maitén (JPG.: 20).

\section{Maytenus boaria}

Celastraceae

“mañío. (Del mapuche mañiu). m. Chile. Árbol semejante al alerce. // 2. Chile. Madera de este árbol" (DRAE: 980).

De mañiw /majiun/. "Mañiu, s. Arbol muy apreciado por la excelente calidad de su madera [...]" (Cañ.: 299) "Mañiu (s.m.) - [...] Es madera de mucho uso en las construcciones" (Cav., 1914: 369, 1921:77); "mañiu, s., el mañiu (árbol [...])" (Aug. I: 131); mañiu, el mañío (Coñ.: 87); mañíu (Gu.: 246247); "Mañíu = el mañío" (Alon., 1985: 140); "Mañiu, mañilahual: "mañío alerce" [...] por su follaje más claro "pino blanco" [...] (Wilh.: 59).

En cronista: "El Maniu [¿mañiu?] es un árbol de especie de Alerze que se halla en la Cordillera [...]" (Ros. I: 228).

\section{Podocharpus nubigena, P. saligna}

Podocarpaceae

"maqui. (Voz mapuche). m. Arbusto chileno, de la familia de las Liliáceas, de unos tres metros de altura, con hojas aovadas y lanceaoladas, flores axilares en racimo, y fruto redondo, de unos cinco milímetros de diámetro, dulce y un poco astringente, que se emplea en confituras y helados. Los indios preparan también con él una especie de chicha" (DRAE: 981).

De maki / maki/, make /make/. "Clon - el maque arbol" (F., Cal.: 456); "Maque arbol-clon, ò cùlon" (F., Voc.: 368); "Clon, arbor dans maque, germanice Morbern" (H., Chil. I: 229); “MAQUI, árbol. Cùlon" (F.-Hern. II: 59); "Maqui, s.- En Chiloé se llama queldon, el árbol y fruto tan conocidos" (Cañ.: 299); maqui (Cav., 1914: 47); " maki, s., las bayas negras comestibles de unos arbustos, como el kal·ónkalon, kaloy y chakaiwa" (Aug. I: 129); 
"maqui [...] En Chile el nombre designa tanto la planta como el fruto (del clon)" (Gu.: 247); "Külonn = el maque. Es medicinal y es compañero fiel de una machi para la curación de la fiebre. Es muy abundante y apetecido por sus frutos" (Alon., 1985: 138); "Maki, palabra mapuche que en su significado genuino es la baya negra, llegó a eclipsar y reemplazar el nombre del arbusto arborescente" [Quëlón] (Wilh.: 91).

En cronistas y J. I. Molina: "Otros árboles se llaman maques y son muy hermosos y frescos, y sirven sus hojas (que lo son en extremo) contra quemaduras y otros accidentes que nacen de calor" (Ov.: 78); Maque (Ros. I: 224); maqui (fruto) (Oliv.: 38); Maqui (Mol.I: 180, 185); maque (Vid.: 146, 149); maque: árbol (Carv. y G.: 12); maqui: arbusto (JPG.: 20). Aristotelia chilensis Elaeocarpaceae

"nalca. (Voz mapuche). f. Chile. Pecíolo comestible del pangue. // 2. Chile. pangue" (DRAE: 1060).

De ngalka/nalka/, nalka /nalka/. "Nalca - lo que se come del pangue" (F., Cal.: 575); "nalca, page" (H., Chil. I: 230); "NALCA. Lo que se come del pangue" (F.-Hern. I: 48); "Nalca, s.- La vara del pangui, que se come, es agria y grata al paladar" (Cañ.: 306); "Nalca (s. f.). Los pecíolos comestibles del pangue" (Cav., 1914: 378); "yal·ka, s., la nalca (planta [...]" (Aug. I: 53); yalka, las nalcas (Coñ.: 101); nalca (Gu.: 253); "Ngalka = la nalca" (Alon., 1985: 138, 1989: 158); “[...] panke o nalka [...]” (Wilh.: 29).

\section{Gunnera tinctoria}

Gunneraceae

"natri. (Del mapuche natrey). m. Arbusto de la familia de las Solanáceas, de dos o tres metros de altura, ramoso, con tallos pubescentes, hojas aovadas, oblongas y puntiagudas, y flores blancas. Es natural de Chile. El cocimiento de sus hojas se ha usado en medicina como febrífugo, y con su jugo, que es amargo, se untan el pecho las mujeres para destetar a los niños" (DRAE: 1063).

De natrüng/nat'ïy/, natri/nat ${ }^{\mathbf{1}} \mathbf{i}$. "Natrren, s.- El natri, arbusto de notables virtudes medicinales [...]" (Cañ.: 306); nathre (Cav., 1914: 47); "natrëy, s., el natri (medicinal) [...]" (Aug. I: 146); natrəy, el natri o yerba de chavalongo (Coñ.: 90); "natri [...] Variantes: natriñ, natre" (Gu.: 254); "Natrüng = el natri”" (Alon., 1985: 139); "Natri, Natreng: diversos arbustos de hojas muy amargas [...]" (Wilh.: 104-105); "natrüng [na't'i $]$ ]: [...] Natre [...]" (Catr.:119).

\section{Solanum gayanum, S. valdiviense Solanaceae}

"notro. (Del mapuche notru, ciruelillo). m. Chile. Árbol de la familia de las Proteáceas, de hojas oblongas, flores numerosas de un color rojo vivo, 
dispuestas en corimbos flojos. Su madera se utiliza para obras de ornato" (DRAE: 1079).

De notru /not ${ }^{\mathrm{r}} \mathbf{u}$ /. "Nothu - el ciruelo arbol; no es frutal, sino otro parecido" (F., Cal.: 568 - 569): "Prunus, notu [notru]" (H., Chil. I: 229), "Notu [notru], prunus" (H., Chil. II: 728); “NOTHU. Ciruelillo, sin fruto" (F.-Hern. I: 49); "Notrro, s. Árbol muy estimado por su madera, que es vetada [...] Dicen también notrru" (Cañ.: 306 - 307); "notru, s., el ciruelillo o notro (árbol y arbusto) [...]" (Aug. I: 150); notru, treumun, el notro o ciruelillo (Coñ.: 88); notro (Gu.: 255); "trewmün, notro el ciruelillo, el notro" (Alon., 1989: 185); "Notru, treumun [...] el notro o "ciruelillo [...]" (Wilh.: 73). El árbol es llamado también trewmün /t/treumïn/ (Aug. I: 231); “notru $\left[\boldsymbol{n o}^{\prime} \boldsymbol{t}^{r} \boldsymbol{u}\right]$ : [...] Notro o ciruelillo" (Catr.: 113).

Embothrium coccineum

Proteaceae

"nuño. (Del mapuche nuyu). m. Planta americana de la familia de las Iridáceas, de raíces fibrosas, bastante drásticas, y flores rosadas" (DRAE: 1083).

¿De nüyü /nïjï/, nuñu /nunu/? "Ñuño, s. - Unas hierbas aromáticas" (Cañ.: 308); "nuño [...] Variante regional, de origen map., de esta planta

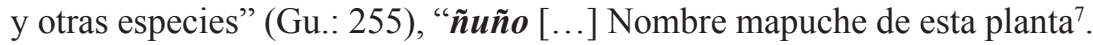

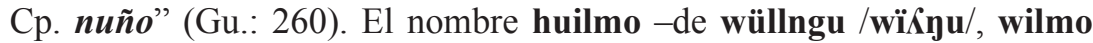
/wilmo/- está documentado: "Simplicia ampiñ lahuen [...] huilmo [...]" (H., Chil. I: 237); "wallyo*, s., cierta planta [...]" (Aug. I: 256); "wëllyo, el huilmo o nuño (Coñ.: 94); "Huëlngu, Huilmo, Nuño: variante de las voces mapuches uё̈̈ngu, wëlngu [...]" (Wilh.: 70). Es probable que provenga de nüyü /nïji/, aunque esta palabra significa 'chupones': "Nùyù - chupones,

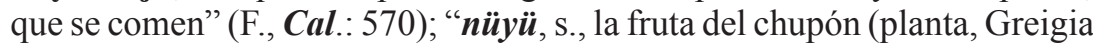
sphacelata)" (Aug. I: 153).

Sysirinchium spp.

Iridaceae

"ñipe. m. Chile. Arbusto de la familia de las Mirtáceas, cuyas ramas se emplean para teñir" (DRAE: 1084).

De ñüpüd /nïpïø/, ñipüd /jip̈̈̈/ 'pegadizo'. “Nipipe - (de ñüped=pegajoso) $\mathrm{m}$. Arbusto cuyas hojas sirven para teñir. Su fruto sirve de liga para cazar pájaros, lo que confirma la etimología. Se emplea también para la curación de heridas [...]" (Cav., 1921:86); "ñüpad, adj, pegadizo [...] cierta planta [...]" (Aug. I: 157), "pegadizo, adj. ñüpad, ñipad (adj.)" (Aug. II: 281); “ñipe, s., el ciruelillo (según algunos) [...]” (Aug. I: 157); "ñipüd pegajoso,

\footnotetext{
Ñuño no está consignado en ningún léxico mapuche colonial; tampoco está en el Diccionario de Augusta.
} 
pegadizo" (Alon., 1989:32), “ñipe el ciruelillo" (Alon., 1989:153). Según Wilhelm, es la misma planta llamada ñipa: "Ñipa (Escallonia illinita K. Presl., E. berberifolia H.B. Kth), arbusto de ramas nuevas y hojas viscosas (de ahí el nombre mapuche, derivado de ñipe: betún)"8 (Wilh.: 81).

\section{Escallonia illinita, E. berberifolia Saxifragaceae}

"ñire. (Voz mapuche). Arg. y Chile. Árbol o arbusto de la familia de las Fagáceas, de hojas caedizas y polimorfas, propio de los bosques andinopatagónicos. Toma frecuentemente un porte achaparrado y carece de valor forestal" (DRAE: 1084).

¿De ngürü /yï.sï/ 'zorro'? yire, el ñirre (Coñ.: 87); ñire, nirre, ñirre (Gu.: 259); Nirre (Wilh.: 52, 72).

\section{Nothofagus antarctica}

Fagaceae

"ñocha. (Voz mapuche). f. Chile. Hierba bromeliácea, cuyas hojas sirven para hacer sogas, canastos, sombreros, esteras y aventadores" (DRAE: 1085). De ñocha /noča/. "ñocha, cañamo, o cabuya" (Vald., Voc.); "Ñocha hierba de que hazen soga: ñocha mau soga de esta hierba" (F., Cal.: 574); "ñocha, ex qua funes corbesque conficiunt" (H., Chil. I: 240, Chil. II:

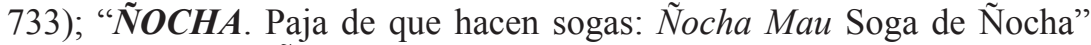
(F.-Hern. I: 51); "Ñocha, s. - Planta fibrosa que les sirve a los indios para hacer cuerdas y sogas de mucha resistencia" (Cañ.: 307); "Ñocha (s. f.). Una bromeliacea de que hacen redes y sogas [...]" (Cav., 1914: 380); "ñocha, s., la ñocha (planta conocida con tal nombre [...]" (Aug. I: 157); ñocha, la ñocha (Coñ.: 94); ñocha (Gu.: 260); “ñocha la ñocha” (Alon., 1989: 153); "Ñocha [...] planta de fibras muy tenaces aprovechadas en la confección de cordeles y canastos [...]" (Wilh.: 67); "ñocha [no'ča]: Planta de hojas largas sentadas y muy firmes. Se utilizan en la confección de cordeles y sombreros" (Catr.: 118).

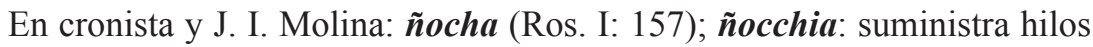
para hacer cuerdas (Mol. II: 24).

\section{Greigia landbeckii}

Bromeliaceae

"palhuén. (De or. mapuche). m. Arbusto americano de la familia de las Papilionáceas, de más de dos metros de altura y menos de tres y muy espinoso" (DRAE: 1123).

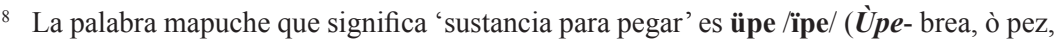
goma, resina, para calafatear: upetun, embrear, calafatear") (F., Cal.: 680), “ïpe+, s. cada sustancia glutinosa que sirve para pegar" (Aug. I: 276).
} 
De palwen /palwen/.palhuén (Cav., 1921: 90); palwen, el palhuén (Coñ.: 89); palhuén (Gu.: 263; "Palwenn= el palhuén. Medicinal" (Alon., 1985: 139); "Palhuén: ramoso [...] grupo de arbustos espinudos con ramos largos y hojuelas muy diminutas, llamadas "espinillos" [...]" (Wilh.: 85).

Adesmia sp.

Papilionaceae

“palpallén. (De or. mapuche). m. Arbusto americano de la familia de las Compuestas, que alcanza dos metros de altura, con hojas aovadas, dentadas y cubiertas de un tomento blanquecino, y flores amarillas" (DRAE: 1127).

De palpal /palpal/, palpalen /palpalen/. "palpal, palpalen, s., arbusto conocido con tal nombre [...]” (Aug. I: 165); palpal, el palpalén (Coñ.: 91); palpal, palpalén (Gu.: 263); "Palpal, palpalen [...] vulgarmente palpalen o "palo de yegua"[...]" (Wilh.: 113).

\section{Senecio yegua}

Compositae

"palpi. (Del mapuche pal-pud). m. Arbusto americano de la familia de las Escrofulariáceas, de unos $30 \mathrm{~cm}$ de altura, con hojas angostas, casi lineares, aserradas y flores amarillas, dispuestas en forma de un tirso alargado" (DRAE: 1127).

¿De palpüd /palpïð/, palpi /palpi/? Palpi (Gu.: 263); “Palpi, Palpüd [...] la "hierba dulce"; arbustito ramoso con hojas lineares, arrugadas y de gusto dulce [...]" (Wilh.: 106).

Calceolaria thyrsiflora

Scrophulariaceae

"palqui. (De or. mapuche). m. Arbusto americano de la familia de las Solanáceas, de olor fétido, con muchos tallos erguidos, hojas enteras, lampiñas, algo ondeadas, estrechas y terminadas en punta por ambos extremos, y flores en panojas terminales con brácteas. Su cocimiento se emplea en Chile contra la tiña, y como sudorífico; y la planta, para hacer jabón" (DRAE: 1127).

De palki /palki/, ¿parki /pa.ski/? "Palqui - el palqui mata conocida" (F., Cal.: 580); "Simplicia. ampiñ lahuen [...]palqui" (H., Chil. I: 237); "PALQUI. Mata medicinal para bebidas i ayudas frescas" (F.-Hern. I: 53); "Palqui, s. - Unas hierbas muy conocidas que son también medicinales" (Cañ.: 309); palqui (Cav., 1914: 192); "palki, s., mata conocida con tal nombre [...]" (Aug. I: 165); palki, el palqui (Coñ.: 90); "palqui [...]; variantes regionales: parqui [...] palque [...]" (Gu.: 263); "Parqui (Palqui ) [...] arbusto conocido entre los ríos Aconcagua y Bío-Bío [...]" (Wilh.: 105); "palki [pal'ki]: [...] Arbusto de tupido follaje[...]" (Catr.: 116). La forma más común es palqui. 
En cronistas y J. I. Molina: Palqui: “yerba hedionda” (Ros. I.: 236, III: 502: "para llagas y calentura"); Palqui: “contra fiebres ardientes" (Mol. I: 177); palque: "contra las calenturas ardientes y malignas" (Vid.: 143); palqui (Carv. y G.: 12).

\section{Cestrum parqui}

Solanaceae

"pangue. (Del mapuche panke). m. Chile. Planta acaule, de la familia de las Gunneráceas, con grandes hojas con más de un metro de longitud y cerca de medio de anchura, orbiculares y lobuladas. De su centro nace un bohordo cilíndrico que lleva muchas espigas de flores. El fruto parece una drupa pequeña porque su cáliz se vuelve carnoso, y el rizoma, que es astringente, se usa en medicina y para teñir y curtir. Es frecuente en los lugares pantanosos y a lo largo de los arroyos" (DRAE: 1130).

De pangke /panke/, pange /pane/. "Panpancallhue-brote, ò renuevo del Pangue, Panque - dicha mata" (F. Cal.: 580); "Arbusta pichi mamll [...] nalca, page" (H., Chil. I: 230), "Agrestes herbae. Relahuen [...]. Panque" (H., Chil. I: 240); "Pangui, s. - Plantas muy comunes en los campos húmedos del Sur, que producen la nalca" (Cañ.: 309); "payke, s., la hoja de la yalka, o la planta entera [...]" (Aug. I: 163); payke, los pangues (Coñ.: 101); pangue, panque, pañque (Gu.: 364); "Pangue (Pangke)" (Wilh.: 97).

En cronistas y J. I. Molina: Pangue "con hojas mayores que adargas" (G. de Naj.: 26); Pangue (Ros. I: 151, 248, III: 502: "para cámaras de sangre"); Panke: su raíz sirve para teñir de negro bellísimo (Mol.I: 150); pangue (Carv. y G.: 11).

Gunnera tinctoria

Gunneraceae

"panul. (De or. mapuche). m. Chile. apio (//planta umbelífera)" (DRAE: 1132).

De panul /panul/. "Panul - la hierba apio" (F., Cal.: 580); "Apium, panul" (H., Chil. I: 236); "Panul., s. - El apio silvestre” (Cañ.: 309); panul (Gu.: 264); Panul (Wilh.: 99).

\section{Apium panul \\ Umbelliferae}

"pañil. (Del mapuche pagil). m. Chile. Árbol de la familia de las Escrofulariáceas, de unos tres metros de altura, con hojas grandes, oblongas, almenadas, arrugadas, con vello amarillento en su cara inferior, y flores anaranjadas dispuestas en cabezuelas globosas. Sus hojas se usan en medicina para la curación de úlceras" (DRAE: 1132).

De palngin /palnin/, palngiñ /palnij/. "Simplicia.ampiñ lahuen [...] palgnin [¿palgin?] [...]" (H., Chil. I: 237); "PAGIL. Mata medicinal, buena para bajar hinchazones, para desconcertadura" (F.-Hern. I: 52); palguín (Cav., 1914: 192, 1921: 20); "palyiñn, s., el arbusto palguín o matico 
[...] Es medicinal [...]" (Aug. I: 165); palyiñ , el palguín, pañil, matico (impropiamente) (Coñ.: 90); palguín, palquín, pañil (Gu.: 263); "Palngiñ = el palguín, medicinal" (Alon., 1985: 139); Pañil, Palguín: el matico (Wilh.: 101); "palngiñ [pal'yin]: [...] Arbusto conocido con el nombre de matico[...]" (Catr.: 116).

En cronista: Palguin (Ros. I: 248, III: 502, "para todas llagas").

\section{Buddleja globosa Budlejaceae}

"patagua (De or. mapuche) f. Árbol de la familia de las Tiliáceas, con tronco recto y liso de seis a ocho metros de altura, copa frondosa, hojas alternas, partidas en tres lóbulos agudos, flores blancas axilares, fruto esférico capsular, y madera blanca, ligera y útil para carpintería" (DRAE: 1153).

De patawa /patawa/. "Arbores non fructiferae. remamll. [....]patagua [...]" (H., Chil. I: 229); "PATAHUA, árbol. Pùtha" (F.-Hern. II: 73); patagua (Aug. II: 279); patagua (Gu.: 265); "Patawa = la patagua" (Alon., 1985: 141); "Patagua [...] árbol de las quebradas y corrientes del centro, de tronco corto pero voluminoso, flores blancas, bastante grandes y vistosas [...]" (Wilh.: 91 - 92). El árbol ha sido llamado también pütra/pïtra/, pücha/pï̌̌a/. En cronistas y J. I. Molina: Patagua (Ros. I: 225); guillipatagua [güillipatagua] (Oliv.: 38); Patagua (Mol. I: 192); patagua (Vid.: 151); pataguas (Carv. y G.: 23); guillipatagua [güilliparagua] (JPG.: 20).

\section{Crinodendron patagua Elaeocarpaceae}

"pehuén. (Del mapuche pewen ). m. Chile. araucaria" (DRAE: 1162).

De pewen /pewen/. "Pehuen - los pinos de esta tierra, y los pinales: pehuen mapu - la cordillera, ò tierra de los Pehuenches" (F., Cal.: 582-583); "Arbores fructiferae. bùn mamll [...] Pinus, pehuen" (H., Chil. I: 229), "Pehuen, pinus" (H., Chil. II: 740); "Pehuen, s. - El árbol que da el piñón en las montañas del Sur" (Cañ.: 309); "pewen, s., el pino [...]" (Aug. I: 172); pewen, los pinos chilenos o araucarias (Coñ.: 87); pehuén, pehuẽ̃ (forma arcaica de pehuén) (Gu.: 266, 268); "Peweñ = el pino araucaria" (Alon., 1985: 140); "Pehuén [...] el soberbio pino chileno, llamado "araucaria", pehuén o "piñón" [...]" (Wilh.: 59); "pewen [pe'wen]: [...] Pino araucaria" (Catr.: 112).

En cronistas y J. I. Molina: Pehuen: pino araucaria (Mol. I: 193, 196); pehuen o pino (Vid: 155); pehuen (Carv. y G.: 12); pehuen: pino (JPG.: 18). Araucaria araucana

Araucariaceae

"pellín (Del mapuche pelliñ, corazón duro de ciertos árboles). m. Chile. Especie de haya cuya madera es muy dura e incorruptible.// 2. Cerno de este árbol. // 3. Persona o cosa muy fuerte y de gran resistencia" (DRAE: 1165). 
De pellin /peKin/, pelliñ /peKijp/. "Pellin- el corazón de roble, ò de otros palos [...]" (F., Cal.: 584); "Arbores non fructiferae [...] Quercus, pellin [...]" (H., Chil. I: 229); "pelliñ , s., el corazón duro de la madera de ciertos árboles, como el roble [...]" (Aug. I: 169); pelliñ, el roble adulto (Coñ.: 87); pellín (Gu.: 267); pellín (Alon., 1985: 140); Pellín: nombre del roble (koyam) cuando ya es viejo, cuya madera interior es de color oscuro-rojizo. "La madera del pellín es casi indestructible en la humedad, material indicado para construcciones hidráulicas y para durmientes de las líneas férreas" (Wilh.: 72).

En cronistas y J. I. Molina: Pillin [sic] (Ros. I: 227), Pellin (Ros. I: 229); pellinos (Mol. I: 179); pellín (Vid.: 148).

Nothofagus obliqua

Fagaceae

"petra. (Del mapuche patra).f. Chile. Planta mirtácea de unos tres metros de altura, con muchas ramas, cubiertas de un vello rojizo las más tiernas, hojas anchas, elípticas, muy variables, y flores blancas, dispuestas en panícula a lo largo de las ramas. La baya es negra semejante a la del arrayán y comestible. Sus hojas y corteza son medicinales, y el polvo de ellas se usa en agricultura como insecticida y constituye un importante ramo de comercio" (DRAE: 1185).

De pütra /pïtra/, pitra /pitra/. "Pùtha - un arbol conocido" (F., Cal.: 610); "Arbores non fructiferae [...] pùta [pütra] [...]" (H., Chil. I: 229), "Pta [pùtra], arbusc." (H. Chil. II: 756); "Peta (de pùtha - un árbol conocido. Febrés) f. Una mirtácea arbórea [...]" (Cav., 1921: 93, 1914: 47); "potra, s., la pitra, arbusto con baya comestible, negra [...]" (Aug. I: 177); pitra, la pitra (Coñ.: 88); pitra (Gu.: 273); "Pitra, Pëtra (Pëta), Pitra-pitra [...] Suelen crecer reunidas en suelos húmedos y pantanosos, los pitrantos [agrupaciones de pitra]" (Wilh.: 96); "pütra [pi'tsa]: [...] Pitra; arbusto con baya comestible; la patagua" (Catr.: 115).

\section{Myrceugenia exsucca \\ Myrtaceae}

"peumo. (Del mapuche peju). m. Chile. Árbol de la familia de las Lauráceas, de hoja aovada y siempre verde, y fruto ovalado y rojizo que contiene una pulpa blanca y mantecosa comestible" (DRAE: 1185).

De pengu /peyu/. "Pegu - el peumo arbol: peguco - agua de peumo, y el estero que pasa por la ciudad vieja de Concepción, corrompido en penco, ò en pemco" (F., Cal.: 582); "Arbores non fructiferae [...] pegu [...]" (H., Chil. I: 229); "Pengo, s. - El peumo, árbol muy conocido por su fruto rojo, su madera y cáscara" (Cañ.: 310); "peyu, s., el árbol peumo [...]" (Aug. I: 168); peyu, el peumo (Coñ.: 88); peumo (Gu.: 268); "pengú = el peumo" (Alon., 1985: 141); "Pengu, peumo [...] el peumo, árbol elegante de dimensiones medianas, con hojas ovales o redondeadas [...]" (Wilh.: 79 - 80). 
En cronistas y J. I. Molina: peugu [sic] (Ov.: 78); pengus (Nuñ. de P.: 354), pengu (Nuñ. de P.: 469); Pegu (Ros. I: 230); Peumo (Mol.I: 193, 199); peumus boldus: "los del país lo llaman boldo" (Vid.: 159); peumo (árbol) (Carv. y G.: 12).

Cryptocaria alba

Lauraceae

"pichi'. (De or. mapuche). m. Chile. Arbusto de la familia de las Solanáceas, con flores blancas, solitarias y muy numerosas en el extremo de los ramos tiernos. Se usa en medicina como diurético" (DRAE: 1188).

De pichi /piči/ 'pequeño, ña'. Pichi (Cav., 1914: 193; "pichi, s., cierto arbusto [...]" (Aug. I: 178); pichí, [el pichi] (Coñ.: 90); pichi (Gu.: 269); "Pichi = el palo pichi; es muy medicinal" (Alon., 1985: 139); Pichi (Wilh.: 84). El nombre se debería a que es un arbusto bajo, pequeño.

\section{Fabiana imbricata \\ Solanaceae}

“pichoa. f. Chile. Planta de la familia de las Euforbiáceas, de raíz gruesa, con muchos tallos, largos de un decímetro o más, poblados de hojas alternas, ovaladas y oblongas que se terminan en umbelas trífidas. Es hierba muy purgante" (DRAE: 1189).

De pichoa /pičoa/. "Simplicia ampiñ lahuen [...]pichoa [...]" (H., Chil. I: 237); "Pichoa, s. - Planta rastrera de propiedades laxantes de primer orden, que puede llegar a ser venenosa según la concentración de la infusión" (Cañ.: 311); Pichoa (Cav., 1914: 193); pichoa (Gu.: 269); "Pichoa, Percü-lahuen [...]: remedio carminativo [...] la pichoga [...]" (Wilh.: 89).

En cronistas y J. I. Molina: pichoa: se purgan con ella (G. de Naj.: 24); Pichoa (Ros. I: 238, 242, III: 501, 502); Pichoa (Mol.I: 161); pichoa (Vid.: 125).

\section{Euphorbia portulacoides}

Euphorbiaceae

“pilapila. (De or. mapuche). f. Chile. Planta de la familia de las Malváceas, de tallo por lo común rastrero, rollizo, ramoso, de de 60 a $80 \mathrm{~cm}$ de longitud y con nuevas raíces junto al pecíolo de cada hoja inferior. Se usa en medicina como atemperante de la sangre" (DRAE: 1194).

De pülapüla /pïlapïla/. "polapola, s., cierta planta [...]" (Aug. I: 173); pëlapëla, la pilapila (Coñ.: 99); pila-pila (Gu.: 270); Pëlapëla [...] la "pilapila, una maleza rastrera, difundida en todo Chile [...]" (Wilh.: 92); "püla püla [pi'lla pi'lla $]$ : Pila pila, planta de tallo rastrero y ramoso con flores rosadas [...]" (Catr.:124).

En cronista: Plapla (Ros. I: 244, III: 502: "para el ahito y para el cabello").

Modiola caroliniana

Malvaceae 
“pillopillo. (Del mapuche pillupillu). m. Chile. Árbol, especie de laurel, de forma piramidal y flores blanquecinas dioicas. Su corteza interior es purgante y vomitiva" (DRAE: 1194).

De püllupüllu /pïKupïKu/. "Pillu-Pillu, s.- Arbusto de hojas perennes, de forma piramidal muy elegante; es medicinal la corteza y las hojas, que se usan como laxantes, febrífugas y antieméticas. Usadas en altas dosis son venenosas y de ellas se sirven los brujos" (Cañ.: 313); "Pellupellu (s. m.). Arbusto perenne, de forma piramidal [...]" (Cav., 1914: 385), "Pillupillu (s.m.) = Pellupellu" (Cav., 1914: 390, tb. 47), "Pellupellu -(de pellupellu = el pillopillo (arbusto [...]" (Cav., 1921: 92); "pallu, pallu s., el pillopillo (arbusto) [...] (Aug. I: 174); pëlupëlu, el pillopillo (Coñ.: 91); pillo-pillo, pellu-pellu, pillu-pillu, pillú-pillú (Gu.: 271); "Püllupülllu= el pillopillo. Es amargo" (Alon., 1985: 139); "Pëllu-Pëllu (Pillopillo): quiere decir arbusto con tallos derechos como las zancas de la garza pillo, cuyo nombre reduplicado designa el vegetal [...]" (Wilh.: 94).

\section{Ovidia pillopillo}

Thymelaeceae

"pilo². m. Chile. Arbusto que vive en sitios húmedos. Tiene hojas menudas y flores amarillas, y su cáscara es un vomitivo muy enérgico" (DRAE: 1194).

De pülu /pïlu/, pülopülo /pïlopïlo/. "Pùlu - un arbol con flor amarilla: su cascara es vomitorio eficaz, y arranca postemas del pecho, y costillas" (F., Cal.: 608); "Arbores non fructiferae remamll [...] plu [pùlu] [...]" (Н., Chil. I: 229), "Plu [pùlu], arbor qua florescente dicunt ferendi tempus esse" (H.,

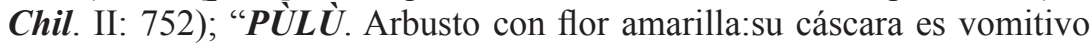
eficaz que arranca a postemas del pecho y costillas" (F.-Hern. I: 61); "Pelú, s. - árbol de forma irregular, de hojas arracimadas y flores amarillas [...]" (Cañ.: 210); "Pelú (s.m.). Arbol que produce una flor amarilla [...]" (Cav., 1914: 193, 384, 418, 1921: 91); "polu, polupolu, s., el pelú (árbol) [...]" (Aug. I: 173); pelu, el pelú (Coñ.: 88); pelu, llamado tb. pilo, mayomonte y toromiro (Gu.: 266); "Pëlu, pëlupëlu [...] el pelú o "mayomonte"; arbusto austral de floración abundante primaveral [...]" (Wilh.: 84).

En cronista: Pelu (Ros. I: 227).

Sophora microphylla Subfamilia Papilionaceae-Fam. Leguminosas

"pilpil'. m. Chile. Bejuco de hojas trifoliadas y flores blancas que produce el cóguil" (DRAE: 1195).

De pülpül /pïlpïl/, püllpüll /pïßpïK/. "Pùlpùl - una mata de cuyas hojas hacen las mugeres cierta uncion para ser queridas: también los Genhuenu, ò dueños del cielo las revuelven en una batea con piedrecitas, para que llueva, ò escampe" (F., Cal.: 607), "Pùllpùll - cierto boqui" (F., Cal.: 608); "Boquis 
varios - voqui, coghùll, nùpù, pùllpùll' (F., Voc.: 317); "Simplicia. ampiñ lahuen [...] plpl [pùlpùl] [...]" (H., Chil. I: 237), "Plpl [pùlpùl], frutex, virgultim. plpln [pùlpùlùn], plplcan [pùlpùlcan], se foliorum succo per ungere, uti solent Indae, ut amentur [...]" (H., Chil. II: 750 - 751); "Pilpil, s. - Unas hierbas de cuyas hojas hacen un brevaje las mujeres, que dan a los hombres para que éstos las quieran" (Cañ.: 313); "pallpall (foki), s., el voqui pallpall o boqui blanco [...]" (Aug. I: 174); pëllpëllfoki, el pilpilvoqui (Coñ.: 92); pil-pil, pillpill-voqui, pilpilvoqui (Gu.: 270); "Pëllpëll-foqui: trepadora muy estrechada [...] Del jugo de la planta se prepara un colirio; también se la usaba como filtro amoroso [...]" (Wilh.: 78).

Boquila trifoliata

Lardizabalaceae

"pingopingo. m. Chile. Arbusto de la familia de las Efedráceas, que a veces alcanza cinco metros de altura, con ramas articuladas y hojas opuestas a manera de escamas, flores pequeñas y por fruto unas nueces pequeñas que, así como sus hojas, son diuréticas y depurativas" (DRAE: 1196).

De pingkopingko/pinkopinko/, pingopingo/pinopino/ 'muchos canutos, tubos'. "PIÑ CO . Carriza caña, con que echan ayuda" (F.-Hern. I: 58); "pingko, s., cañuto [...]" (Aug. I: 179); piyopiyo el pingopingo (Coñ.: 91); pinco-pinco, pingo-pingo (Gu.:272); "Pingopingo = pingopingo" (Alon., 1985: 139); "Pingo-pingo: tubos, canutos [...] arbustos dioicos de aspecto estrafalario y hojas rudimentarias, caducas o nulas. En el folklor chileno es simbolo y nombre de caballos flacos, huesudos y malos [...]" (Wilh.: 60). En cronista: "El Pincopinco es admirable contra el humor gálico [...]" (Ros. I: 237, III: 502).

\section{Ephedra andina Ephedraceae}

"pircún. (De or. mapuche). m. Arbusto americano, de la familia de las Fitolacáceas, muy conocido por su raíz en forma de nabo grueso, que es en extremo purgante y emética" (DRAE: 1201).

De pirkün /pi.skïn/, pürkün /pïıkün/."pircùlahuen" (H., Chil. I: 237); "Pircun. - Un arbusto" (Cañ.: 313); përkü̈n, el pircún (Coñ.: 90); pircún (Gu.: 273); "Përcün: flato, Përcünlahue: remedio emético [...] el pircún [...]" (Wilh.: 76). No es seguro que pirkün signifique 'flato', pues la palabra correspondiente ha sido y es perkün /pe.skïn/.

En cronista: pircunlaquen [¿pircunlagüen?] (Ros. I: 241, III: 502: "para purgas").

\section{Anisomeria littoralis $\quad$ Phytolaccaceae}

“pitao. (Del mapuche pithau, callo). m. Árbol americano de la familia de las Rutáceas, de cinco a siete metros de altura, siempre verde, con hojas 
oblongas, aovadas, lampiñas, algo aserradas y grandes, flores blancas, dioicas, y fruto compuesto de cuatro drupas monospermas. Sus hojas son resolutivas y antihelmínticas (DRAE: 1204).

De pitraw /pit'au/, pitrao /pitrao/ "callo'. "Pitao, callo" (Vald., Voc.); "Pithau, pithao - callo" (F., Cal.: 597); "callum, pitau" (H., Chil. I: 288), "Pita, pitau, callum" (H., Chil. II: 749); "PITHAO Callo de pies o de mano, PITHAU. Ampolla de quemadura" (F.-Hern. I: 58); "pitrau, s., la ampolla [...]" (Aug. I: 184); pitao, pitau (Gu.: 273); Pitran [sic]: callo, ampolleta [...] el pitao o "canelillo" [...]" (Wilh.: 87). Su fruto tendría la semejanza de un callo, o de una ampolla.

\section{Pitavia punctata Rutaceae}

"piune. (Del mapuche piune, romerillo). m. Árbol americano de la familia de las Proteáceas, de hojas grandes, cubiertas de un vello color de orín por debajo y con racimos flojos de flores amarillas. Se cría en los montes y se usa como medicamento" (DRAE: 1205).

De piüne /piïne/. "Piùne - el romero o romerillo" (F., Cal.: 598), "Romerillo - piùne" (F., Voc.: 396); "Piune, s. - El romero aromático que es muy medicinal" (Cañ.: 314); piune, huingue, huique, fuinque (Gu.: 273); "Huinque (Fuinque), Piune, Moré [...] nombres indígenas y de uso vulgar, "romerillo" (Wilh.: 73). Se llama actualmente en mapuche wengkü/weykï/ (Aug.II: 337). De este nombre proceden las denominaciones hispanizadas huingue, huique, fuinque.

\section{Lomatia ferruginea}

Proteaceae

"póquil. (Del mapuche pocull). m. Hierba americana de la familia de las Compuestas, con hojas superiores estrechas, cabezuelas globosas, flores hermafroditas hinchadas, cortas y casi cerradas, que se emplean para teñir de amarillo" (DRAE: 1224).

De poküll /pokïK/, pokül /pokïl/. "Pocùll - una flor con que tiñen amarillo" (F., Cal.: 599); "POCU்LL. Flor con que tiñen amarillo" (F.-Hern. I: 59);

"Poquil ó Pocül, s. - Una hierba tintorea muy conocida" (Cañ.: 314; pokil, el póquil (Coñ.: 103); póquil, poquill, póquel, póquell (Gu.: 275); "Pocüll: [...] el póquil, planta sufrutescente y ramificada, lleva sobre largos sustentáculos desnudos capítulos solitarios [...]" (Wilh.: 112).

En cronistas y J. I. Molina: Poquel (Mol. I: 149); poquel (Vid.: 130); poquell (Carv. y G.: 11).

\section{Helenium glaucum Compositae}

"puya². (Del mapuche puuya). f. Bol. y Chile. Planta de la familia de las Bromeliáceas, de que existen varias especies. Su altura varía de dos a cinco 
metros. Tiene hojas tendidas, verdes y blancas en la cara inferior, flores amarillas y en alguna especie azules, con largos pétalos que se arrollan en espiral al secarse" (DRAE: 1269).

De puüya /puïja/, puya /puja/. "Puѝya - cardones de que se hacen boyas" (F., Cal.: 605), "Cardos - nùyù, puùya" (F., Voc.: 321); "Arbusta pichi mamll. [...] viscum, puùya" (H., Chil. I: 229); "Puya, s. - La vara que da el cardón en los campos del país" (Cañ.: 315); "Puya: [...] tiene ocho especies chilenas [...] Las flores lucen refulgores metálicos: azules (Puya chilensis Mol.), verdoso-azulejos (Puya alpestris (Poepp) Gay), amarillas (Puya chilensis Mol.), y otras". "Vulgarmente se designa la especie de este hermoso género en el norte con la palabra quechua chagual, en el centro con la chilena "cardón" y en el sur con la araucana puya" (Wilh.: 67).

En J. I. Molina: Puya: es como alcornoque (I: 170, 171).

Puya chilensis

Bromeliaceae

"quelenquelén. (Del mapuche clenclen). m. Chile. Planta medicinal de la familia de las Poligaláceas, de la que hay varias especies, caracterizadas por tener sus flores pequeñas, rosadas y en racimos" (DRAE: 1272).

De külenkülen /kïlenkïlen/ 'muchas colas'. "Simplicia. Ampiñ lahuen [...] clenclen [...]” (H., Chil. I: 237), "Clenclen, herb." (H., Chil. II: 629); këlenkëlen, el quelénquelén (Coñ.: 98); quelen-quelén, var.: quilen-quilen (Gu.: 277); “Quëlen-quëlen (Quilenquilen), Clen-Clen: numerosas colas, es decir espigas florales; designa varias especies de ambos géneros poligaláceos [...]" (Wilh.: 88). El nombre puede significar efectivamente 'muchas colas'. En cronista y J. I. Molina: clenclen (Ros. III: 502: "para ventosidades"); Clinclin (Mol. I: 161).

Polygala gnidioides Polygalaceae

“queule. (Del mapuche queul, una fruta). m. Chile. mirobálano (//árbol). // 2. Chile. Fruto de este árbol" (DRAE: 1274).

De kewli /keuli/, kewlli /keûii/. "Queul - una fruta amarilla con huesito dentro" (F., Cal.: 615); "Queulli, arbor fructificans" (H., Chil. I: 229), "Queulli, arb." (H., Chil. II: 763); "keuli, s., cierto árbol" (Aug. I: 83); keuli, el queule (Coñ.: 88); queule (Gu.: 278); "keuñi o $\boldsymbol{k e u l i}=$ el queule, parecido al avellano" (Alon., 1985: 141); "Queuli [...] el queule, hermoso y frondoso árbol forestal, algo común en la provincia de Concepción, es de hábito parecido al lingue del sur o al belloto del centro" (Wilh.: 79).

En cronistas y J. I. Molina: Queul, "árbol de robusto tronco" (Ros. I: 229); Keule o lucuma keule (Mol. I: 202, 203); "El queule es un bellísimo árbol 
que crece mucho, con hojas ovales, largas seis o siete pulgadas, de un verde alegrísimo" (Vid.: 160); queuli, árbol (Carv. y G.: 12).

Gomortega keule

Gomortegaceae

“quiaca. (De or. mapuche). f. Árbol americano de tres a seis metros de alto, ramas largas y flexibles, hojas sencillas, oblongas, lanceoladas y aserradas, flores pequeñas, blancas y dispuestas en corimbo terminal compuesto" (DRAE: 1274).

De kiaka /kjaka/. "Quiaca (s. f.) Caldcluvia paniculata. Es un árbol de flores aromáticas" (Cav., 1914: 47,48, 400, 1921: 103); “kiaka, s., la tiaca (árbol[...])" (Aug. I: 88) kiaka, la quiaca o tiaca (Coñ.: 88); quiaca, tiaca (Gu.: 278-279); “kütrakütra, kiaka la tiaca" (Alon., 1989: 132); “Quiaca, (Triaca) [...] árbol elevado en relación al grosor reducido de su tronco, llamado también tiaca [...]" (Wilh.: 82).

En cronista: Quiaca (Ros. I: 228).

\section{Caldcluvia paniculata Cunoniaceae}

“quila (Del mapuche cula, caña).f. Am. Mer. Especie de bambú, más fuerte y de usos más variados que el malayo" (DRAE: 1275).

De küla /kïla/. “ Cùla - una especie de cañas, ò colehues: cùlantu - cañaveral, o monte donde los hay" (F., Cal.: 470); "Cùla [...] canna” (H., Chil., II: 642); "C光 $\boldsymbol{L}$ A. Quila, especie de colehue" (F.-Hern. I: 16); quila (Cav., 1914: 47, 193, 400, 1921: 103); “küla, s., la quila (=gramínea elevada y ramosa [...]" (Aug. I: 104); küla kachu, la quila (Coñ.: 92); quila (Gu.: 279); “küla = la quila" (Alon., 1985: 140);"Cüla: la caña [...] las "quilas", nombres colectivos de todo el género [...]" (Wilh.: 64); “kü $\underline{l} \boldsymbol{a}[\boldsymbol{k i} \mathbf{i} \underline{\mathbf{l}} \boldsymbol{a}]$ : [...] La quila (gramínea elevada y ramosa [...]" (Catr.: 115).

En cronistas y J. I. Molina: Quila: caña gruesa (Mol. I: 163, 164); quila (Vid.: 138); quila: "sirve para cestas, y camillas de ropa que allí llaman zahumadores [...]” (Carv. y G.: 11).

\section{Chusquea quila}

Gramineae

“quillay. (Del mapuche cúllay, cierto árbol). m. Arg., Bol. y Chile. Árbol de la familia de las Rosáceas, de gran tamaño, madera útil y cuya corteza interior se usa como jabón para lavar telas y la cabeza de las personas. Su tronco es alto, derecho y cubierto de corteza gruesa y cenicienta, muy frondoso, con hojas menudas, coriáceas, elípticas, obtusas, algo dentadas, lampiñas y cortamente pecioladas. Sus flores tienen pétalos blanquecinos y cáliz tomentoso por fuera, y su fruto es un folículo tomentoso" (DRAE: 1275).

De killay /kïKai/, killay /kiKai/. "Cùllay, jabon de indios"(Vald., Voc.); "Cùllay, ò quillay - un arbol, cuya corteza sirve para lavar la cabeza, y 
haze espuma como jabon: cùllaytun, quillaytun, lavar la cabeza assi" (F., Cal.: 471); "Quillay - un Arbol, cuya corteza sirve para lavarse la Cabeza, y ropa: quillaytun - lavarse assi la Cabeza v. Cùllay" (F., Cal.: 615), "Jabon - cabon, v. quillay" (F., Voc.: 360); “Arbores non fructiferae. remamll. [...] cúllai [cùllai]" (H., Chil. I: 229), "Cùllay, arbor, cujus cortice utuntur ad lavandum. cùllaitun, hujus arboris corticem ad lavandum adhibere" (H., Chil. II: 643); "C $\boldsymbol{C} \boldsymbol{U} \boldsymbol{L} \boldsymbol{A} \boldsymbol{Y}$. Arbusto cuya corteza que hace jabon, sirve para lavarse la cabeza" (F.-Hern. I: 17); Quillay (Cañ.: 319); "kollai, s., el quillay [...]" (Aug. I: 85); küllay, el quillay (Coñ.: 88); quillay (Gu.: 280); “küllay = el quillay, medicinal” (Alon., 1985: 141); “Cüllai (quillay): voz araucana latinizada y aceptada como género científico (Quillaja Mol.) con una sola especie (Quillaja saponaria Mol.)" (Wilh.: 82); "küllay [ki'fay]: [...] Árbol cuya corteza se utiliza para lavar y teñir lana" (Catr.: 113).

En cronistas y J. I. Molina: Quillai (Ros. I: 228, 241), quillailaguen [quillailagüen] (Ros. III: 502); Quillay (Mol. I: 117,186, 187, 188); quillay (Vid.: 147); quillay: levanta espuma como jabón (JPG.: 20).

\section{Quillaja saponaria}

Rosaceae

"quilmay. (De or. mapuche). m. Chile. Planta trepadora, de la familia de las Apocináceas, que se distingue por sus flores, comúnmente blancas, y sus hojas grandes, aovadas, de un verde subido y lustrosas por encima, como la camelia. Su tallo está cubierto de un vello blanquecino y su raíz es medicinal" (DRAE: 1275).

De külmay /kïlmai/. "Quilmay, s. - Arbusto cuya raíz y hojas secas son purgativas y estornutatorias [...]" (Cañ.: 319); quilmay (Cav., 1914: 47, 193); "külmai, s., el boqui quilmai [...]" (Aug. I: 104); külmai, el quilmay (Coñ.: 92); quilmay (Gu.: 279); "külmay = el quilmay" (Alon., 1985: 140); "Quilmái $[\ldots]$ el quilmái, vulgarmente llamado también "poroto de campo" [...]" (Wilh.: 101).

Elytropus chilensis

Apocynaceae

"quilo3. (Del mapuche quelu, colorado). m. Chile. Arbusto de la familia de las Poligonáceas, lampiño, de ramos flexuosos y trepadores, hojas oblongas algo asaetadas, flores axilares o aglomeradas en racimo, y fruto azucarado, comestible, del cual se hace una chicha. // 2. Chile. Fruto de este arbusto" (DRAE: 1276).

Probablemente de külo /kïlo/ (y no de kelü/kelï/ 'rojo', 'colorado'). pëlaifoki, el quilo (Coñ.: 92); quilo, quiloquilo (Gu.: 279); “Quilo, Quilo-quilo [...] una liana facultativa de importancia fisonómica para extensas regiones del centro y norte [...]" (Wilh.: 75). Si proviniera de kelü 'colorado', el nombre españolizado sería queli , quelu o quelo. 
En cronista: "El quilu enreda también en los árboles, i arrimado a las paredes de los huertos presenta deliciosa vista por su hermoso verde perpetuo, por su flor exquisita [...]" (Carv. y G.:12).

\section{Muehlenbeckia hastulata}

Polygonaceae

"quilquil. (del mapuche culcul, mata). m. Chile. Helecho arbóreo de la familia de las Polipodiáceas, cuyo tronco tiene a veces un metro de altura y sus ramas casi otro tanto" (DRAE: 1276).

De külkül /kïlkïl/. "Simplicia ampiñ lahuen [...] Clcl [cùlcùl] [...]" (H., Chil. I: 237); "CÙ $\boldsymbol{L C} \boldsymbol{U} \boldsymbol{L}$. Mata que tiene roscas en la raíz: i lavándose con ella las indias, dicen que se ponen rojas" (F.-Hern. I: 16); "külkül, s., (=kalkal) el helecho quilquil [...]" (Aug. I: 104); këlkël, el quilquil (Coñ.: 104): quilquil (Gu.: 280); "küllkül = el quilquil" (Alon., 1985: 138); "Cül-cül: el quilquil [...], por la forma y posición de sus pínulas también llamado "costilla de vaca", helecho característico de los ñadis [arbustos] del sur [...]" (Wilh.: 54). Blechnum chilense

Polipodiaceae

"quinchamalí ( Del mapuche quinchamallín) m. Arg. y Chile. Planta medicinal, de la familia de las Santaláceas, que mide entre 10 y $20 \mathrm{~cm}$ de altura, con hojas alternas, lanceoladas, y flores amarillas terminales, dispuestas en espigas cortas apretadas" (DRAE: 1276).

De künchamalin/kïnčamalin/, kinchamalin/kinčamalin/. "Cùnchamalin, ò quinchamalin - una yerba medicinal" (F., Cal.: 473); "Simplicia. ampiñ lahuen.[...]cùnchamalin [...]" (H., Chil. I: 237); "CÙNCHAMALI. Yerba medicinal" (F.-Hern. I: 17); künchamalliñ, quinchamali (Coñ.: 101); quinchamalí (Gu.: 280); “Quinchamalí [...] La gente de la cordillera usa su decocción con mucha fe contra la gripe y los resfriados" (Wilh.: 74).

En cronistas y J. I. Molina: quinchamalí: yerba "nombre de un cacique que halló su virtud" (G. de Naj.: 24); Quinchamalí (Ov.: 22); quinchamalí (Oliv.: 38; Quinchamali (Ros. I: 231, III: 502); Quinchamali, Quinchamaly (Mol. I: 155, 159, 160); quinchamalí (Vid.: 124); quinchamalí (JPG.: 18).

\section{Quinchamalium chilense}

Santalaceae

"quinchihue. m. Am. Mer. Planta anual de color verde claro, pelada, olorosa, con hojas opuestas, cabezuelas numerosas, pequeñas, cilíndricas, dispuestas en corimbos terminales, y flores amarillas. Es también medicinal" (DRAE: 1276). ¿De künchiw(e)/kïnčiw(e)/?, kinchiw /kinčiu/, kinchiwe/kinčiwe/. quinchihue (Gu.: 280 - 281);"Quinchiu, quinchihue [...] hierba elevada y ramosa, muy olorosa [...]”(Wilh.: 112).

En cronista: Quinchiu: "son unas ramas hediondas, pero provechosas para ayuda” (Ros. I: 248), Quichiu [¿Quinchiu?] (Ros. III: 502).

\section{Tagetes minuta}

Compositae 
"quintral. (Del mapuche cauthal). m. Chile. Muérdago de flores rojas, de cuyo fruto se extrae liga, y sirve para teñir. // 2. Cierta enfermedad que sufren las sandías y los porotos" (DRAE: 1278).

De küntral /kïntral/. "Cùnthal - una flor como el ùtriu, y sirve de liga, ò para teñir" (F. Cal.: 473), "Liga- cùnthal, uthiv [ùthiv]" (F., Voc.: 363); "Gluten, viscus, cùntal [cùntral]" (H., Chil. I: 520), "Cùntal [cùntral], viscus" (H., Chil. II: 644); quinthral (Cav., 1914: 47); “ïntriu*.s., (ütriu) el quintral (parásito) [...]" (Aug. I: 276), "quintral, m., (cierto parásito vegetal conocido con tal nombre) üntriu*, ütriu+ + " (Aug. II: 314); quintral (Gu.: 281); "Quintral [...] Con este nombre común se designa una docena de especies de plantas parásitas chilenas que maduran unas bayas con pulpa azucarada, apetecida por los pájaros [...]" (Wilh.: 73-74).

En cronistas: Quintal [¿Quintral?] (Ros. I: 234, III: 502: “sácase de él la liga - para llagas de garganta"); Quinthal: para teñir de negro (Carv. y G.: 11). Tristerix tetrandus

Loranthaceae

"radal. (Del mapuche raral, nogal silvestre). m. SO Arg. y Chile. Arbusto de la familia de las Proteáceas, de follaje persistente, cuyas hojas son simples, aovadas, y sus flores blancas, cubiertas de un vello rojizo. Es planta ornamental y forestal. Su corteza se emplea en medicina para las afecciones al pecho" (DRAE: 1282).

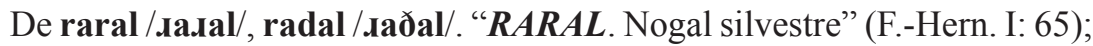
"Ralral (s. m.) - Un árbol semejante al nogal en la hoja y al limón en la flor [...] Llamáseles también Raral y Rarán" (Cav., 1914: 403); "radal, raral, s., el radal, vulg. tb. "nogal" [...]" (Aug. I: 193); raral, el radal (Coñ.: 88); radal, ralral, raral, radán; tb. ralralmilén (Gu.: 281 - 282); "Radal = el radal; es medicinal y se emplea en la tintura" (Alon.,1985: 141, 1989: 101); Radal, Raral (Wilh.: 73).

Lomatia hirsuta

Proteaceae

"raulí. (Del mapuche ruylín). m. Arg. y Chile. Árbol de gran porte, de la familia de las Fagáceas, con hojas caedizas, oblongas, doblemente aserradas, pálidas en su cara interna, y fruto muy erizado. Es característico de los bosques andinos, y de valor forestal por su madera" (DRAE: 1291).

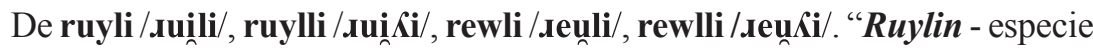
de roble que llamamos reuli." (F., Cal.: 625); "Arbores non fructiferae [...] reuli, ruili [...]" (H., Chil. I: 229), "Ruili [ruylli], arbor robori non absimilis. Reuli [reulli], eadem." (H., Chil. II: 773,); "ruili*, s., el raulí (árbol [...])". (Aug. I: 200); ruili, el raulí (Coñ.: 87); raulí; var.raulén, railli, variantes: raulén, raillí (Gu.: 282); "Ruili = el raulí" (Alon., 1985: 140); “Ruili: [...] el raulí, rey de la selva araucana [...]" (Wilh.: 71-72). 
En cronistas: raulí (Oliv.: 38); raulí: cedro imperfecto (JPG: 20).

\section{Nothofagus alpina}

Fagaceae

"rimu. (De or. mapuche). Planta americana de la familia de las Oxalidáceas, con flores amarillas, y que brota con las primeras lluvias de abril" (DRAE: 1341). De rimu /ıimu/, rümu /.ümu/, rümü /ı̈̈mï/. “Rimu - flor amarilla, que comen las perdizes: unen rimu, inan rimu - los dos meses, ò lunas de Invierno, Abril y Mayo" (F., Cal.: 623); "Flores. râuú ica [...] Rimu, flos crocei coloris, deliciae perdicum" (H., Chil. I: 245), "Rimu, flos heluus, deliciae perdicum" (H., Chil. II: 771); "rümü, s., (=shemü) yerba pradera con flores amarillas, cuyo bulbito [...], de sabor dulce, es comido por las perdices, y también gusta a la gente chica. La "flor de la perdiz" o "flor de Mayo [...]" (Aug. I: 204); rümü, la flor de mayo o de la perdiz (Coñ.: 98); rimu, rimurimu (Gu.: 283-284); "Ramü [sic], rëmu [...] la "flor de mayo" o "flor de la perdiz" [...]" (Wilh.: 87).

En J. I. Molina y cronista: Rimu: flor de perdiz (Mol. I: 154); rimu: flor de la perdiz (JPG.: 12).

\section{Oxalis mallobolba \\ Oxalidaceae}

"sandialahuén. m. Chile. Planta de la familia de las Verbenáceas, de tallo tendido, hojas pinatífidas y flores rosadas, en espiga. Se usa como aperitivo y diurético" (DRAE: 1372).

De sandía y lawen /lawen/ 'yerba medicinal', 'remedio': 'yerba de la sandía'. sandía-lahuén (Gu.: 285); "Sandía-lahuén: yerba de la sandía [...] Planta muy recomendada por los curanderos como remedio diurético, emenagogo y balsámico para las vías urinarias" (Wilh.: 102).

En J. I. Molina: Sandía-lahuén (I: 161).

\section{Glandularia laciniata}

Verbenaceae

"temu. (De or. mapuche). m. Chile. Árbol de la familia de la Mirtáceas, de madera muy dura y semillas amargas semejantes al café" (DRAE: 1462).

De temu /temu/. "Temu - un arbol” (F., Cal.: 631); "Arbores non fructiferae. remamll [...] temu [...]" ( H., Chil. I: 229), "Temu, arbor" (H., Chil. II: 785); "TEMO. El temo, árbol” (F.-Hern. I: 69); "temu, s., el árbol conocido con tal nombre [...]" (Aug. I: 214); temu, el temo (Coñ.: 88); temu, var. temo (Gu.: 288); "Temu = el temu. Es un árbol de madera muy dura, se emplea en la fabricación de tintura" (Alon., 1985: 141, 1989: 89); Temu [...] (Wilh.: 95).

En cronista y J. I. Molina: Temu (Mol.: 186), Temo (Mol.I: 191); temu, blanco y amarillo (Vid.: 153).

Temu divaricatum

Myrtaceae 
“tenío. m. Chile. Árbol de la familia de las Saxifragáceas, cuya corteza es medicinal. // 2. Chile. Madera de este árbol" (DRAE: 1464). "tineo. m. Chile. tenío" (DRAE: 1479).

De teniw /teniu/. "TINEO, árbol. Mudehua, mùdehuan" (F.-Hern. II: 99); "Teniu (s.m.) Árbol que da una madera usada para construcciones [...]" (Cav., 1914: 194, 409); teniu, el tinel o palo santo (Coñ.: 88); teníu var. tineo, tenío, tinel. Se llama también maden. (Gu.: 288); "Teñíu (Tinel, Tineo), Madén, Mëdehue [...] vulgamente conocido además como "palo santo" [...] (Wilh.: 82). Weinmannia trichosperma Cunoniaceae

“tepú. m. Chile. Árbol pequeño de la familia de las Mirtáceas. Se cría en lugares húmedos y forma a veces selvas enmarañadas difíciles de atravesar. Su madera se utiliza para leña" (DRAE: 1466).

De tepu /tepu/. "Tepu, s. - Árbol elevado y corpulento que vive en los terrenos encharcados, cuyas aguas tiñe de color rojo negrusco con la savia de sus raíces" (Cañ.: 323); "tepú (s. m.). La mirtácea llamada tepualia stipularis. Da una madera excelente para leña" (Cav., 1914: 147, 409, 1921: 112): tepu, el tepu (Coñ.: 88); tepu; var. trepú, trepual (Gu.: 288); “Tepú [...] Voz latinizada para término genérico con una sola especie [...]" (Wilh.: 88).

\section{Tepualia stipularis}

Myrtaceae

“tiaca. f. Árbol sudamericano de la familia de las Saxifagáceas, de tres a seis metros de altura, con hojas lanceoladas, aserradas y flores pequeñas, blancas en corimbo. Las ramas flexibles sirven de zunchos para toneles" (DRAE: 1474).

Vid. quiaca.

"tique". (Del mapuche tuque). m. Chile. Árbol de la familia de las Euforbiáceas, con hojas lampiñas, muy pálidas por debajo, cubiertas de escamas de lustre metálico. El fruto es una drupa dura semejante a una aceituna pequeña" (DRAE: 1480).

De tüke /tïke/. "TUUQUE. Palo muerto, árbol" (F.-Hern. I: 71); "Tique (s. m.) -Teque, árbol denominado científicamente Aextoxicum punctatum. De "tùque: palo muerto, árbol" (Febrés adic. por Hern. Calz.)" (Cav., 1914: 413, tb. 47, 1921: 114); "tüke, s., el árbol tique o palo muerto (Aextoxicum punctatum)" (Aug. I: 220); tüke, el olivillo o tique (Coñ.: 88); teque; var. tique (Gu.: 288); "tüque [...] el tique (teque) [...] árbol alto muy común en el sur [...]" (Wilh.: 88). Es llamado también, además de palo muerto, aceitunillo y olivillo.

En cronista: Tigue (¿Tique?): "es como el laurel” (Ros. I: 228). Aextoxicum punctatum

Aextoxicaceae 
"tralhuén. m. Chile. Arbusto espinoso de la familia de las Ramnáceas, cuya madera se utiliza para hacer carbón" (DRAE: 1499).

De tralwen /t'talwen/.tralwen, el talhuén (Coñ.: 89); Talhuén; var. tralhuén (Gu.: 286); Tralhuén [...] el talhuén [...] (Wilh.: 90).

En cronista: "Talguen [Talgüen]: de madera colorada (Ros. I: 229, 249; III: 502).

Trevoa quinquenervia

Rhamnaceae

"trebo. m. Chile. Arbusto espinoso de la familia de las Ramnáceas, que se utiliza para formar setos" (DRAE: 1509).

De trevu $/ \mathbf{t}^{\mathrm{r}} \mathbf{e v u} /$, trefu $/ \mathbf{t}^{\mathrm{r}} \mathbf{e f u}$ /. " trefo $^{+}$, s. (pronunciación castellana) cierta planta [...]" (Aug. I: 228); trefu, el trevu (Coñ.: 89); trefo (Gu.: 290), “Trëfo [...] "cadillo" de hojuelas muy pequeñas, aserradas y flores reunidas en cabezuela globosa; vegetal de grato aspecto [...]" (Wilh.: 83).

Trevoa trinervis

Rhamnaceae

"trique 2 (De or. mapuche). m. Planta americana de la familia de las Iridáceas, cuyo rizoma se usa como purgante" (DRAE: 1515).

¿De tregül / $/ \mathbf{t}^{\mathrm{r}} \mathbf{e}$ ïl/ 'el pájaro treile o frailecillo? trike /t'tike/.trique, triqueñtriqueñ (Gu.: 291); “Trique: (variante de la voz tregle) designa una especie menos cespitosa (por eso sin duplicación) y más escasa, de flores azules [...]" (Wilh.: 69 - 70).

\section{Libertia sessiliflora \\ Iridaceae}

"trun. m. Chile. Fruto espinoso de algunas plantas, que se adhiere al pelo o a la lana como los cadillos o amores" (DRAE: 1520).

De trun /t'tun/. "trun, s., la potentila (yerba)" (Aug. I: 237); trun walal·awen, los cadillos, amores secos, pimpinelas y potentiles (Coñ.: 98); trun (Gu.: 291); "trun la potentilla, amor seco, el trun" (Alon., 1989: 193); "Trun: gancho, Hualalahuén: hierba de la huala [....]; son los trunes, "cadillos" [...], "amores secos", "pimpinelas" y "zarzaparrillas" de los campesinos [...]" (Wilh.: 83). La palabra documentada en Febrés para cadillos, amores secos y la melosa es vrokiñ [vï.sokin] (Cal.: 664).

Acaena pinnatifida

Rosaceae

"tupa². (De or. mapuche). f. Chile. Planta de la familia de las Lobeliáceas, con flores grandes de color de grana, en largos racimos terminales, y que segrega un jugo lechoso tóxico" (DRAE: 1523-1524).

De trupa /t' - las manchas, ò pintas como del tigre" (F., Cal.: 647); "Topan [Tropan], multicolor, versicolor, discolor" (H., Chil. II: 789); "Thrrubalahuen. - 
Plantas muy pequeñas que en forma de orugas se encuentran en las islas de Apiao y Chuit, del grupo de las de Quinchao, en Chiloé, y que sirve a los isleños para curar el mal de aire [...]" (Cañ.: 327); "Thrupa. Es yerba venenosa. Se aplica a los dolores de muelas y dientes" (Cav., 1914: 194, tb. en 412); "Tropa, s., la pinta, la mancha, sea natural o adquirida. /s.*, el "tabaco del diablo" (planta) [...]" (Aug. I: 236); tropa, la trupa o tabaco del diablo (Coñ.: 101); trupa (Gu.: 291 - 292); "tropa la pinta, la mancha natural o adquirida, el tabaco del diablo" (Alon., 1989: 191); "Trupa, Tupa: mancha, comprende varias especies [...] vulgarmente trupa, y por sus anchas hojas "tabaco del diablo"[...]" (Wilh.: 109).

En cronista: Tupa, antichavalongo (Ros.I: 240; III: 501: "para chavalongo y fríos").

\section{Lobelia tupa}

Lobeliaceae

“uñi. m. Chile. Arbusto de la familia de las Mirtáceas, con flores rojizas y por fruto una baya comestible" (DRAE: 1532).

De üñü /ïnï/, üñi /ïni/ 'murta' o 'murtilla'. "Ghùñi - una murta, que se come”" (F., Cal.: 491), "Murta, murtilla - ghùñi"' (F., Voc.: 373); "MURTILLA. mata comestible. Ghùñi" (F.-Hern. II: 64); "ï̈ñü, s., la murta comestible [...]"

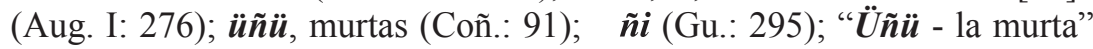

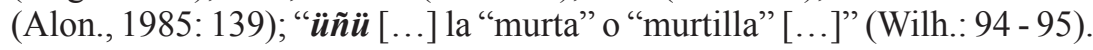
En cronistas y J. I. Molina: uñi: murtilla. "Es colorada y como una pequeña uva, mayor que garbanzos remojados [...]" (Ov.: 78. Descripción que el autor toma de la Historia de las Indias, de Antonio de Herrera); Uñi, murtilla (Ros. I: 227); Ugni [uñi] ${ }^{9}$, murtilla (Mol. I: 172); uni, murtilla (Vid.: 141).

\section{Ugni molinae}

Myrtaceae

"uñoperquén. m. Chile. Planta herbácea de la familia de las Campanuláceas, de unos $30 \mathrm{~cm}$ de altura, con hojas lineares y flores blancas algo azuladas. Crece en terrenos pedregosos" (DRAE: 1532).

De wüñoperkün /wïnope.ıkïn/, uñopürkün /ujopï.ıïn/, de wüño /wïno/, uño /uno/ 'volver a hacer', 'hacer de nuevo' y perkün /pe.skïn/ 'peerse', 'pedo'. "Uño, del verbo uñon, es volver a hacer, o reiterar [...]" (F., Cal.: 670), "Percùn - peerse, ventosear" (F., Cal. 585); "Pedo, percûn" (H., Chil. I: 288); "perkün, n., peer" (Aug. I: 171); uñi-pserquen, uño perkén (Gu.: 293); "Hueño-përkü̈n, uño përcün carminativo [...] la "hierba del flaco

9 "NOTA. La escritura ugni está tomada de la edición italiana de MOLINA i no debería usarse ni como nombre científico, por $\boldsymbol{u} \tilde{\boldsymbol{n}} \boldsymbol{i}$ ' (L. DE.: 760). 
[¿flato?]" [...] La infusión de sus hojas y flores blanco-azulejas sirve para expeler los gases intestinales" (Wilh.: 109).

\section{Wahlenbergia linarioides Campanulaceae}

"votri. m. Planta trepadora que crece en Chile, de hojas ovaladas, muy carnosas, flores que tienen la corola en forma de tubo muy abultado, que se estrecha antes del limbo, y fruto capsular" (DRAE: 1575).

De votri(d) $/ \operatorname{vot}^{\mathbf{r}} \mathbf{i}(\boldsymbol{\delta}) /$, fotri(d) $/ \mathbf{f o t}^{\mathbf{1}} \mathbf{i}(\boldsymbol{\theta}) /$. "Votri s. m. - "Una linda plantita de hojas carnosas. Sarmienta repens" (Lenz) (Cav., 1914: 415; 1921: 118); "fotridfotrid, fotrifotri (en San Juan de la Costa), s., =pín'cha foki*" (Aug. I: 51); fotridfotrid pindafoki, el voqui del picaflor (Coñ.: 92); votri (Gu.: 297); "Fotrid (Votri): chupado por los colibríes [...] la "medallita", planta epífita cuyos tallos radicales se arrastran a lo largo de los troncos, aprovechándose de los detritus que el tiempo haya depositado en las grietas de la corteza [...]" (Wilh.: 107).

\section{Sarmienta repens}

\section{Gesneriaceae}

"yáquil. m. Chile. Arbusto espinoso de la familia de las Ramnáceas, cuyas raíces, que producen en el agua una espuma jabonosa, se usan para lavar tejidos de lana" (DRAE: 1581).

De llaki / Kaki/, llakil/Kakil/. "Llagui, s.- Hierba medicinal febrífuga" (Cañ.: 229); "llaki+, s., cierta planta baja muy ramosa, con tallos muy espinudos, sin hojas, flores fragantes. La raíz es usada en vez de jabón para limpiar de insectos la cabeza" (Aug. I: 120); kuyko llaki, el cunco o crucero (Coñ.: 89); yaquil; variantes: yaqui, yaque (Ilaque) (Gu.: 300 - 301); "Ilaki llaqui; es una planta baja, ramosa, de tallo muy duro, de flores fragantes. La raíz es usada como jabón para limpiar de insectos la cabeza" (Alon., 1989:145). "Llaqui, Yáquil [...]"cruceros" [...]" (Wilh.: 91).

Colletia spinosissima Rhamnaceae

\section{ZOÓNIMOS}

Calquín, canquén, cascas, cauque, chape, chercán, chilla, chinchemolle, chinchimén, chincol, chingue, chirigüe, cholga, choroy, chucao, chucho, coicoy, coipo, colicoli, coliguacho, colocolo, concón, culpeo, cururo, diuca, diucón, dóllimo, fíofio, guairabo, guala, guarén, güemul huemul, güillín huillín, laucha, loco, lloica loica, macha, nuco, pequén, peuco, pichihuén, pidén, pillo, pilme, pilpilén, pilvén, pinuca, pirgüín-pirhuín, 
pitihué, pitoitoy, piuquén, piure, pololo, pudú, queltehue, quetro, quiltro, quique, rara, taca, tagua, tenca, tiuque, traro, tricahue, trile, tucúquere, turca, yal, yeco.

“calquín. (De or. pampa). Arg. Variedad mediana del águila, que vive en los Andes patagónicos" (DRAE: 275).

De kalkin /kalkin/. "Calquin-aguila grande [...]" (F., Cal.: 436), "Aguila mayor - calquin: otra menor, aguilucho- ñamcu" (F., Voc.: 303); "Aquila major, callquin, calquin [...]” (H., Chil. I: 223); "Calquin, s. - El águila real, la más cazadora y audaz porque se atreve hasta a las aves de las casas [...]" (Cañ.: 257).

En cronistas y J. I. Molina: Calquin "aguila mayor" (Oliv.: 31); “Calquin: águila grande" (Mol. I: 260, 261); "[...] la grande águila llamada calquín" (Vid.: 252); calquin: aguila mayor (JPG.: 26). La documentación demuestra que el águila ha habitado en Chile.

\section{Geranoaetus melanoleucus Accipitridae}

“canquén. (Del mapuche canqueñ). m. Chile. Ganso silvestre que tiene la cabeza y el cuello cenicientos, el pecho, plumas y cola bermejos, y las patas negras y anaranjadas. La hembra tiene en casi todo el cuerpo fajas negras. En algunos lugares es doméstico" (DRAE: 289).

De kankeñ /kankej/. "Canqueñ - un ave como cigüeña" (F., Cal.: 438); "Aves voraces, ùrcùn ùñm [...] canquen [...]" (H., Chil. I: 224), "Canqueñ, avis, ciconiae non absimilis" (H., Chil. II: 617); “Canqueñ. - (de canque ̃̃ = un ave como cigüeña" Febrés) m. Es una bernicla o sea un ave semejante al ganso. Se domestica fácilmente [...] (Cav., 1921: 23); "kaykeñ, s. [...] el canquén, ave como cigüeña de color blanco con café oscuro [...]" (Aug.I: 73); kaykeñ, canquén (Coñ.: 113); "Kankeñ = el canquén" (Alon., 1985: 134).

\section{Chloephaga poliocephala Anatidae}

"cascás, m. Chile. Insecto coleóptero, notable por sus mandíbulas en forma de gancho" (DRAE: 319).

De kadkad /kaðkað/. "kadkad *, s., cierto insecto negro, menor que el sanjuán" (Aug. I: 72); kadkad, el kadkad de color negro (Coñ.: 114).

Apterodorcus bacchus Lucanidae

"cauque. m. Chile. Pejerrey grande" (DRAE: 328)

De kawke /kauke/. "Pisces. pu Challua [...] cauque [...]" (H., Chil. I: 226); kauke, s., el pejerrey" (Aug. I: 79). 
En cronistas y J. I. Molina: cauques (Oliv.: 34); Cauque (Mol. I: 248); cauque (Vid.: 235); los cauques (JPG.: 25).

Basilichthys australis

Atherinidae

"chape. m. Chile. // 2. Chile. Ciertas clases de moluscos, alguno comestible" (DRAE: 351).

¿De chapüd /chapüð/ 'aplastado', 'chato'? “Chapes [...] Musculi [...] Mussles [...] die Muscheln las conchas" (Herck., en Schul.: 12, 40, 57); "Chape (s. m.) - un marisco comestible del género fissurella. También tiene una significación obscena: pudenda muliebra" (Cav., 1914: 325); "Chape. Marisco comestible del género fissurella // Organo genital femenino" (Cav., 1921:37). Hemos oído ambos significados en el sur de Chile (Xa Región). También aplicado el nombre a babosas, por ejemplo, a la babosa grande de jardín (Limax maximus, familia Limacidae). "limax, mutchape" (H., Chil. I: 222).

Fissurella crassa

Fissurellidae

“chercán. (Del mapuche chedcañ). m. Chile. Pájaro semejante al ruiseñor en la forma y el color, pero de canto mucho menos dulce. Es insectívoro y muy doméstico" (DRAE: 355).

De chedkeñ /čeðkep/, chedkañ /čeðkap/. "chedcañ - un paxarito que parece ruyseñor, Chedqueñ - un paxarito" (F., Cal.: 445); "Aves indolis ab aliis diversae, $\boldsymbol{c a} \boldsymbol{x}$ [ùñm] [...] chedken [...]" (H., Chil. I: 224); "Chedquen, avis" (H., Chil. II: 623); “CHEDCAN , CHEDQUEN. Pajarito parecido al ruiseñor” (F.-Hern. I: 9); “Chedcañ, s. - El chercán, pajarito muy conocido por su figura, su plumaje, por su canto y por sus costumbres, pues siempre vive cerca del hombre" (Cañ.: 266); "chedkeñ, s. cierto pajarito de color pardo que según los indígenas debe su nombre a su grito "chedched" (el chircán [sic])" (Aug. I: 19); chedkeñ, el chircán (chedkén) (Coñ.: 111); "Chedkeñ = el chercán" (Alon., 1985: 133).

En cronista: Chedcan: ruiseñor (Ros. I: 318).

Troglodytes aedon

Trogloditidae.

"chilla ${ }^{3}$. (De or. mapuche). f. Chile. Especie de zorra de menor tamaño que la europea común" (DRAE: 358).

De chilla /čiKa/. "Chilla, vnas raposas grandes" (Vald., Voc.); "Chilla - una raposa [...]" (F., Cal.: 448); "Belluae silvestres [...] vulpes, vulpecula, grú [grù], chilla, huancu" (H., Chil. I: 220), "Chilla, vulpecula (H., Chil. II: 624); Chilla, s.- zorra pequeña (Cañ.: 267).

En cronistas y J. I. Molina: chilla: raposa chica (Ros. I: 327); chilla: zorra 
montaraz (Mol. I: 304); chilla o zorra campestre (Vid.: 267); chilla: zorra menor (JPG.:24).

Pseudoalopex griseus Canidae

"chinchemolle. m. Chile. Insecto sin alas que habita bajo las piedras y se distingue por su olor nauseabundo" (DRAE: 359).

¿De chinchinmoyo/činčinmojo/? Chinchinmoyo, el tabolango (Coñ.: 115); Chinchinmayo [sic]: tabolanga [sic] (Alon., 1985: 135).

Agathemera crassa

Phasmatidae

"chinchimén. Chile. Especie de nutria de mar, de unos $30 \mathrm{~cm}$ de longitud sin la cola" (DRAE: 359).

De chinchimen /činčimen/, chimchinko / čimčinkol. "Chimchimem [sic] - animal maritimo como gato" (F., Cal.: 449), “Gato- [...] otro del mar [...] chimchimem [sic]" (F., Voc.: 353); "chimchinko, s., gato marino que tiene su cueva en las piedras a orillas del mar" (Aug. I: 23); chimchinko, ñunul, el gato marino o chimgungo (Coñ.: 108).

En cronistas y J. I. Molina: chinchimen, gato marino (Mol. I: 320); "El chinchimen, al que los españoles dan el nombre de gato marino [...]" (Vid.: 271).

\section{Lontra felina}

Mustelidae

"chincol. m. Am. Mer. chingolo" (DRAE: 359).

"chingolo. m. Arg. Pájaro conirrostro de la familia de los Fringílidos, de canto muy melodioso y color pardo rojizo, con copete" (DRAE: 360$)$.

¿De chingkol/činkol/? Aunque el ave es conocida desde antiguo en Chile, y se la encuentra actualmente desde Atacama (IV Región) hasta las islas Guaytecas (XI ${ }^{\mathrm{a}}$ Región), su nombre no está consignado en los léxicos mapuches. Sí ocurre en algunos topónimos como Chincolco 'agua de chincol' (un pueblo, un estero y dos quebradas de la V ${ }^{a}$ Región de Valparaíso, y un cerro de la IV ${ }^{a}$ Región de Coquimbo). Se la denomina en mapuche meñkutoki /mejkutoki/ (Aug. I: 135; Coñ.: 111). Hemos oído chinkó / činkó/ en el sector del Alto Bío-Bío. Podría ser préstamo de otra lengua. Según Lenz, "Es mapuche, aunque no está en los diccionarios [...]" (DE.: 297). El chincol es llamado también regionalmente copete, tío Agustín, etc.

Zonotrichia capensis Emberizidae

"chingue.m. Chile. mofeta (//mamífero) (DRAE: 360).

De chinge /čine/, chiñge /čijye/. "Chiñiúe, raposas que hieden mucho" (Vald., Voc.); "Chinghe - animalito bonito, cuyos orines son muy hediondos" (F., Cal.: 449); "Bellua silvestres. Chige est sciuri species; sed 
albinigrum, cujus urina diu ac terribiliter foedet” (H., Chil. I: 220), “Chiñúe, animalculum albo nigrum ejusdem cum sciuro formae \& magnitudinis; cujus urinae graveolentia nimia est, diuturna, \& vix ferenda" (H., Chil. II: 625); "CHINGHE. Animalito, cuyos orines son mui ediondos [sic]" (F.-Hern. I: 10); Chingue. s. Animalito cuadrúpedo que vive en cueva. Para contrarrestar a los animales más fuertes y mayores, la naturaleza le ha dado el arma de sus orines que son por extremo fétidos, que los arroja en chisguetes contra estos" (Cañ.: 268); "chine=chiñqe, s., el chingue (cuadrúpedo)" (Aug. I: 22, 23); chine; shañi, el chingue (Coñ.: 108).

En cronistas y J. I. Molina: Chinique [sic], chingue (Ros. I: 327); chingue "zorra pequeña" (Oliv.: 31); chingue (Mol. I: 325, 326, 327, 328); chingue (Vid.: 272); chingue :"animalito fétido" (Carv. y G.: 13); chingue: zorrillo pequeño (JPG.: 24).

\section{Conepatus chinga Mustelidae}

“chirigüe. (De or. mapuche). m. Chile. Pájaro común de color, de aceituna por encima, alas negras, garganta, pecho y abdomen amarillos y el pico y las patas brunos" (DRAE: 361$)$.

De chirif/či.sif/, chirüf/či.üf/. "chirif, chirüf, s. (=shiwü) el pajarito chirigü [sic], de plumaje amarillo" (Aug. I: 24); chidëf, el chirihue (Coñ.: 111); "tridüf, chüríu el chirigüe, o chirrío" (Alon., 1985: 187).

\section{Sicalis luteola Emberizidae}

"cholga. f. Arg. Bol. y Chile. Molusco bivalvo marino comestible, de la misma familia que el mejillón, pero de mayor tamaño. Abunda en la zona del canal de Beagle y del estrecho de Magallanes" (DRAE: 364). También cholgua (DRAE: ibíd).

De chollwa /čoswa/. "Chollhua - cáscara de choros blancos" (F., Cal.: 450); "Chollhua" (H., Chil. II: 626); "CHOLLHUA. Cáscara de choros blancos" (F.-Hern. I: 11); "Cholhua, s. - Un crustáceo bivalvo del mar y de río" (Cañ.: 269); "cholga (s. f.) - Molusco comestible, parecido al choro [...]" (Cav., 1914: 331), también cholhua (Cav., 1921: 44); chollwa, chollwe, las cholgas o collhues [¿cholhues?] (Coñ.: 120).

En crónicas y J. I. Molina: Chalgua [sic] (Mol.I: 222); cholguas (Carv. y G.: 21).

\section{Aulacomya atra}

Mytilidae.

"choroy. m. Chile. Especie de papagayo, término medio entre el loro y la catita. Anda en bandadas y perjudica mucho los sembrados" (DRAE: 365). De choroy /čo.roi/. "Choroy, papagayos chicos" (Vald., Voc.); Choroy Psittacus [...] A Parrot [...] der Papegay [sic] el papagayo" (Herck., en 
Schul.: 13, 22, 40,57); "Choroy - papagayos pequeños, ò catalinitas" (F. Cal.: 451); "CHOROY. Pájaros así llamados, especie de papagayos" (F.Hern. I: 11); "choroi, s. Especie de papagayo, pequeño, de plumaje vistoso; es gregario, y por esto siempre anda en bandadas por los campos" (Cañ.: 269); "choroy, s., el choroy, especie de loro verde" (Aug. I: 25); choroi, el choroy verde (Coñ.: 112); "Chorroy = el choroy o cachaña" (Alon., 1985: 133); “choroy [čo'roy]: Choroy" (Catr.: 159).

En cronistas y J. I. Molina: choroi, jaguilma (Mol. I: 287); choroy (Vid.: 246); el choroy: catalina (JPG.: 27).

Enicognathus leptorhynchus

Psittacidae

“chucao. (De or. mapuche). Chile. m. Pájaro del tamaño del zorzal, de plumaje pardo, y que habita en lo más espeso de los bosques" (DRAE: 366).

De chukaw /čukau/. "Chucau, ò vudad - un paxaro del monte [...]" (F., Cal.: 452); "Aves indolis ab aliis diversae, ca $\boldsymbol{x}$. [ùñm $][\ldots]$ chucau $[. .$.$] " (H., Chil.$ I: 224), “Chúcau, udud, avis sylvestris” (H., Chil. II: 627); “CHUCAU. Pájaro así nombrado: chucau vemlayñ te chi? ¿Hemos de estar como los chucaos metidos en el monte?" (F.-Hern. I: 11); “Chucao, s. - Ave pequeña de plumaje pardo oscuro, de poco volar y que vive en los bosques más espesos" (Cañ.: 269); "Chucao (s.m.) [...] Sibila de los bosques o sea ave agorera que predice a los caminantes la buena o mala ventura" (Cav., 1914:333, 1921: 45); "chukau, s., el pajaro chucau” (Aug. I: 26); "chukaw el chucao o gallareta” (Alon., 1989: 82). Scelorcilus rubecula

Rhinocryptidae

"chucho5. (De la onomatopeya chu-chu, que imita el grito del ave. m. Chile. Ave de rapiña, nocturna y diurna, de poco tamaño y cuyo graznido se toma vulgarmente como de mal agüero para la casa en que lo lanza" (DRAE: 367).

Del chu(n)chu /ču(n)ču/. "Chucho - un paxaro i Avuela" (F., Cal.: 452); "Chucho, s. Pequeña lechuza diurna y nocturna. Es tenida por de mal agüero, por lo que cuando canta cerca de una habitación, los supersticiosos dicen que alguien morirá pronto allí" (Cañ.: 269); “chuncho, m., (cierto pájaro nocturno) kilkil' (Aug. II: 99); "Killkill= el chuncho. Es [de] muy mal agüero e instrumento eficaz de los brujos para hacer el mal" (Alon., 1985: 133).

Glaucidium nanum

Strigidae

“coicoy. (Por su grito particular, en que parece repetir la sílaba coy). m. Chile. Sapo pequeño que tiene en la espalda cuatro protuberancias a manera de ojos" (DRAE: 394).

De koy(willa) /koi(wiKa)/. "koiwilla, s., especie de sapitos. Empiezan a cantar después de San Juan, y su canto suena para los indígenas como "wiwi" 
(Aug. I: 91); koiwilla, el sapo coicoi (Coñ.: 119); “koiwilla: sapito coihuilla (barómetro)" (Alon., 1985: 134).

\section{Pleurodema thaul Leptodactylidae}

“coipo. (Del map. coipu) m. Arg. y Chile. Roedor de hábitos acuáticos, cuyo pelaje, entre bayo ocráceo y castaño, es valorado comercialmente. Tiene las orejas redondas, el hocico largo y cubierto de barbas, las patas cortas y la cola larga desprovista de pelos" (DRAE: 394).

De koypu /koipu/, koypo/koipo/. "Coypu-animal de río como gato" (F., Cal.: 458). "Lutra, huillin, coipo [...]" (H., Chil. I: 221), "Amphibia [...] coipo [...]" (H., Chil. I: 221), "Coipo, coipu, lutra” (H., Chil. II: 632); “COYPU. Animal de río como gato, la nutria" (F.-Hern. I: 13); "Coipo, s. - Especie de nutria que vive de preferencia en los pajonales. Es roedor, hace cuevas para vivir y es anfibio" (Cañ.: 260); "koipu, s., el coipu, mamífero roedor que tiene sus ubres laterales [...]" (Aug. I: 91); $\boldsymbol{k o i p u}$, el coipu (Coñ.: 109); "Koipu = el coipo o la nutria" (Alon., 1985: 132); “koypu [koy'pu]: Coipo" (Catr.: 148). En cronistas y J. I. Molina: coipu (Ros. I: 308); coipo (Oliv.: 31); coipú (Mol. I: 324); coipu: ratón acuático (Vid.: 272); coipu: pequeño castor (Carv. y G.: 14); соури: anfibio (JPG.: 24).

\section{Myocastor coipus Myocastoridae}

"colicoli. (de or. mapuche). m. Chile. Especie de tábano, de color pardo, muy común y molesto" (DRAE: 398).

De kolikoli /kolikoli/, kolükolü /kolïkolï/ 'muy pardo', 'muy castaño', 'muy colorado'. "Coli coli, moscardas" (Vald., Voc.); "Colicoli - moscardon pardo" (F., Cal.: 458), "Moscardones-v. pùlomen, colicoli" (F., Voc.: 372); "Coli coli, asilus" (H., Chil. II: 632); "COLICOLI. Moscardón pardo" (F.Hern. I: 13)"; "colicoli, m.n. vulgar de un insecto díptero (Tabanus spec. GAY, Zool.VIII 481. En el testo VII 391 i sig. bajo 'tabanus' no se da ningún nombre vulgar Cp. colihuacho. Molina 419 da colicoli como n.vulg.de los insectos en jeneral" (L., DE.: 198-199). "Colù, coli o colli-color bermejo, colorado: aplícanlo al color pardo, y el castaño de los caballos [...]" (F., Cal.: 458); "Colù, color heluus, ravus" (H., Chil. II: 632); "kolü, adj., color café claro y obscuro, pardo, bruno, castaño" (Aug. I: 92). La reduplicación de un término indica en mapuche 'intensidad', 'abundancia'.

En J. I. M. Molina: Insectos, Colicoli (I: 229).

\section{Tabanus sp.}

Tabanidae

“coliguacho. (Del mapuche collihuacho). m. Chile. Moscardón negro, especie de tábano, con los bordes del coselete y el abdomen cubiertos de pelos anaranjados o rojizos" (DRAE: 398). 
De kolliwacho /koßiwačo/, kolwachu /kolwaču/, kollwatu /koßwatu/. "Collihuacho - un moscardon renegrido, y fiero" (F., Cal.: 459), "Tábanos - colicoli, colihuacho" (F., Voc.: 403); "Insecta volucria. leflu llavacha [...] crabro, oestrum, colhuachu [...]" (H., Chil. I: 224), "Colhuachu, crabro, oestrum" (H., Chil. II: 632); "COLLHUATU. Tábano, moscardon" (F.Hern. I: 13); "kollwato, s., el coliguacho (insecto), especie de tábano [...]" (Aug. I: 92); kollwatu, colihuachos (Coñ.: 116); "Kollüwachú = el tábano colihuacho" (Alon., 1985: 136).

Scaptia lata

Tabanidae

"colocolo (De or. mapuche. m. Chile. Especie de gato montés "(DRAE: 400).

De kodkod /koðkoð/, kollkoll//koאkoא/, kolokolo /kolokolo/ 'gato montés'. "Codcod, colocolo - gato montés" (F., Cal.: 457); "Bellua sylvestres [...] catus, felis sylvestris, $\operatorname{cod} \operatorname{cod}$ [...]" (H., Chil. I: 220); "Codcod, felis, catus ferus, sylvestris" (H., Chil. II: 631); "COLLCOLL. Gato montés" (F.Hern. I: 13); "Codcod, s. El gato montés, vulgarmente huiña" (Cañ.: 259); "kodkod, s., la huiña (gato montés) amarillenta con pintas negras" (Aug. I: 90); kodkod, wiña, gatos monteses (Coñ.: 108); "Kodkod = la huiña o gato montés" (Alon., 1985: 132, 1989: 229) Una especie de gato montés. Nombre de un célebre cacique, de la primera época de la conquista, exaltado por Alonso de Ercilla y Zúñiga, debido a su sabiduría y prudencia.

En cronistas y J. I. Molina: codcod, collcoll, gatos monteses (Ros. I: 322); colocolo: gatos monteses (Mol. I: 332, 333); "La guiña, es un gato montés que tiene las mismas propiedades del colocolo" (Carv. y G.: 14).

Felis colocola

Felidae

“concón. (De or. mapuche). m. Chile. autillo² (DRAE: 415).

De kongkong /koykoy/. "koykoy, s., el buho (ave nocturna)" (Aug. I: 91); koykoy, el concón (Coñ.: 111); "Kongkong = el concón" (Alon., 1985: 133).

Strix rufipes

Strigidae

“culpeo. (Del mapuche culpeu). m. Chile. Especie de zorra más grande que la común europea, de color más oscuro y cola menos pelosa" (DRAE: 482). De kulpew /kulpeu/. "Culpeu, raposa grande" (Vald., Voc.); "Culpeu-raposa grande" (F., Cal.: 464); "Bellua silvestres [...] vulpes maior, culpeu [...]" (H., Chil. I: 220), “Culpeu, vulpes major" (H., Chil. II: 637); "CULPEU. Raposa, zorra, el macho" (F.-Hern. I: 14); "Culpeo, s. - Zorro grande, más desarrollado que el común de los de su especie" (Cañ.: 202); el culpeu 
(Cav., 1914: 51); "zorra, f., yərü; (una especie mayor) kulpeu" (Aug. II: 418); kulpeu, el zorro grande o culpeu (Coñ.: 108).

En cronistas y J. I. Molina: Gulpeu [¿Culpeu?]: raposa grande (Ros. I: 327); Culpeu: zorra grande (Mol. I: 330, 331, 332); culpeu (Vid.: 275); culpeu: una de las especie de zorros (Carv. y G.: 13): culpeo: zorra grande (JPG: 24).

\section{Pseudoalopex culpaeus Canidae}

"cururo. m. Chile. Especie de rata campestre, de color negro y muy dañina" (DRAE: 487).

Probablemente de kurü-lu /ku.ıї-lu/, 'el que es negro', o por el grito que emite. El nombre del animal ha sido yamka/jamka/. "yamka +, s., el topo (mamífero roedor)" (Aug. I: 282); yamka, el cururo (Coñ.: 109).

\section{Spalacopus cyanus Octodontidae}

"diuca. (De or. mapuche). f. Ave de Chile y de la Argentina, de color gris apizarrado, con una lista blanca en el vientre" (DRAE: 567).

De diwka /djuka/. "Diuca, vn pajaro" (Vald., Voc.); "Diuca-paxarito conocido, como gorrion" (F., Cal.: 478); "Aves oscines seu canorae, ulcatun [ùlcatun] [....] Diuca" (H., Chil. I: 223); "Diuca, avis” (H., Chil. II: 651); "VIUCA. La viuca, avecilla" (F.-Hern. I: 81); "Viuca (s. f.). Diuca" (Cav., 1914: 415); “diuka, s., el pájaro diuca" (Aug. I: 33); diuka, la diuca (Coñ.: 111); "shiuka =la diuka" (Alon.: 1989: 133); “diwka [oiw'ka]: Diuca" (Catr.: 154). Se registra también el nombre viuca, pero el más común es diuca.

En cronistas y J. I. Molina: diuca: "ave de color celeste" (Oliv.: 32); Diuca (Mol. I: 278); diuca (Vid.: 242); tiuca [sic]: "especie de gorrión de color celeste" (JPG.: 27).

\section{Diuca diuca \\ Emberizidae}

“diucón. (Del aum. de diuca). m. Chile. Pájaro mayor que la diuca y muy parecido a ella" (DRAE: 567).

De diwka /djuka/. Es llamado también urco, de wüdko /wïðko/ ['wəөko, 'wəðko].

Pyrope pyrope

Tyrannidae

"dóllimo. (de or. mapuche). m. Molusco pequeño de agua dulce, de concha bivalva que se cría en Chile" (DRAE: 571).

De dollüm /ðoKïm/. "Dollùm - unos choritos, con cuyas cáscaras se hacen la barba, y las llaman ùthiv" (F., Cal.: 478); "Conchae quibus sibi pilos barbae radicitus extrahunt, $\boldsymbol{d o l l m}$ " (H., Chil. I: 227); "DOLL $\dot{\boldsymbol{U} M}$. Unas conchitas con que se hacen la barba: dollùmtun, hacérsela así: las llaman ùthiv" (F.Hern. I: 19); "Dóllimo, s. - Pequeño molusco bivalvo que se encuentra en 
los ríos y lagunas, que se parece al choro" (Cañ.: 272); "Dolleme (s. m.) - Marisco de agua dulce. De "dollüm": unos choritos (Febrés) [...]" (Cav., 1914: 337, 1921: 49); "dollom, s., especie de choros pequeños que existen en los ríos o lagunas" (Aug. I.: 33), "dollüm $=$ dollom" $=$ shollom=shollüm" (Aug. I: ibíd.); dolləm, el dóllim (Coñ.: 120); “dollüm, shollüm choritos de agua dulce" (Alon., 1989:108). Los mapuches usaban las conchas del molusco para quitarse la pilosidad facial.

En cronistas y Molina: Dollum [¿dollùm?], Pellu, Uthif: almejas de agua dulce (Mol. I: 222); Dollin (Carv. y G.: 21)

Diplodon chilensis

Bivalvia: Hyriidae

"fíofio. (Voz onomat.). m. Chile. Pájaro insectívoro, de plumaje verde aceitunado, blanquecino por el vientre y la garganta, y con una cresta blanca" (DRAE: 719).

¿De wiyu /wiju/, wiw /wiu/? "Vuio, s. ave pequeña del bosque" (Cañ.: 330); "- el fiofio [...]" (Cav., 1914: 51); "wiyu, s., cierto pajarito; su nombre es onomatopéyico" (Aug. I: 268); wiyu, el fiofio (Coñ.: 111 - 112); “wiyu el pájaro huiú" (Alon., 1985: 133), “Wiyu el huíu” (Alon., 1989: 235).

Elaenia albiceps

Tyrannidae

"guairabo. m. Chile. Ave nocturna zancuda, de plumaje blanco y cabeza y dorso negros" (DRAE: 788).

¿De wawraw /waun..au/, /wayraw/ /wain.ıaun/? "Aves de la tierra son [...] guavras (qu'es un ave a manera de cuervo que tiene su propiedad de comer las cosas muertas [...]" (Viv.: 159). Es la única documentación en fuentes coloniales que podría corresponder al guairabo. El nombre en singular transcrito fonológicamente sería /waư.ıa/, y coincidiría con el más común actualmente que es wagda /warea/. "waqda, s., el huadrado, guairabo [...]" (Aug. I: 245); waqda, guairavo (Coñ.: 113), "waqda, warda el guairado, el guadrado, ave nocturna de color castellano" (Alon., 1989: 204). También se registra vauda /bauda/, en Chiloé: "Vauda (s. f.) - Ave considerada fatídica, cuyo grito anuncia desgracias" (Cav., 1914: 414). Hemos oido weyravü /wei..ıavi// en el Alto Bío-Bío, un sector lingüísticamente conservador.

Nycticorax nycticorax

Ardeidae

"guala. (Del mapuche wala). f. Chile. Ave palmípeda, con el pico verdoso, el plumaje rojo oscuro, y blanco por el pecho" (DRAE: 788).

De wala /wala/. "Huala-unos patitos" (F., Cal.: 504); "Aves aquatiles, co ùñm. Anas, huala [...]" (H., Chil. I: 223), "Huala, anas minor" (H., Chil. II: 669); "HUALA . Unos patitos" (F.-Hern. I: 27); “Huala, s. - Una ave del 
agua que no vuela, es mayor que la tagua, y de color pardo oscuro" (Cañ.: 278); wala, la huala (Coñ.: 113); "wala, s., ave acuática zambullidora, conocida con el nombre de guala o huala [...]" (Aug. I: 244); "Wala= la huala" (Alon., 1985: 134, 1989: 202); “wala [wa'la]: Huala o ave acuática o zambullidora [...]" (Catr.: 158).

\section{Podiceps major \\ Podicipedidae}

"guarén. m. Chile. Rata de gran tamaño" (DRAE: 793).

De waren /wa.ıen/. "Waren Glis [...] A Rat [...] die Ratze [...] el ratón" (Herck., en Schul.: 11, 25, 39, 56); "Bellua sylvestres [...] sorex, huaren" [...]" (H. Chil. I: 220).

\section{Rattus norvegicus Muridae}

"güemul. m. Arg. y Chile. huemul" (DRAE: 795). "huemul. (Voz mapuche). $\mathrm{m}$. Cérvido de los Andes australes, de formas robustas, cola corta y orejas bastante desarrolladas. Su pelaje es corto y áspero, de color pardo intenso, con la parte inferior de la cola blanca. Habita en estepas y bosques abiertos" (DRAE: 837).

De wemul /wemul/. "Huamul [sic], cieruo" (Vald., Voc.); "wemul, s., el ciervo chileno" (Aug. I, Suplemento: 13); wemul, el huemul (Coñ.: 36, 109); "wemul el ciervo chileno" (Alon., 1989: 212).

En cronistas y J. I. Molina: Guemúl [Güemúl] o Huemúl (Mol. I: 364, 365); guemul [güemul] (Vid.: 285); huemul "en todo parecido a los burros" (!) (Carv. y G.: 14).

\section{Hippocamelus bisulcus Cervidae}

"huillín. (Del mapuche williñ). m. Especie de nutria de Chile" (DRAE: 838). Tb. güillín (DRAE: 796).

De willin /wiKin/, williñ /wiKijp/. "Huillin v. ghùyllin - que es la nùtria, animal anfibio" (F., Cal.: 517), "Nutria-ghùyllin" (F., Voc.: 376); "Amphibia. huillin, coipo [...]" (H., Chil. I: 221), "Huillin, lutra" (H., Chil. II: 680); "HUYLLIN. Animalito anfibio, la nutria" (F.-Hern. I: 32); "Huillin, s. Animal anfibio, muy estimado por su piel. Es roedor" (Cañ.: 280); el huillín (Cav., 1914: 51); "williñ, s., la nutria [...]” (Aug. I: 263); williñ, el huillín o la nutria (Coñ.: 108); "Williñ: =el huillín" (Alon., 1985: 132), "williñ la nutria" (Alon., 1989: 227).

En cronistas y J. I. M. Molina: Guillin [Güillin]: nutria (Ros. I: 308); coipo y guillin [güillin]: "animales anfibios" (Oliv.: 31); el Guillino [Güillino] y el Coypú:, quadrúpedos fluviales (Mol. I: 321,322); guiglin [sic]: especie de 
castor (Vid.: 272); guillin [güillin]: pequeño castor (Carv. y G.: 14); guillin [güillin]: anfibio (JPG.: 24).

Lutra provocax

Mustelidae

"laucha (Del mapuche laucha o llaucha) f. Arg., Bol. y Ur. ratón (// mamífero roedor) (DRAE: 917).

De llawcha / auuča/, lawcha /lauča/. "Llaucha, raton de casa" (Vald., Voc.); "Laucha, llaucha--ratoncillo" (F., Cal.: 530); "Bellua silvestres [...] musculus, llaucha [...]" (H. Chil. I: 220); "LA UCH A. Ratoncillo" (F.-Hern. I: 40); "Laucha, s. - Ratón pequeño" (Cañ.: 287); "laucha, llaucha, s., [...] ratoncillo (pachi dewï)" (Aug. I: 111); pichike dewü, las lauchas (Coñ.: 109). Mus musculus

Muridae

"loco" (Voz mapuche). m. Chile. Molusco de carne comestible, pero dura, que se come guisado" (DRAE: 945).

De loko/loko/. "Loco - cierto marisco" (F., Cal.: 534); “Cubùll, lafquentu. Omne comestibile, quod prehenditur in mari [...] Pellu, piur, macha, locos, conchae marinae" (H., Chil. I: 226-227), "Loco, species conchae" (H., Chil. II: 697); "LOCO corù. Marisco llamado loco" (F.-Hern. I: 38); "Loco, s. Un molusco del mar, que vive adherido a las rocas, cubierto con una concha muy frente [sic]" (Cañ.: 291); locos (Cav., 1914: 52); loko, s., el loco, cierto marisco de muy buen sabor [...]" (Aug. I: 116); loko, los locos (Coñ.: 120); "loko el marisco "loco"” (Alon., 1989: 141).

En cronistas y J. I. Molina: loco (Ov.: 60); loco (Oliv.: 34); el Loco (Mol.I: 224); conchas y testáceos [...] locos [...] "El loco es apreciado de todos por el buen gusto de su carne" (Vid.: 216, 217); locos (Carv. y G.: 21).

\section{Concholepas concholepas Muricidae}

"loica. (Voz mapuche). f. Pájaro chileno algo mayor que el estornino, al cual se parece en el pico, pies, cola y aun en el modo de vivir y alimentarse. El macho es de color gris oscuro, manchado de blanco, a excepción de la garganta y pecho, que son de color escarlata. Se domestica con facilidad y es muy estimado por su canto dulce y melodioso" (DRAE: 946). También lloica (DRAE: 946).

De lloyka / Koika/, loyka /loika/. "Loyca, lloyca - un pájaro pechicolorado, que come el maiz" (F., Cal.: 534); "Aves indolis ab aliis diversae [...] lloica [...]" (H., Chil I: 224); "LOICA. Pájaro pechicolorado que se come las sementeras al brotar" (F.-Hern. I: 38); "Lloica, s. - Pájaro muy conocido por su pechuga color rojo y por su canto" (Cañ.: 294); "loika, s., la loica (pájaro)" (Aug. I: 116); loika, la loica (Coñ.: 112); "Lloika = la lloica" (Alon., 1985: 133), "loyka, lloyca [lloyka] la loica" (Alon., 1989: 141); "lloyka [Koi'ka] Lloica o loica" (Catr.: 157). 
En cronistas y J. I. Molina: lloicas, "Llaman los españoles estos pájaros pechicolorados, porque no hay grana ni escarlata que llegue a la fineza del rojo de su pecho [...]" (Ov.: 66); loica (Ros. I: 319); Loyca (Mol. I: 282, 283); loyca (Vid.: 243); lloica o pichi "que los españoles llaman Pechicolorado [...]" (Carv. y G.: 25); la lloica, pechicolorada (JPG.: 27).

\section{Sturnella loyca}

Icteridae

"macha. f. Molusco de mar, comestible y muy abundante en los mares de Chile y Perú" (DRAE: 955).

De macha /mača/. "Macha - cierto marisco" (F. Cal.: 544); "Cubùll, lafquentu .omne comestibile, quod prehenditur in mari [...] macha $[\ldots]$ " (H., Chil. I: 226-227), "Macha, concha" (H., Chil. II: 706); "macha, s. Cierto marisco muy abundante en ciertas playas y muy conocido por esto" (Cañ.: 294); la macha (Cav., 1914: 52); "macha, s., la macha, cierto marisco [...]" (Aug. I: 127); "macha, las machas" (Coñ.: 120).

En cronistas y J. I. Molina: macha: marisco (Nuñ. de P.: 933); "La Machi [sic], Solen Macha [...] es del genero de aquellos Testáceos, llamados Cuchillos de mar en consideración á su hechura [...]" (Mol. I: 222]; machas: navajuelas (Vid.: 219); machas (Carv. y G.: 21).

\section{Mesodesma donacium}

Mesodesmatidae

"nuco. (Del mapuche nucu pájaro de mal agüero). m. Chile. Ave de rapiña, nocturna, semejante a la lechuza" (DRAE: 1081).

De nuku /nuku/, nuko /nuko/. "Nucu, vn pajaro," (Vald., Voc.); "Nucuave de mal agüero, como buho" (F., Cal.: 569); "Aves nocturnae, aì̀pun $\boldsymbol{x}$. [ùñm], bubo, nисо, nиси [...]" (H., Chil. I: 223); "Nucu, bubo" (H., Chil. II: 729); "nuku*, s., el nuco (ave de mal agüero [...])" (Aug. I: 150); $\boldsymbol{n} \boldsymbol{u} \boldsymbol{k} \boldsymbol{u}$, el nuco (Coñ.: 111); "Nuku = el nuco" (Alon.: 133).

En cronistas: nuco y chonchon: "aves semejantes a la lechuza" (Oliv.: 32); nuco: "semejante a la lechuza en figura y color" (JPG.: 27).

Asio flammeus

Strigidae

"pequén. (Del mapuche pequeñ). m. Chile. Ave rapaz, diurna, del tamaño de un palomo, muy semejante a la lechuza, pero que habita en cuevas a campo raso, de las cuales despoja a algún roedor. Su graznido es lúgubre y muy frecuente" (DRAE: 1171).

De pekeñ /peken/. "Pequeñ, mochuelo" (Vald., Voc.); "Pequeñ mochuelo ave" (F., Cal.: 586); "Aves oscines seu canorae, ulcatun [ùlcatun] [...] asio, pequeñ" (H., Chil. I: 223), "Pequeñ. Asio" (H., Chil. II: 742); "Pequen, s. - Pájaro de rapiña muy parecido a la lehuza. Es diurno y nocturno" (Cañ.: 210); "pekeñ, s., el mochuelo, (ave) [...]" (Aug. I: 168); pekeñ , el mochuelo (Coñ.: 111); "Pekeñ = el pequén. Ave 
nocturna y de mal agüero" (Alon., 1985: 133);"pekeñ [pe'ken]: Pequén [...]" (Catr.:155).

En cronistas y J. I. Molina: Pequen (Mol. I: 293); pequen: especie de ave nocturna (Vid.: 246).

\section{Athene cunicularia Strigidae}

"peuco. (Del mapuche peuco). m. Chile. Ave de rapiña, diurna, semejante al gavilán, aunque el color varía según la edad y el sexo del animal, dominando el gris ceniciento. Se alimenta de pájaros, palomas y aun de pollos de otras aves, y a falta de ellos, come lagartijas y otros reptiles" (DRAE: 1185).

De pewku /peuku/. "Peucu, gauilocho" (Vald., Voc.); "Peиcu - gavilan ave de rapiña" (F., Cal.: 587); "Aves aucupes. Tuvoe pu ùñm [....] accipiter, peucu [...]" (H., Chil. I: 223), "Pеucu, accipiter" (H., Chil. II: 743); "PEUCU. Peuco ave de rapiña" (F.-Hern. I: 54); Реиси (Cañ.: 157); "peuko, s., el halcón [...]" (Aug. I: 171).

En cronistas y J. I. Molina: peucus (Ov.: 66); реиси (Ros. I: 318); “[...] los peucos $[\ldots]$ los alcones $[\mathrm{sic}][\ldots]$ los varis $[\ldots]$ las águilas $[\ldots]$ todas aves de rapiña [...]" (Vid.: 251); "el peuco, que solo habita en lo más aspero e los montes de los Andes [...]" (Carv. y G.: 13); реисо (JPG.: 26).

\section{Parabuteo unicinctus Accipitridae}

“pichihuén. (Del mapuche pichi, pequeño, y huenu, 'arriba'). m. Pez acantopterigio comestible, de las costas de Chile, que suele tener unos 40 cm de longitud" (DRAE: 1188).

Probablemente de pichi /piči/, püchi /pïči/ 'pequeño/a y wün/wïn/ 'boca' 10 . El nombre no está consignado en léxicos del mapuche; tampoco en las crónicas.

\section{Menticirrhus ophicephalus Sciaenidae}

"pidén. (Del mapuche pideñ).m. Chile. Ave parecida a la gallareta o foja española. Es de color aceitunado por encima y rojizo por el vientre, pico rojo en la base, que se va tornando azulado y verdoso en el extremo, ojos purpúreos y tarsos y pies rojos. Frecuenta las riberas y se alimenta de gusanos y vegetales. Es muy huidiza y su canto es melodioso" (DRAE: 1190).

De pideñ /piðen/, /piøen/. "Pideñ - un paxaro negro de los esteros [...]"

\footnotetext{
10 "Pichigüen, Lichigüen. Bajo la mandíbula inferior y en la inmediata proximidad de su extremo anterior se implanta una barbilla corta y gruesa que suele desaparecer, por retracción, en ejemplares embalsamados" (Mann: 245).
} 
(F., Cal.: 590); “Aves praedatrices .muntuvoe $\boldsymbol{x}$ [ùñm] [...] Piden; pifen. Cancros sub qua venatur" (H. Chil. I: 223); "pideñ , pifen, avis" (H., Chil.

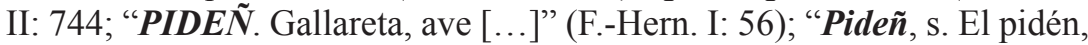
que vive en los pajonales, de plumaje negro, de poco vuelo" (Cañ.: 311); Piden, o cotuta (Cav., 1914:317); "pideñ, s., ave palúdica, conocida con tal nombre [...]" (Aug. I: 179); pideñ , el pidén (Coñ.: 113); "Pideñ = el pidén" (Alon., 1985: 133).

En cronista: Piden: gallinilla (Vid.: 256).

\section{Pardirallus sanguinolentus Rallidae}

"pillo". (Del mapuche pillu). m. Ave zancuda, especie de ibis, de color blanco con manchas negras, patas muy largas en proporción del cuerpo del ave, así como el cuello, que tiene unos $60 \mathrm{~cm}$ y del cual pende una bolsita o papo. El pico es grueso, convexo y puntiagudo, de $1 \mathrm{dm}$ de largo y desnudo de plumas hasta la frente. Tiene cuatro dedos en cada pie, unidos por una membrana, y la cola corta. Vive en los lugares húmedos y se alimenta de reptiles" (DRAE: 1194).

De pillu /piאu/. "Pillu - un ave mayor que la cigüeña, come sapos, culebras, etc." (F. Cal.: 593); “Aves praedatrices. montuvoex $[\dot{u} \tilde{n} m][\ldots]$ pillu [....]" (H., Chil. I: 224); "Pillu, ardea, ardeola, ciconia" (H. Chil. II: 746); "PILLU. Un ave blanca como cigüeña, garza" (F.-Hern. I: 57); "Pillu, s. - El pillo, pájaro de la familia de los zancudos" (Cañ.: 313); "pillu, s., especie de cigüeña blanca* [...]" (Aug. I: 182); pillu, el pillo (Coñ.: 113); "Pillú = el pillo" (Alon., 1985: 134).

En cronistas y J. I. Molina: Pillu: ibis de color blanco variado de negro (Mol. I: 270, 271); el pillu (JPG.: 26).

\section{Ciconia maguari Ciconiidea}

"pilme. (Del mapuche pulmi). m. Chile. Coleóptero de color negro, muy pequeño, que causa mucho daño en las huertas" (DRAE: 1194).

De pülmi /pïlmi/. "Pùlmi - unos moscones negros venenosos como avechuchos" (F., Cal.: 607); "Insecta volucria. leflu llavacha [...] asilus, pllmi [pùllmi] [...]" (H., Chil. I: 224), "Plmi [pùlmi], crabro, asilus, oestrum; musca venenosa, virulenta" (H., Chil. II: 751); "Pülmi. s. - La cantárida del país" (Cañ.: 314); "pülmi, s., el pilme (vulg.), un coleóptero negro" (Aug. I: 191); pülmi, el pilme (Coñ.: 114).

En cronistas y J. I. Molina: Pilmo [sic]: arruina las plantas leguminosas. Es un escarabajo negro (Mol. I: 229); pilme (Vid.: 223).

\section{Epicauta pilme}

Meloidea 
“pilpilén. (De or. mapuche). m. Chile. Ave zancuda y ribereña, de pico rojo y largo, que le sirve para abrir las valvas de los mariscos de que se alimenta. Tiene tres dedos en cada pie, sin pulgar, tarsos rojos y plumaje negro y blanco, con grandes manchas de cada color" (DRAE: 1195).

De pilpilen /pilpilen/. "pilpil (s.m.). - Un ave zancuda [...]" (Cav., 1914: 389); "pilpilen, s., el pájaro pilpilén o come machas [...]" (Aug. I: 180); pilpilen, el pilpilén o comemachas (Coñ.: 113).

Haematopus palliatus

Haematopodidae

"pilvén. (De or. mapuche). m. Pez de agua dulce, americano, que tiene unos diez cm de longitud y nada siempre en cardumen" (DRAE: 1195).

¿De vül /vïl/, *pül /pïl/ 'cosa unida, amontonada' y vün/vïn/ 'carne (cuerpo)': "cuerpo(s) unido(s)"? Ello porque los peces forman cardúmenes estrechamente unidos, compactos (como las frutas). "Vùll-it.: cosa junta, pegada, ò seguida, o amontonada", "Vùln- juntarse, pegarse, arrimarse, o amontonarse", "Vün- las carnes del cuerpo, y la fruta, y cosa cuaxada como las frutas" (F., Cal.: 666); "Vì̀l, res unita, conglutinata, copulata", "Vìnn, caro exos; pulpa etiam pomorum [...] vn,vnn, esse densum, spissum" (H., Chil. II: 612).

El nombre del pez no está consignado en los léxicos mapuches; tampoco en las crónicas. La posible etimología dada por Lenz (DE.: 645, sub pulven ) no es verosímil; la propuesta por Román, solo parcialmente (T. 4: 288 - 289). Trychomycterus areolatus

Trychomycteridae

"pinuca.f. Chile. Marisco de cerca de un decímetro de longitud y dos centímetros de anchura, de piel gruesa, coriácea, blanco, pardusco y arrugado. Es comestible" (DRAE: 1198).

¿De pinuka /pinuka/? "Pinuca (s.f) - Un marisco del género de las holoturias [...]" (Cav., 1921: 96). No está documentado en los léxicos coloniales del mapuche. La única documentación es la consignada. Podría provenir de otra lengua.

\section{Urechis chilensis}

Urechidae

"pirgüín. (De origen mapuche). m. Chile. Especie de sanguijuela de una pulgada de longitud, que vive en los remansos de los ríos y aguas dulces estancadas y penetra en el hígado e intestinos del ganado, al que suele causar la muerte. // 2. Chile. Enfermedad causada por este parásito"(DRAE: 1201). También pirhuín (DRAE: ibíd.).

De. pidwin /piðwin/, püdwiñ /pïðwị/. "Pidhuiñ - un gusano, v. pùdhuiñ " (F., Cal.: 590); "Pdhuin [pùdhuin], hirudo, sanguisuga" (H., Chil. II: 739); 
"PÙDHUIÑ. Gusano negro, o sanguijuela, que se cría en los montes o gualbes, si la come el gusano [¿ganado?] se apesta [...]" (F.-Hern. I: 61); "Piduiñ , s. El pirgüin, gusano que se encuentra en la raíz el cuerno de los carneros enfermos" (Cañ.: 311); "pədwiñ , s., animal molusco, parecido a la sanguijuela y como ésta chupador de sangre; el piruin o pigüin [sic]" (Aug. I: 173); pëdwiñ , pirhuines (Coñ.: 121); "Pëdwiñ = la sanguijuela, pirhuín" (Alon., 1985: 135); “püdwiñ [pio'win]: Pirhuín o gusano parásito que ataca el hígado o intestinos de los animales cuando estos beben agua en charcos o lagunas de aguas estancadas" (Catr.: 161).

\section{Fasciola hepatica}

Fasciolidae

"pitihué. (Voz onomat., del canto del ave).m. Chile. Ave trepadora, variedad del pico' ${ }^{2}$. Habita en los bosques y matorrales, se nutre de insectos y fabrica su nido en los huecos de los árboles" (DRAE: 1204).

De pütiw/pïtiu/, püchiw/piěiu/. "Aves indolis ab aliis diversae, $\boldsymbol{c a} \boldsymbol{x}$ [ùñm] [...] ptiu [...]" (H., Chil. I: 224); "PITHIU. Ave como tordo cenicienta o parda" (F.-Hern. I: 58); "Pitiu, s. - Ave silvestre, que dicen que es agorera y que tiene cuatro pies, lo que no es efectivo" (Cañ.: 313); "pochiu, s., el pájaro pichíu o pitigüe. Colaptes Pitius" (Aug. I: 172); pëchiu, el pitihue (Coñ.: 112); "Pütiu = el pitío, carpintero menor" (Alon., 1985: 133).

En J. I. Molina: Pitiu (I: 261, 262).

\section{Colaptes pitius}

Picidae

"pitoitoy. (Voz onomat., por el grito que emite al emprender el vuelo). m. Am. Ave zancuda de las costas, de plumaje compacto, oscuro por el lomo y blanco con manchas por el vientre, pico corto y tarsos altos" (DRAE: 1204).

De pütrü /pït'ï/ 'mucho(s) y troy /t' $\mathbf{o i} /$ 'coyuntura', 'articulación': 'el zancudo'. 'Pùthun - haver mucho, no poco" (F., Cal.: 611), "Troy - coyuntura $[\ldots]$ vuta [vùta] thoygey dicen de uno de piernas largas, ò zancudo" (F., Cal.: 646); "Ptùn, abundantia, copia, ubertas, affluentia: abundo [....]" (H., Chil. II: 757); "Toi, commissura, junctura; articulus, punctum [...] vìta toi gei, oblongis cruribus" (H., Chil. II: 788); "potrü, adv., en abundancia, mucho [...]" (Aug. I: 178); "troi, s., articulación, coyuntura (de plantas y animales), nudillo de dedo [...] Füchake troi gei. Tiene las piernas muy largas" (Aug. I: 234), "zancudo, adj. Ser - o [...] füchake troi yen $[. .$.$] "$ (Aug. II: 417); "[...] pitoitoi: "unas aves zancudas de la familia de los escolopécidos" (Cav., 1914: 393, 1921:97). Es verosímil que el nombre se deba a sus patas largas, y no a la acción de picotear (Vid L., DE.: 614). Tampoco sería onomatopéyica.

\section{Tringa sp.}

Scolopacidae 
"piuquén. (Del mapuche piuqueñ). m. Chile. Especie de avutarda, mayor que la europea, de color blanco, menos la cabeza, que es cenicienta, así como los cuchillos de las alas, y negras las primeras guías. La cola es corta y tiene 18 plumas blancas. Se alimenta de hierbas y no se reproduce hasta los dos años. Es mansa, se domestica con facilidad y su carne es comestible" (DRAE: 1205).

De piwkeñ /piunkej/. "Piùqueñ - unos patos grandes" (F., Cal.: 598); "peukeñ = el ganso salvaje" (Alon., 1985: 133).

En cronistas y J. I. Molina: piuquenes: pájaros parecidos a los gansos (G. de Naj.: 34); piuquén: "es ave grande como el pavo" (Oliv.: 31); Piuquén: avutarda mayor (Mol. I: 291), piuquen: "especie de otarda" (Vid.: 256); el piuquén: "especie de pato del grandor de un pavo" (JPG.: 26).

Chloephaga melanoptera

Anatidae

"piure. (Del mapuche piur). Chile. Animal precordado, de la clase de los Tunicados, sedentario, cuyo cuerpo, de color rojo y de cuatro a seis centímetros de longitud, tiene la forma de un saco con dos aberturas, que son, respectivamente, la boca y el ano y es comestible" (DRAE: 1205).

De piür /piï.ı/, piwü /piwï/. "Piùr - un marisco colorado muy sabroso, y sobre todo el de Chiloé" (F. Cal.: 598; "Cubùll, lafquentu [...] omne comestibile, quod prehenditur in mari [...] piur [...], conchae marinae" $(\mathrm{H}$., Chil., I: 226-227), "Piur, conchae species [...]" (H., Chil. II: 750); "PIÜR. Piures marisco colorado, mui sabroso, especialmente el de Chiloé [...]" (F. -Hern. I: 58); "Piur.s. - Marisco que vive en celdas de una peña especial" (Cañ.: 314); "piwü, s., cierto marisco llamado "piur" [...]" (Aug. I: 186); piwü, los piures (Coñ.: 121).

En cronistas y J. I. Molina: piur (Oliv.: 34; Piúres (Mol. I: 214, 215, II: 214); piure (Vid.: 214).

\section{Piura chilensis}

Pyuridae

"pololo". (De or. mapuche). m. // 2. Chile. Insecto como de un centímetro y medio, fitófago, y que al volar produce un zumbido como el moscardón. Tiene la cabeza pequeña, el cuerpo con un surco por encima y verrugas, élitros cortos y de color verde, vientre ceniciento, patas anteriores rojizas, y posteriores verdes" (DRAE: 1220).

Según Lenz, la etimología es mapuche: "FEBRÉS: pùldu, pùl-lu 'mosca' cp. pùlomen - un moscardon. Habrá que pensar en una derivación participial en -lu: pùl-lu-lu "el que es, vuela, zumba como mosca". La palabra es evidentemente onomatopéyica" (L., DE.: 622-623). Es posible, pero no hay documentación que ratifique la etimología. El nombre mapuche del insecto es actualmente wülo /wïlo/ ['wəlo]. ("sanjuán, m., (coleóptero verde conocido 
con tal nombre) walo+" (Aug. II: 346); wëlo, el pololo (Coñ.: 114); “wülo = el pololo o sanjuán" (Alon., 1985: 135). En español se lo llama también sanjuán.

Hylamorpha elegans Scarabaeidae

"pudú. (Del mapuche pudu). Arg. y Chile. Cérvido pequeño, de aproximadamente $35 \mathrm{~cm}$ de altura, cuernos chicos, sencillos y rectos, que habita en los bosques de los Andes" (DRAE: 1260).

De puüdu /puïðu/, püdu /pïðu/. "Puùdu, venado," (Vald., Voc.); "Puedo Caprea" (Herck., en Schul.:25); "Puùdu, puùyu-un venado" (F., Cal.: 605); "Belluae silvestres. Caprea, puyu, puùdu" (H., Chil. I: 220), "Puùdu, puyu, cervus, caprea, dorcas, capreolus" (H., Chil. II: 759); "PUUUDU. Venado" (F.-Hern. I: 60); "Pudu.s. - Venado" (Cañ.: 314); el pudú, pequeño venado (Cav., 1914:50); "püdu, s., el venado [...]" (Aug. I: 190); püdu, el venado chileno (Coñ.: 36, 109); "Pudú = venado" (Alon., 1985: 131); "püdu [pi'eu]: Pudu o venado" (Catr.: 148).

En cronistas y J. I. Molina: Pudu: "cabra montés" (Mol.I:349), el pudu: especie de cabra silvestre (Mol. II: 13); pudú (Vid.: 267), pudo: "es muy análogo al cabrito" (Carv. y G.: 14); pudu: venado (JPG.: 24).

\section{Pudu pudu Cervidae}

"queltehue. (De or. mapuche). m. Ave zancuda de Chile parecida al frailecillo, que habita en los campos húmedos y que domesticada se tiene en los jardines porque destruye los insectos nocivos" (DRAE: 1272).

De kültew/kïlteu/, keltew/kelteu/. "qlteu, fraylecillo" (Vald., Voc.); “Threl (s. m.) -Thréguil, queltehue, frailecillo [...] (Cav., 1914: 411); kilteu, s., (exp. argentina) el pájaro tregle o jardinero [...]" (Aug. I: 88).

En cronistas: Culteu (Ov.: 68); kelteu (Vid.: 262). Al parecer, el nombre más común del ave es actualmente treile, de tregül $/ \mathbf{t}^{\mathrm{r}} \mathbf{e}$ ïl $/$.

\section{Vanellus chilensis Charadriidae}

"quetro. (Del mapuche quetho, cosa desmochada). m. Chile. Pato muy grande, caracterizado por tener las alas sin plumas, de modo que no vuela; los pies, con cuatro dedos, palmeados, y el cuerpo vestido de una pluma larga, fina y rizada como lana y de color ceniciento" (DRAE: 1274).

¿De kütro/kïtro/ o ketro/ketro/ 'mudo', 'tartamudo' o 'mocho'? “Quetrro, s. - especie de pato grande de los canales de Chiloé [...]" (Cañ.: 318); "Quetho (de quetru: el quetro, pájaro que abunda en el sur de Chile F.de A.) $\mathrm{m}$. Pato muy grande en el sur de Chile. Tiene alas pequeñas que no le sirven para volar" (Cav., 1921: 102-103); "kotru, s., el pato quetru [...] Su voz es kakaka" (Aug. I: 87); këtru, el pato quetro (Coñ.: 113); "Ketró = el 
quetró o mudo" (Alon., 1985: 134). Si significa 'mocho', se debería a que sus alas son muy cortas. Sin embargo, el nombre del ave es en mapuche kütro $/ \mathbf{k i ̈ t}^{\mathrm{r}} \mathbf{o} /$, con un significado probablemente diferente.

\section{Tachyeres pteneres Anatidae}

"quiltro, Bol. y Chile. m. Perro y, en particular, el que no es de raza" (DRAE: 1276).

No está documentado en los léxicos, pero debe provenir de kültru / $\mathbf{k i ̈ l t}{ }^{\mathrm{r}} \mathbf{u}$, kültro/kïltt $\mathbf{r} /$; no parece ser un préstamo de otra lengua amerindia. "Quiltro, s.- Perro del país muy ladrador y de mal carácter" (Cañ.: 319).

En cronistas y J. I. Molina: Molina sospecha que, antes de la llegada de los españoles al Reino de Chile, existían dos razas de perros "[...] el Borbon pequeño llamado Kiltho, y el Thegua ó perro comun, los quales han sido encontrados en todas las tierras que se han descubierto hasta el Cabo de Hornos" (Mol. I: 302); "Por el quiltro entienden una casta de pequeños perros lanudos y por thehua una casta de perro mediano de pelo corto" (Vid.: 265); “[...] quiltros que tenían los indios" (Carv. y G.: 16).

"quique. (Del mapuche quiqui). m. Am. Mer. Especie de comadreja" (DRAE: 1278).

De kiki /kiki/. "Quiqui, comadreja" (Vald., Voc.); "Quiqui - comadreja" (F., Cal.: 617); "Bellua sylvestris [...] comadreja, quiqui" (H., Chil. I: 220); "Quiqui [...] comadrecha [sic]" (H., Chil. II: 765); “QUIQUI. Comadreja, uron [sic]" (F.-Hern. I: 64); "Quiqui o quique, s. - Cierto cuadrúpedo pequeño, extremadamente irascible, que persigue a las ratas penetrando en sus cuevas. Es roedor" (Cañ.: 318); "kiki, s., la comadreja chilena [...]" (Aug. I: 88); kiki, el quique (Coñ.: 108).

En cronistas y J. I. Molina: Quiqui "especie de huron de color pardusco" (Mol. I: 330); quiqui: "animal feroz por su naturaleza y sumamente colérico. Este es una especie de huron" (Vid.: 274); quiqui: "es un animalejo pequeño" (Carv. y G.: 14): quique: comadreja (JPG.: 24)

\section{Galictis cuya} Mustelidae

"rara. (Voz onomat.). f. Am. Mer. Ave del tamaño de la codorniz, con el pico grueso y dentado, de color gris oscuro por el lomo, blanquecino por el vientre y negro en las puntas de las alas. Se alimenta de plantas tiernas, por lo cual es dañosa en las huertas y sembrados" (DRAE: 1288).

¿De rara /.ıa.ıa/? El nombre no aparece consignado en los léxicos coloniales, pero sí en las obras de Molina (I: 283) y G. de Vid. (248). Según Molina, "[...] Tiene por canto un grito ronco e interrumpido, que exprime [expresa] en cierto modo las sílabas de su nombre [...]" (I: 284). Según Vid., la rara es 
ave maligna (248). El nombre documentado es kamtrü /kamt'ï/. "Camtù, avis quae fabis ac floribus delectatur, vescitur [...]" (H., Chil. II: 617); CANTHI. La rara ave (F.-Hern. I: 6); "kamtrü, s., el pájaro "rara" [...] Es parecido a la loica, pero con pecho amarillento. Sus huevos son verdes, su grito es ka ka ka. Hace mucho perjuicio en las habas" (Aug. I: 76); kamtrü, la rara (Coñ.: 112).

\section{Phytotoma rara Phytotomidae}

"taca'. (De or. mapuche). f. Chile. Marisco comestible, de concha casi redonda, estriada, blanca, con manchas violadas y amarillas" (DRAE: 1441).

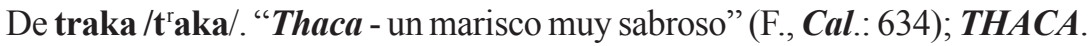
Marisco muy sabroso" (F.-Hern.: I: 71); "Trraca, s. La taca, ese bivalvo tan común en nuestras playas" (Cañ.: 324); "Taca (s.f.). Marisco [...]" (Cav., 1914: 408, 1921: 111); chakañ, las tacas (Coñ.: 120); “chakañ, s., cierto marisco con la concha más redonda que la de la macha" (Aug. I: 16).

En cronistas y J. I. Molina: "[...] se coge un género muy regalado de marisco, que llaman tacas [...]" (Ov.: 38); Taca (Ros. I: 301); taca (Oliv.: 34); Thaca, thacas (Mol. I: 222, II: 214); tacas (Vid.: 216); tacas (Carv. y G.: 21). Actualmente se llama también. chakañ /čakaj/.

\section{Protothaca thaca Veneridae}

"tagua. f. Chile. Ave, especie de fúlica, que vive en las lagunas y pajonales" (DRAE: 1442).

De trawatrawa/trawatrawa/. "Thahuathahua - cierto pato" (F., Cal.: 634); "THAHUA-THAHUA. Pajarito negro que anda en los ríos" (F.-Hern. I: 71); "trawatrawa, s., la tagua, ave acuática, del porte de un pato, color negro, pico encorvado y agudo, membrana natatoria en cada dedo separadamente, cresta amarilla en forma de hoja pegada sobre la raíz del pico [...]" (Aug. I: 227).; trawatrawa, la tagua (Coñ.: 113); "trawatrawa la tagua" (Alon., 1989: 182).

\section{Fulica armillata Rallidae}

"tenca. f. // 2. Arg. y Chile. Alondra de tres colas" (DRAE: 1462).

De trengka /t'tenka/, tenka/tenka/. "Calandria - thenca" (F., Cal.: 319); "Aves oscines seu canorae, ulcatun [ùlcatun] [...] Tenca" (H., Chil. I: 223), "Tenca, calandria" (H., Chil. II: 785); "tregka, s., la tenca (pájaro, Mimus thenca)" (Aug. I: 228); treyka, la tenca (Coñ.: 112); "Thrënka = la tenca" (Alon., 1985: 133, 1989: 183); "trengka [t'ey'ka]: Tenca" (Catr.: 157).

En cronistas y J. I. Molina: Tenca: calandria (Ros. I: 318); Thenca (Mol. I: 279); Thenca (Vid.: 243); la tenca: calandria (JPG.: 27). 
“tiuque. m. Arg. y Chile. Chimango"(DRAE: 1484).

De triwke /t'tiuke/, chiwke /čiuke/, triwkü/t'tiukï/, chiwkü/čiukï/. "Tiuque, vn pajaro" (Vald., Voc.); "Thiuque, ò chiuque - ave de rapiña, y gritona, conocida" (F., Cal.: 645); "Aves indolis ab aliis diversae, $\boldsymbol{c a} \boldsymbol{x}[\dot{\boldsymbol{u}} \tilde{\boldsymbol{n}} \boldsymbol{m}][\ldots]$ tiuque [...]" (H., Chil. I: 224); “Tiuque, chiuque, avis" (H., Chil. II: 787); "CHIUQUE. Ave gritona" (F.-Hern. I: 10); "Trriuque, s. - El tiuque, tan conocido" (Cañ.: 326); "Chiuque. (s. m.) - Tiuque [...]" (Cav., 1914: 331, 1921: 43); "chiukü, s., el tiuque (ave de rapiña). Su voz suena chiuchiu" (Aug. I: 24); chiukü, el tiuque (Coñ.: 111); "Trhiukü =el tiuque o chimango" (Alon., 1985: 133); “chiwkü [čiw'ki] : Tiuque" (Catr.: 155).

En cronistas: tiuque: "ave de rapiña" (Carv. y G.: 24); el tiuque (JPG.: 26).

\section{Milvago chimango}

Falconidae

"traro. (Del mapuche traru). m. Chile. Ave de rapiña, de color blanquecino, salpicado de negro. Los bordes de las alas y la punta de la cola son negros. Lleva en la cabeza una especie de corona de plumas negras, y los pies son amarillos y escamosos" (DRAE: 1504).

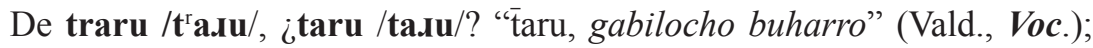
"Traru -el taro ave de rapina [sic], bien conocida [...]" (F., Cal.: 618); "Aves praedatrices [...].muntuvoe $\boldsymbol{x}$. [ùñm] Milvus, milvius, taru [...]" (H., Chil. I: 223); "THARU. El taro ave de rapiña" (F.-Hern. I: 73); “Trraro, s.- El traro, ave de rapiña tan conocida" (Cañ.: 324); traros (Cav., 1914: 51); "traru, s., el traro, ave de rapiña [...]" (Aug. I: 227); traru, el traro (Coñ.: 111); "Trarú el traro, ave de rapiña" (Alon., 1989: 181). ); "traru [t'a'ru]: El traro o ave de rapiña [...]" (Catr.: 154).

En cronistas y J. I. Molina: taro (Ros. I: 318); Tharu: "especie de aguila" (Mol. I: 295); "El tharu es otra especie de águila muy común en Chile" (Vid.: 252); taru: ave de rapiña (Carv. y G.: 24); el traro (JPG.: 26).

La denominación predominante en la actualidad parece ser traro.
Polyborus plancus
Falconidae

"tricahue. (Del mapuche thucau).m. Chile. Loro grande que habita en los barrancos de la cordillera" (DRAE: 1512).

De trükaw /t'ïkau/. "Thùcau-papagayo grande" (F., Cal.: 650); "Aves oscines seu canorae, ulcatun [ùlcatun] Psittacus minor, tcau, tùcao" (H., Chil. I: 223); "Tcan [Tcau], tucao [tùcao], psittacus" (H., Chil. II: 777); "PAPAGAYOS [...] Thùcao[...]" (F.-Hern. II: 71); "trokau, s., el loro amarillo o tricao [...]" (Aug. I: 231); füchá trëkau, el loro grande o papagayo (Coñ.: 112); "trükaw el loro amarillo o tricao [...]" (Alon., 1989: 186). En cronistas y J. I. Molina: tecau: papagayo grande (Ros. I: 318); Thecau 
(Mol. I: 285); tucau: papagallos [sic]; trecahues: los polluelos (JPG.: 27). Cyanoliseus patagonus

Psittacidae

"trile". (Del mapuche trili). m. Chile. Pájaro negro parecido al tordo, que tiene dos manchas amarillas debajo de las alas y anida en lugares húmedos" (DRAE: 1513).

De trili /t'tili/, chili /čili/. "tìli, tordo que tiene manchas amarillas en las alas" (Vald., Voc.); "Thili, ò chili-el tordito con manchas amarillas en las alas: de este nombre opinan algunos llamaron Chile a este Reyno los Españoles" (F., Cal.: 644); "Aves indolis ab aliis diversae [...] chili [...]" (H., Chil. I: 224), "tili [trili], chili, avis" (H., Chil. II: 786); "THILI. Pajarito negro con alas blancas" (F.-Hern. I: 74); "Trrili, s. - El trile, ese tordo, con los lados de las alas amarillas como el oro" (Cañ.: 326); Thriles (Cav., 1914: 51); "traitrayen, s., (=traitraitrome) el pájaro trile" (Aug. I: 223), "trile, m., (pájaro) traitrayen, traitráitrome, l·eufü koreu [tordo de río]" (Aug. II: 387).

En cronistas y J. I. Molina: "Thili, o Chili es una especie de tordo que [...] parece que dio nombre a todo aquel Reyno [...]" (Mol. I: 278); thile o chile "que probablemente da el nombre al Reino [...]" (Vid.: 242); tili "de cuyo nombre pretenden algunos haber derivado aquel país la denominación de Chile" (Carv. y G.: 25); thilli: "pajarito negro con una pinta amarilla en el encuentro de las alas" (JPG.: 27).

Agelaius thilius Icteridae

"tucúquere. m. Chile. Búho de gran tamaño" (DRAE: 1521).

¿De tuku /tuku/ onomatopeya y ukür /ukï.// 'búho', o sea, tukukür / tukukï.// 'buho que grita tuku'? "veqr, género de lechuza; vqr, buho (Vald., Voc.) [v equivale a u]. El nombre no se encuentra en otros léxicos. Por otra parte, según el vocabulario de Herckmann, tuco significaba 'búho' (en Schul.: 12, 23). El ave es llamada actualmente towtow /toutou/. "toutou, s., cierta ave nocturna, negra, del porte del jote (voz onomatopéyica) (Aug. I: 216); toutou, el tucúquere (Coñ.: 111).

El nombre no está documentado en los léxicos de Febrés y Havestadt; tampoco en las crónicas.

Bubo virginianus Strigidae

"turca' ${ }^{2}$ (Del mapuche thurcu). f. Chile. Pájaro conirrostro, de plumaje pardo rojizo, alas cortas, y las patas con tarsos muy fuertes y uñas muy largas" (DRAE: 1524).

De trurku /t'tusku/, /trürku /t'ï.sku/. "Thurcu - un paxaro" (F., Cal.: 650); trürko, la turca (Coñ.: 112).

Pteroptochos megapodius

Rhinocryptidae 
"yal. m. Chile. Pájaro pequeño conirrostro, con plumaje gris y pico amarillo" (DRAE: 1581).

¿De yal /jal/, yali /jali/? "Yali, s.- Un pájaro parecido al jilguero y unos mosquitos zancudos" (Cañ.:230).

Phrygilus fruticeti

Fringillidae

"yeco. m. Chile. Especie de cuervo marino" (DRAE: 1582).

De yeku /jeku/. "Yecu - unos patos negros, que llamamos cuervos" (F., Cal.: 525); "Aves praedatrices, muntuvoe $\boldsymbol{x}[\dot{\boldsymbol{u}} \tilde{n} \boldsymbol{m}][\ldots]$ corvus, $\boldsymbol{y e c u}[\ldots]$ " (H., Chil. I: 223), "Yecu, corvus" (H., Chil. II: 687); "YECU. Cuervos de la mar" (F.-Hern. I: 35); "Yecu, s. - Unos patos negros" (Cañ.: 330); "Yeco (de yecu: ave negra, cuervo). m. El cuervo. Phalacrocorax brazilianus" (Cav., 1921: 119); "yeku, ave negra, vulg. "cuervo" [...]" (Aug. I: 283 [...]; yeku, el cuervo marino (Coñ.: 113); "Yecu = el cuervo" (Alon., 1985: 134, 1989: 241); "yeku [ye'ku]: Cuervo [...]" (Catr.: 156).

Phalacrocorax brasilianus

Phalacrocoracidae

\section{CULTURA MAPUCHE}

Auca, camarico, chamal, chigua, chope, cuicuy, cultrún, guachi, guillatún, imbunche, llanca, lonco, machi, machitún, maloca, malón, pillán, Rengo, ruca, toqui, trarigüe, trauco, trutruca.

"auca². (De or. quechua). adj. Se dice del indio de una rama de los araucanos, que corría la Pampa en las cercanías de Mendoza. U.t. c. s. //. Perteneciente o relativo a esta rama [...]" (DRAE: 167$)$.

De awka /auka/ 'rebelde', 'alzado'. "aucapuche vfchiduamlay, los aucaes (=los mapuches rebeldes) no quieren dar la paz" (Vald., Arte: 39); “Auca alzado, rebelde, ò cimarron, montaraz: auca chanchu - puerco alzado. Aucan - alzarse, rebelarse" (F., Cal.: 432), "Alzado, rebelde - auca" (F., Voc.: 306), "Alzarse, rebelarse" (F., Dic. Brev.: 160); "Rebellis, perduellis, auca" H., Chil. I: 336, 434); “Auca, rebellis [...] (H., Chil. II: 609); “AUCA. El a[1] zado: auca cuchi. Chancho alzado. AUCAN. Alzarse, rebelarse" (F.-Hern. I: 4); "auka, adj., alzado, rebelde, muy travieso. / s. las yeguas (porque suelen ser chúcaras [...] - $\boldsymbol{n}, \mathrm{n}$., sublevarse. /s., el alzamiento, la rebelión" (Aug. I: 12); aukañma pu logko: caciques sublevados (Coñ.: 280); “auka alzado, 
no domado, silvestre, no amansado" (Alon., 1989: 27); “Awka [aw'ka]: Salvaje; no domado" (Catr.: 173).

En cronistas y J. I. Molina: "Afuera avuncaes -que quiere decir "traydores" 11 - que ya y'os e muerto a vuestros señores y caçiques [...] (Vivar: 70); “[...] finalmente viven como gentiles aucaes [...] (Ov.: 401); “[ ...] se había vuelto auca, y contra nosotros [...]" (Nuñ. de P.: 308); Aucá: franco o libre, "Este pueblo, constantemente adicto á la independencia, ama con gusto ser llamado Aucá, esto es, franco, ó libre" (Mol. II: 52).

La voz es originalmente quechua, pero fue adoptada por el mapuche. De ella se han derivado awkan /aunkan/ 'sublevarse', awkangen /aunkayen/ 'estar en guerra', awkalün /aukalïn/ 'alborotar a otros', awkankulme /aukankulme/ 'belicoso'.

"camarico. (De or. quechua). m. Ofrenda que hacían los indios americanos a los sacerdotes, y después a los españoles. // coloq. Chile. Amorío, enredo amoroso. Tener un camarico" (DRAE: 277).

De kamariku /kama.ıiku/. "Camaricu, se llama el tambo adonde reciben al español, y lo que le traen de regalo para comer" (Vald., Voc.); "Camaricu-lo que traen de regalo al Español: camaricun - hacer este regalo" (F., Cal.: 437); "Donum, munus reverentiae \& honoris causa oblatum, camaricu" (H., Chil. I: 384), "Camaricu, munuscula e.g. ova, gallinae, agnus, et similia, quae dant Hispanis et Patribus Missionariis, quando eos adeunt paesertim prima vice: et aegerrime ferrent, si quis ea, quae offerunt, non admitteret; et est eorum modus petendi, et contractus innominatus do ut des: nam semper sperant et expectant plus quam dederint; nec unquam desinunt petere plura et plura; et si ultimum ipsis negetur, quamvis anteriora omnia aeque multa et abundanter acceperint; abeunt tristes, nec sunt contenti; quare expedit ex ipsis quarere, quid petant, quid cupiant, desiderent; et eo usque urgere, donec omnia dixerint. Quibus omnibus patienter auditis aliqua negare excusando; et aliqua concedere: at semper dare quam valuerit, id quod attulerunt et dono dederunt; et solum hac ratione discedunt laeti et contenti; secus autem P. Missionarius apud illos audit avarus \&c" (H., Chil. II: 616-617); "CAMARICU. Lo que en sus juntas dan de regalo al español", "CAMARICUN. Hacer dicho regalo" (F.-Hern. I: 6); “kamarikun [ka'marikun] Antiguamente fue una fiesta de integración social y de diversión. En algunas regiones todavía se celebra con un sentido más religioso" (Catr.: 234).

11 “Aucca. Enemigo traydor contrario" (GH.: 38). 
En cronistas: camarico (Nuñ. de P.: 704).

La palabra proviene del quechua kamarikuy 'prepararse', 'alistarse', pero debe haber sido adoptado por el mapuche en época antigua, por lo cual aparece consignado en el léxico del P. Valdivia. Actualmente kamarikun es sinónimo de ngillatun (por ejemplo, en el Alto Bío-Bío).

"chamal.m. Arg. y Chile. Antigua prenda de vestir mapuche hecha con un paño rectangular, que la mujer llevaba a modo de túnica y el hombre sujetaba a la cintura. //2. Chile. Manta de las indias en la misma región" (DRAE: 348). De chamall /čamaर́/, chamal/čamal/. "Chamall, chamal - la manta de las Indias con que se cubren todo el cuerpo, a modo de sotana, y aun a nuestra sotana tal vez la llaman ellas chamal" (F., Cal.: 443); "Toga, vestis, chamal, choñe" (H., Chil. I: 298), "Chamall, stragulum, vestis" (H., Chil. II: 621); "CHAMAL. La manta de las indias con que cubren todo el cuerpo" (F.-Hern. I: 8); "chamall, s., paño cuadrado con el cual los indios hombres envolvían su cuerpo de la cintura para abajo. Hoy día los usan solamente los chicos y unos ancianos [...]" (Aug. I: 17), "Kuifike wentru em niefui chamall En tiempo antiguo los hombres vestían el chamall" (Coñ.: 209, 210).

En J. I. Molina: chiamal: túnica "es larga hasta los pies, sin mangas, atada sobre la espalda con dos hebillas o broches asimismo de plata" (II: 57).

"chigua. f. Chile. Especie de serón o cesto hecho con cuerdas o corteza de árboles, de forma oval y boca de madera, que sirve para muchos usos domésticos y hasta de cuna" (DRAE: 357).

¿De chiwa? "Chincùll, ò chincùlhue - chigua, como canastos para llevar los chuycos a caballo" (F., Cal.: 449); "CHINCÜLHUE. Chihuas como canastos" (F.-Hern. I: 10), "CHIHUAS. Chincùlhue" (F.-Hern.II:20); "Chihua,s. Construcción parecida á la valva(valva), formada de dos óvalos de varillas flexibles llamados, chimilhues, iguales en tamaño, tejidas con sogas hechas de látigos ó fibras de corteza de árboles ó de plantas filamentosas y revestidas por uno de sus lados con hojas, ramas de árboles ó juncos del campo. Se las liga con varillas y apretándolas una contra otra, llevan entrambas con seguridad lo que se deposite en ellas. En Chiloé sirven además de medida, vendiéndose la papa, el trigo y otros cereales por chihua o sea seis almudes, en que se calcula la capacidad de cada una" (Cañ.: 267); "Chihua (s.f.). Tejido de voqui, armado en una circunferencia de madera de huinque $[\ldots] \mathrm{u}$ otra igualmente flexible. En Chiloé es una medida para las papas y cereales. Su cabida es de seis almudes" (Cav., 1914:328); "[...] ngeyküfünge ti chiwa ñi umautuam ñi püñeñ mece la cuna para que duerma la guagua" (Alon.,1989:171).

En J. I. Molina: chigua: cuna colgada (II: 119). 
Podría provenir del quechua, pero no creemos que de achihua 'sombrilla' o 'quitasol' (Achihua. Tirasol, o, quitasol" (GH.:13), “achihua. el quitasol [...] (Midd.: 15). Vid. L., DE.: 277-278. Según Román, se ha usado más "para cuna en las casas y ranchos de los pobres" (T.2:31). Si es quechua, debe haber sido tempranamente adoptada por el mapuche. Actualmente la palabra usual para cuna es kupülwe /kupïlwe/, y es diferente de la chigua.

"chope. m. Chile. Palo con un extremo plano para sacar de la tierra los bulbos, raíces y para otros usos del campo. // 2. Chile raño (//garfio de hierro) // 3. Chile. Guantada, puñetazo" (DRAE: 365).

De chope /čope/. "Chope. Gancho, garavato [sic]" (F.-Hern. I: 11). Es la única documentación de la voz, con tal significado. Se encuentra también en Augusta, pero con el significado de 'pugilato' (I: 25).

"cuicuy. (Del mapuche cuycuy, puente). m. Chile. Árbol derribado que sirve de puente" (DRAE: 480).

De kuykuy /kuikui/. "Cuycuy, puente de rio" (Vald., Voc.); "Cuycuy-puente: cuycuy cura - puente de piedra [...]" (F., Cal.: 463); "Pons, cuicui" (H., Chil. I: 262), "Cuicui, Pons [...]" (H., Chil. II: 635); "CUYCUY. Puente" (F.-Hern. I: 14); “Cuicui, s.- Puente: el puente que se derriba á orillas de los ríos ó corrientes, quebradas o zanjones y que atravesado sobre éstos sirve para pasar a la opuesta orilla; palo puesto en el sentido longitudinal de dos caminos, por sobre los cuales trafica la gente de a pie" (Cañ.: 262); "cuicui (s. m.) - Puente natural, especialmente el formado por un árbol caido [...]" (Cav., 1914: 319, 1921:24); "kuikui, s., puente de un palo, o sea de un sistema de palos que descansan en los árboles que hay a uno y otro lado de un riachuelo" (Aug. I: 97); "kuykuy el puente de palo" (Alon., 1989: 133); "kuykuy ['kuy'kuy]: Puente" (Catr.: 118).

"cultrún. m. Chile Instrumento de percusión utilizado en rituales mapuches" (DRAE: 483).

De" kultrung /kult'uy/ 'tambor'. "Cultunca, atambor" (Vald., Voc.); "Cultrun, cultrunca - un tamborcito, que tocan en sus bebidas [...]" (F., Cal.: 464); "Tympanum, cultun, cultunca. Tympanum Machiis proprium tùntùnca. Aliud minusculum, ralli cultun" (H., Chil. I: 512), "Cultunca, tympanum" (H., Chil. II: 637); "kultruy, s., tambor o caja de que se sirven las machis para espantar al wekufü y con que acompañan su propio canto [...]" (Aug. I: 98); kultruy, tambor (Coñ.: 162 et pássim), "Kultrun: El kultrun es uno de los instrumentos de mayor importancia y categoría de percusión entre los instrumentos autóctonos [...]" (Alon., 1985: 121). 
"guachi. (Del mapuche huachi). m. Chile. Alambre en forma de lazo atado a una estaca enterrada en el suelo que sirve de trampa para cazar aves, conejos o liebres" (DRAE: 787).

De wachi /wači/. "Huachin, armar lazos" (Vald., Voc.); "Huachi-trampita de lazos para coger aves: huachitun-armarlo, o coger aves assì [...]" (F., Cal.: 503); "Huachi, tendicula, decipula: machina irretiendis aviculis aut bestiis capiendis comparata. huachin, tendicula fallere" (H., Chil. II: 668); "HUACHI. Trampita de lazo para cazar" (F.-Hern. I: 27); "Huachi, s., trampa que emplean para cazar pájaros. Consiste en una varilla arqueada y enterrada en la tierea por uno de sus extremos; en el otro extremo colocan una soguilla de clin, que lleva una lazada corrediza en donde se cazan los pájaros" (Cañ.: 277); “wachi, s., trampa de hilos para cazar pájaros - $\boldsymbol{n}$, tr. coger con trampa [...]" (Aug. I: 243); wachi, trampa (Coñ.: 36); "wachi la trampa de hilo para cazar pájaros" (Alon., 1989: 200). La trampa se confecciona también con alambre, como la describe el $\boldsymbol{D} \boldsymbol{R} \boldsymbol{A E}$. En este caso para cazar, por ejemplo, conejos.

En J. I. Molina: guaches: "industriosas especies de lazos" (II: 24).

"guillatún (Del map. yillatun, pedir, rogar). m. Arg. y Chile. Entre los mapuches, ceremonia en la que ruegan a la divinidad lluvia o bonanza" (DRAE: 796).

Del ngillatun /niאatun/ 'pedir otra vez', 'rogativa'. "Gillatun - pedir otra vez: it.: gillatun, gillatucan - llamar al demonio, ò al Pillan, lo cual hacen con un cigarro de tabaco" (F., Cal.: 496); "gillatun, repetere, iterum petere. gillatun, gillatucan superstitionis genus inter Indos Chilenses frequens [...]" (H., Chil. II: 663); "GILLATUN. Valerse de otro suplicándole [...]” (F.-Hern. I: 25); “Guillatun, v. - Rogar, implorar. Los indios celebran sus ngillatunes cuando ocurren necesidades o peligros [... ]" (Cañ.: 274 - 277); "[...] yillatun, tr., pedir algo; rogar, pedir a alguno" (Aug. I: 62); yillatun: oraciones (Coñ.: 362 y ss.), nguillatun: función religiosa popular (Coñ.: 371 y ss.); "Ngillatun - Rogativas" (Alon., 1985: 39 y ss.); "ngillatun [yiKa'tun]: Ritual que se realiza conforme a las tradiciones aprendidas de los antepasados, pedir o rogar a los cuatro dioses del wenumapu (tierra de arriba) y mantener o restituir el bienestar de los habitantes del mapu. Se celebra cada cuatro años, pero este orden puede variar cuando se presentan problemas inesperados u otros fenómenos extranaturales según los sueños de las machis y las visiones" (Catr.: 204). La frecuencia varía según los lugares. Por ejemplo, en el Alto Bío-Bío se celebran tres cada año, en los meses de marzo, abril y diciembre. 
"imbunche. (Voz mapuche). m. Chile. En la tradición popular, ser maléfico, deforme y contrahecho, que lleva la cara vuelta hacia la espalda y anda sobre una pierna por tener la otra pegada a la nuca. Se creía que los brujos robaban a los niños y les obstruían todos los agujeros naturales del cuerpo y los convertían en imbunche, cuya misión era guardar los tesoros escondidos. // 2. Chile. En la tradición popular, brujo o ser maléfico que hacía tal maleficio a los niños. // 3. Chile. Maleficio, hechicería" (DRAE: 848).

De ivümche /ivïmče/, ivumche /ivumče/. "Yvúmche, encantador" (Vald., Voc.); "Ivum, ò ivùm - animales pequeños quadrupedos, ò monstruos". "Ivumche - los que consultan los bruxos en sus cuevas, donde los crian desde chiquitos para sus hechizerias, ò encantos: a estos llaman las indias, ivùm coñi" (F., Cal.: 523); "Ivùm, quaedam parvae quadrupedes bestiae. ivùm coñi, partus animalis.item.monstrum. Ivùmche, homo bestia. Fama est inter Indos; veneficos suos in quidam specu nutrire hominum genus, quibus adhuc lactentibus oculos, os, anumque consuunt, ita ut crescentes in aliam figuram speciemque degenerent; atque hos esse ipsorum Consiliarios ac Consultores, quorum consilium in suis antris, quae renu [renù] vocantur, convenientes exquirant" (H., Chil. II: 686); "IVUMCHE. Ente de razon, a quien consultan los adivinos i machis en sus cuevas para sus hechicerias i encantos [...]" (F.Hern. I: 34); "Ivunche, s. - ser racional ó animal imaginario, que los brujos crian en sus cuevas y de los que se valen para consultarles sus hechicerías [...]" (Cañ.: 286); "Invunche - (de ivùm =animal pequeño, monstruo y che $=$ hombre) $\mathrm{m}$. Ser mitológico, deforme y contrahecho, que lleva la cara vuelta hacia la espalda, y anda con una pierna por tener la otra pegada por detrás al pescuezo o a la nuca. Algunos pronuncian ivunche, lo que es más correcto" (Cav.1921: 65- 66).

En J. I. Molina: Ivunches: (hombres animales) discípulos de los hechiceros (II: 88).

"llanca. (Voz quechua). f. Chile. Mineral de cobre de color verde azulado. // 2. Chile. Piedras pequeñas de este mismo mineral o parecidas a él, que usaban y usan todavía los mapuches para collares y sartas, y para adornos de sus trajes" (DRAE: 941).

De llanka / Kanka/, llangka/Kanka/ 'chaquira'. "Llanca, vnas piedras verdes, que los indios estiman" (Vald., Voc.); "Llanca - unas piedras verdes, que estiman mucho, con que pagan las muertes, y se toma por otras qualesquiera pagas de muertes llancatu - las gargantillas de las Indias, hechas de dichas piedras, ò también de chaquiras, ò cuentas de vidrio, y las mismas cuentas" (F., Cal.: 538 - 539); "Llanca, lapis pretiosus, viridis" (H., Chil. I: 260), "Llanca, lapilli virides durissimi, qui perforati rotundique sunt maximi 
inter Indos pretii; hisque homicidia redimunt, emuntque necessaria [...]" (H., Chil. II: 700); "llayka, s., una chaquira grande, gruesa, verde, maciza, que los indios usaban antiguamente" (Aug. I: 119); kelü llayka, chaquiras coloradas; chod llayka, chaquiras amarillas; karü llayka, chaquiras verdes; wirin llayka, chaquiras rayadas (Coñ.: 211, 212); "llangka la chaquira, perla grande o chica de color verde, azul, blanco, rojo, que los Mapuche usaban para su adorno" (Alon., 1989: 144); "Ilangkatu [Kan'katu]: Chaquiras de diversos colores utilizadas como adornos en forma de collares" (Catr.: 206).

En cronistas y J. I. Molina: "Las joyas que más estiman son unas piedras brutas sin algun labór, polideza o forma, feas, broncas y cavernosas, y aunque tiran a verdes, no son transparentes como las esmeraldas, con las cuales, hechas sartas, usan a adornarse los caciques, puestas en los sombreros los que las tienen, o en los apretadores de sus cabelleras, en que ponen toda su gala, a las cuales sartas llaman llancas" (G. de Náj.: 47); "Ilancas, que son, como entre nosotros, cadenas y piedras preciosas, y esto se acostumbra con los hombres principales y de suerte" (Nuñ. de P.: 498); "Y estas muertes se pagan siempre con llancas, que son las piedras verdes y negras, variadas con vetas de uno y otro color, que estiman mas que los diamantes y esmeraldas, de que no hazen caso" (Ros. I: 133, 134); llianca: falsas esmeraldas con que se adornan la cabeza las mujeres. Las aprecian mucho (Mol. II: 57-58).

No se encuentra en diccionarios quechuas importantes, de Santo Tomás, González Holguín, Middendorf, etc. Llanka forma parte de los nombres mapuches - usados actualmente como apellidos- que tienen un origen milenario, como Llankafilu, Llankamañke, Llankapangi, Llankakewpü, etc. Tradicionalmente han sido llamadas chaquiras, $y$, al parecer, ya no se usan.

"lonco. m. Chile. Entre los mapuches, jefe de un grupo de indígenas" (DRAE: 947).

De longko/loyko/ 'el jefe de una comunidad; también el cacique'. "Loncon, loncogen - ser, estar de cabeza, principal, superior \&c." (F., Cal.: 535); "Vúta [vùta] loncogei, Dux magnae auctoritatis, jurisdictionis, dominii est" (H., Chil. I: 269), "Lonco gei habet subditos, Vuta [Vùta] Lonco gei, insigni Praefectura ornatus, multos subditos numerat" (H., Chil. I: 386), "Factionis princeps, dux, primipilus, Chiliarcus, Tribunus, centurio, \&c. gudol [gùdol], lonco, Apo" (H., Chil. I: 434); PRINCIPAL, que gobierna. Apo, lonco: serlo, loncon, loncogen [...] (F.-Hern. II: 80); "loyko, s., la cabeza, el jefe [...]" (Aug. I: 116); loyko, cacique(s) (Coñ.: 13 et pássim), ñidol-loyko, cacique(s) principal(es) (Coñ.: 14 et pássim); "longko [loy'ko]: Jefe de la comunidad" (Catr.: 208). La voz significa también 'cabeza', 'cabellos', 'espiga de trigo'. 
"machi. (Voz mapuche). com. Chile. En la cultura mapuche, curandero de oficio, especialmente cuando es mujer" (DRAE: 956).

De machi /mači/ 'el curandero', 'la curandera'. "ta calcu gelu chi pu Machi[...] [...] los Machis que son hechizeros [...]" (Vald., Serms.: 11); "Machi Medicus [...] A Chirurgeon [...] ein Artzt [sic], oder Genäsemeister, un médico, un curandero" (Herck., en Schul.: 8, 26, 35, 52); "Machi - el curandero, ò curandera de oficio", "Machin, machitun - curar él, ò ella según su usanza, que es con cien mil disparates, y riculezes" (F., Cal.: 544); "Machios medicinam adhibere, machitun" (H., Chil. I: 455), "Machi, Indorum Medici viri ac mulieres; plerumque mulieres, quorum officium est, partem dolorem affectam sugere vel lambere; ut ita hиесиbu veneficum extrahent: Hi nunquam medentur absque ramis cinnamomi rehue: quos in domo infirmi ordinatim disponunt vel terrae infigunt. machitun, dicto modo curare, curari" (H., Chil. II: 706); "MACHI. Curanderos a su usanza, tanto hombres como mujeres. MACHITUN. Cura a su usanza, curar así, que es con mil disparates y ridiculeces" (F.-Hern. I: 41); "Machi, s. - Brujo que entiende la hechicería; curandero que se sirve de hierbas y otras artes para curar las enfermedades y curan las enfermedades y adivinan quien ha hecho el daño o impuesto el mal al enfermo [...]" (Cañ.: 294 - 295); "Los Machis llamados aquí médicos de la tierra (porque medicinan con yerbas y raíces) son unos indígenas que pretenden curar enfermedades por medio de sortilegios y conjuros, cuando no por las virtudes de ciertas plantas y raíces [...]" (Cav., 1914: 114); "machi, s., los médicos y las médicas indígenas que curan a los enfermos según las supersticiones antiguas de su raza [...]-tun, tr., curar la machi a un enfermo con sus supercherías, machitucarlo./s., el machitun o sea la curación de un enfermo que hacen las machis" (Aug. I: 127); machi, machi (110, 331 et pássim), machitun, curaciones hechas por machis (Coñ.: 350 et pássim); "Machi son las personas que se dedican y se consagran al servicio de la salud y son de ambos sexos" (Alon.1985: 47 y ss.), "machitun o datun "[...] la acción de curar y sanar las enfermedades, hacer el exorcismo para auyentar el mal, causante de las enfermedades [...]" (Alon., 1985: 47), "machi médica - o mapuche" (Alon., 1989: 74); "machi [ma'či]: Chamán, curandera o curandero de la comunidad mapuche. Dirige la ceremonia del machitun. En varias regiones propicia la ceremonia del ngillatun" (Catr.: 224), "machitun [mači'tun] Ceremonia ritual de cura de enfermos invocando a los dioses y utilizando plantas medicinales" (Catr.: 225).

En J. I. Molina: "[...] y sus medicos, llamados Machi y Ampive, son herbolarios peritos [...]" (I: 155), "machin curar o medicar" (II:367)).

Machi designa tanto al hombre como a la mujer que practica la sanación; en el presente predominan las mujeres. 
"machitún. m. Chile. Entre los mapuches, reunión de carácter religioso, en la que participan los machis" (DRAE: 956).

De machitun /mačitun/ 'la ceremonia de sanación'. Vid. supra.

"maloca. (Del mapuche malocán). f. Am. Mer. Invasión de hombres blancos en tierra de indígenas, con pillaje y exterminio. // 2. Am. Mer. Ataque inesperado de indígenas contra poblaciones de españoles o de otros indígenas" (DRAE: 967).

De malokan /malokan/Vid. infra.

"malón. (Voz mapuche).m. Am. Mer. Irrupción o ataque inesperado de indígenas [...]" (DRAE: 967).

De malon /malon/ 'el ataque sorpresivo'. "Malocan, pele[a]r" (Vald., Voc.), "Malon, pelea o batal[l]a" (Vald., Voc.), "Malon, malocan - hazer hostilidad al enemigo, ò entre si por agravios, saqueando sus ranchos, y robando quanto topan, y dicha hostilidad" (F., Cal.: 546); "Bellum, malon" (H., Chil. I: 435), "Malon, malocan, bellum. item. bellum conflare, apparare, suspicere, adornare, inferre, gerere; bello persequi, premere, urgere, oppugnare" (H., Chil. II: 708-709); "malon, s., guerrilla, correría para saquear las casas o llevarse animales [...]" (Aug. I: 129); malon, malón (Coñ.: 124 et pássim).

En cronistas y J. I. Molina: malocas: correrías ligeras (Ros. I: 122); malocas: latrocinios (Oliv.: 60); malocas: correrías "donde destruyen o queman todo aquello que no pueden transportar" (Mol. II: 66), "malon saquear" (Mol. II: 367).

"pillán. m. Chile. Entre los mapuches, poderosa divinidad con dominio sobre las personas y los fenómenos naturales" (DRAE: 1194).

Del map. pillan /piKan/, pillañ /pi Kan/ 'espíritu protector de un antepasado, el cual podía residir en los volcanes. Por ello la palabra llegó a significar también 'volcán'. "Pillan, antú, leuvúyúca, mahuydayùca, moḡellechi ta mi pin meu, mi ufchiabiùm újtupobimi? As nombrado para reuerenciarle al Pillan, al Sol, Rios o cerros, pidiendoles vida?" (Vald., Conf.), Pillan (Vald., Serm.: 7 et pássim); "Pillan Tonitru[...] Thunder [...] der Donner el trueno" (Herck., en Schul.: 6, 21, 33, 50);"Pillañ , pillan - llaman al Diablo, ò a una causa superior, que dicen hace los truenos, rayos, relámpagos, y rebentazones de bolcanes, y a estos mismos efectos llaman Pillañ " (F., Cal.: 593); "Pillañ causa prima, cui varios effectus naturae E.g. Tonitrua, fulgura, fulmina, aliaque ejusmodi attribuunt [...]" (H. Chil. II: 745); "PILLA N . El diablo, o una causa superior que dicen hace los truenos, relámpagos y rebentazones de

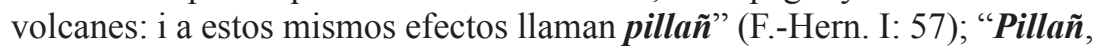


s. - Los truenos de las tempestades atmosféricas; las mismas tempestades y quien, según ellos, las producen. Pillañ es un ser poderoso e invisible, que tiene el poder de conmover los elementos [...]" (Cañ: 312); "pillañ (o pillan), s., cualquier volcán*. Un medio - dios de cuyo favor depende la productividad de los campos y de los seres animales y que da a conocer su cólera en todos los fenómenos ígneos que tienen relación real o imaginaria con los volcanes, mientras que los indios de la costa le atribuyen más bien las avenidas de los ríos, salidas del mar u otras calamidades; mas hay que notar que tal superstición es hoy día sostenida solamente por las machis y por los indios viejos, quienen en el pillañ ven aun el dios especial de los araucanos [...]" (Aug. I: 181); pillan, volcán (es), cordillera (Coñ.: 82 et pássim); "pillan [pi'রan]: Dios dueño de la productividad e los campos y causante de fenómenos y calamidades naturales. Volcán" (Catr.:127).

En cronistas y J. I. Molina:"Solo invocan al pillan, y ni saben si es el demonio ni quien es; mas, como se les aparece a los hechizeros y les habla, les da a entender que es alguno de sus parientes o caciques difuntos, y como a tal le hablan, sin hacerle adoración [...]" (Ros. I: 162); Pillan: el demonio, pillan algüe: el demonio (Nuñ. de P.: 121, 667); "Pillan: Ente supremo autor de todas las cosas, y denota el espíritu por excelencia. El es el gran Toqui del mundo invisible, y como tal tiene sus Apo - Ulmenes, y sus Ulmenes, á los quales entrega la administración de las cosas inferiores" (Mol. II: 84), "Dios Pillán" (Mol. I: 407). Sin duda, la palabra no significaba originalmente 'diablo'.

"Rengo" (De Rengo, nombre de un guerrero indio de La Araucana, obra del poeta español A. de Ercilla, 1533 - 1594). Dar a alguien con la de - fr. Matarlo de un golpe [...]" (DRAE: 1319-1320).

De rünkoy /.ünkoi / 'talón', 'calcañar'. "Rùncoy - talón, ò carcañal” (F., Cal.: 618); “Talus, calx, rncoi”' (H., Chil. I: 280), "Rncoi, talus, calx” (H., Chil. II: 772); “rüykoi/namun, s., el talón, calcañar" (Aug. I: 203). El nombre es recurrente en La Araucana.

"ruca2 ${ }^{2}$ (de or. mapuche). f. Arg. y Chile. Vivienda de los aborígenes pampeanos y patagónicos" (DRAE: 1354).

De ruka /.ruka/ 'casa', 'habitación'. "Ruca, casa" (Vald., Voc.); "Ruca Domus [...] A House [...] das Haus la casa" (Herck., en Schul.: 8, 36,53); "Ruca - la casa, rancho [...]" (F., Cal.: 624); "Ruca, domus, aedes, domicilium [...]" (H., Chil. II: 773); "RUCA. Casa, rancho" (F.-Hern. I: 67); "Ruca, s. - Casa, hogar, habitación" (Cañ.: 321); "ruka, s., choza, casa, edificio [...]” (Aug. I: 201); ruka, casa(s), edificio(s) (Coñ.: 13 et pássim); "ruka [ru'ka]: Casa; habitación" (Catr.: 60). La ruka fue habitación de todos los mapuches de Chile. 
"toqui. m. Chile. Entre los antiguos mapuches, jefe del Estado en tiempo de guerra" (DRAE: 1490).

De toki /toki/, troki / $\mathbf{t}^{\mathrm{r}} \mathbf{0 k i}$ / 'hacha', trokin $/ \mathbf{t}^{\mathrm{r}} \mathbf{k} \mathrm{kin} /$ 'mandar, 'gobernar', 'ordenar', 'disponer'; 'el general en jefe o capitán general'. "Toqui, hacha”" (Vald., Voc.), "Nentoque Gubernator [...] A Ruler [...] der Gebieter el amo" (Herck., en Schul.: 8, 26, 35, 52); "Thoqui - dizen a los que goviernan en tiempo de guerra, y su insignia, que es una piedra a modo de hacha: gen thoqui el mismo, porque tiene la insignia en su poder" (F., Cal.: 647648); "Caciquius armorum pro tempore Praefectus Generalis, Toqui [...] Imperatoria rudis, Toqui" (H., Chil. I: 382), "Imperator, generalis armorum Praefectus, Toqui, gen toqui' (H. Chil. I: 434), “Toqui, supremus Belli Dux ac armorum militiaeque Praefectus. item. securis lapidea [...]"(H., Chil. II: 779); "toki, s., el hacha (=kachal*). La acepción de "jefe de guerra" ya no es conocida" (Aug. I: 216); toki: hacha (Coñ.: 339); "toki [to'ki]: Hacha" (Catr.: 65).

En cronistas y J. I. Molina: "Los títulos que tienen sus ministros en ella son Toqui, Pilquitoqui y Nitoqui, los cuales tienen sus insignias diferenciadas, que son unos bastones con una piedra injerida en cada uno" (G. de Naj.: 98); "Habiendo oído al gobernador todos con gran silencio y atención se levantó Alvepillán, que en Quilacura era el primer toque, señalado entre los otros (llámanse toques, entre los indios, los más principales, a quien obedecen los otros en la guerra) asegurando al gobernador de su fe y de la verdad con que profesaba su amistad y la de los demás cristianos [...]" (Ov.: 267), toque. capitán general (Ov.: 325), toquis de los caciques "que son unas hachas, insignias de los más principales" (Ov.: 396); “[...] toque principal, que es más que cacique [...]" (Nuñ. de P.: 89), "toques: insignias, a modo de un hacha de piedra, que está en poder de los caciques más principales llamados [también] toques" (Nuñ. de P.: 330); “[...] el Toqui general y los convoca sacando su hacha de pedernal negro, ensangrentado, como el estandarte de guerra [...]" (Ros. I: 112), "Por este razonamiento tiene el toqui o pedernal negro ensangrentado, y el está en pie junto al Toqui con una flecha y un cuchillo en la mano [...]" (Ros. I: 113), "Ay entre ellos un Toqui general, que es uno de los caciques, a quien todos los caciques rconocen por más antiguo o más noble en linage" [...], Gentoqui: toqui general "que significa señor, gobernador y general de la guerra por herencia [...]" (Ros. I: 138); "Los toquis $[\ldots]$ son los que absolutamente mandan; y su nombre lo dice, porque toqui es derivado del verbo toquin, que significa mandar [...]" (Oliv.: 59); "Los Toquis: que pueden llamarse Tetrarcas, porque son quatro preceden a los Butalmapus. Se denominan Toquis del verbo toquin, que significa juzgar o mandar y son independientes entre ellos, bien que conferederados por el bien común [...]", "La insignia distintiva del Toqui es un hacha de pórfido, 
ó de mármol" (Mol. II: 61 et passim); toqui: capitán general (JPG.: 48). El toki era un general, o generalísimo, mapuche en tiempo de guerra, cuya insignia de mando era un hacha de piedra.

"trarigüe. m. (Del mapuche tharin, atar).m. Chile. p. us. Faja o cinturón de lana que usan los indios" (DRAE: 1504).

De trarüwe/ $\mathbf{t}^{\mathrm{r}}$ a.ïwe/, trariwe $/ \mathbf{t}^{\mathrm{r}} \mathbf{a}$..iwe/ 'faja', 'cinturón'. "'tarihue, cinto, $o$ cinta" (Vald., Voc.); Tariwe loun: Fascia, diadema (Herck., en Schul.: 10); "[....] tharicùnohue - un cinchón de cuero de baca [sic], que trahen atado a la cintura: [...] tharihue - lo mismo, ò cualquiera otro cinchón para amarrar, ò atadura" (F., Cal.: 637); "THARIHUE, o Thari. Faja, ceñidor, cualquier atadura o amarra" (F.-Hern. I: 72); “[...] trarüwe, s., el cinturón (ancho) de las mujeres; cualquier ceñidor" (Aug. I: 227); trarü̈we, faja; cinturones de hombres y mujeres (Coñ.: 209, 228); "Trariwe la faja laboreada que confeccionan las mujeres mapuches" (Alon., 1989: 182); "trariwe [t'a'riwe]: Cinturón o faja de lana para ajustar los pañales al cuerpo del bebé" (Catr.: $33)$.

"trauco. m. Chile. En la mitología popular, ser dotado de un poder cautivador, que atrae a las mujeres vírgenes y las deshonra" (DRAE: 1508).

¿De trawün /t'awïn/ 'juntarse', 'reunirse' y ko /ko/ 'agua'? Ello porque suele acechar -según se dice- a las jóvenes cuando van a buscar agua a una fuente, o pozo. "Trrauco, s.- Ser imaginario, en figura de hombre; es enano y contrahecho; vive en los bosques y viste de tejidos de plantas filamentosas como la quilineja. Los habitantes de las islas orientales del Archipiélago [de Chiloé] lo imaginan brujo y capaz de producir enfemedades en los niños y aun en los grandes, que alcanza a ver, torciéndolos y jorobándolos [...]" (Cañ.: 324-325); "[...] El Thauco tiene alguna analogía con el "Duende" de los pueblos el Norte. Como el Duende, nuestro Thrauco persigue a las mujeres; es, como él, de pequeña estatura, si bien no tiene la apariencia de niño con que aquél se deja ver; como él, molesta a los moradores de una casa casi hasta hacerlos desesperar [...] El Thrauco tiene por morada habitual los troncos y a veces las copas de los árboles; su indumentaria, incluso el sombrero, que es de forma cónica y semejante a un cucurucho, es toda de quilineja; sus pies, sin talón ni dedos, son unos muñones informes; su aspecto es aterrador y espeluznante, y su mirada, como la del basilisco, mata a la persona que aún no ha reparado en él, o bien la deforma espontáneamente, dejándola con el cuello torcido y sentenciado a morir antes del año. Sin embargo, por una justa compensación, perece, como el basilisco, si ha tenido la desgracia de ser avistado primero [...] El Thrauco anuncia su visita a una casa enviando sueños lúbricos a las personas del sexo opuesto, y transformándose en esos 
sueños en un joven de buena presencia o en un religioso [...] Sunt feminae quae noctu a monstro opprimuntur; quis vero usque adeo insanita ut tam vafris puellis habent? Nonne talia fingunt ut parentum iram effugiant? [...] El Thrauco desflora a las doncellas que vagan por la montaña; superstición funesta que no pocas veces asegura la impunidad de las culpables, dado así alas al vicio y a la licencia [... El Thrauco no vacila en arrojarse al mar en seguimiento de su víctima, hasta sucumbir, cual nuevo Leandro, en medio de las olas, a la vista de su amante Hero [...]" (Cav., 1914: 96 - 97).

"trutuca. f. Chile. Especie de corneta larga usada por el pueblo mapuche en ocasiones especiales" (DRAE: 1521).

De trutruka / $\mathbf{t}^{\mathrm{r}} \mathbf{u} \mathrm{t}^{\mathrm{r}} \mathbf{u k a / .}$ "Tultunca A Trumpet [...] die Trompette [...] la trombeta [sic], corneta" (Herck., en Schul.: 37, 54); "Tutuca - la trompeta y la espinilla de la pierna [...]" (F., Cal.: 633); "Bucchina arundinea vel ossea ex tibia hostis ab ipsis trucidati, tutuca [trutruca]" (H., Chil. I: 512), "Tutuca, tuba, tibia bellica: fit vel ex canna, vel ex tibia cujusdam hostis ab ipsis trucidati" (H., Chil. II: 780); "THUTHUCA. Clarín de la tierra" (F.Hern. I: 76); "trutruka, s., instrumento de soplo cuyo largo varía entre 3 y 4 metros; consta de coligües ahuecados y un cuerpo, y exige buenos pulmones para tocarlo" (Aug. I: 237); trutruka, trutruca (Coñ.: 13, 163 et pássim); "Trutruka. La trutruca es un instrumento largo de colihue que está hueco por dentro. Su tamaño es variable: de dos metros a cinco metros y termina en un extremo en un cacho de vacuno que le sirve de percusión" (Alon., 1985: 120, 1989: 194). El instrumento musical se confecciona actualmente también de mangueras de goma y tiene forma circular. Al parecer también era denominado así, en época antigua, el tambor de las machis.

\section{OTROS SUSTANTIVOS}

Araucanista, cahuín, calcha, calchona, cancato, chalcha charcha, chamanto, chapalele, chape, charchazo, charquicán, chilenismo, chopazo, chuico, chuica, coironal, coligual, contre contri, copucha, curanto, curiche, gualve, guata, guatazo, laque, linao, macal, mallín, natral, pangal, percán, pichintun, pilcha, piñén, pirco, pirquén, pirquinero, pololo, poncho, poto, quiltro, rulo, trumao, trutro, ulpo.

"araucanista. com. Persona entendida en el idioma o en las costumbres de los araucanos" (DRAE: 131). 


\section{De Arauco. Vid. araucaria (Fitónimos).}

"cahuín. m. coloq. Chile. intriga (// enredo). // 2. coloq. Chile. Situación confusa" (DRAE: 264).

De kawiñ /kawip/ 'junta', 'fiesta', con ingesta de vino. "Cahuin, junta o regua, do auitan indios, Cahuintu, la borrachera" (Val., Voc.); "Kawinto Convivium [...] A Meal" (Herck., en Schul.: 11, 38); "Cahuiñ -borrachera, ò junta para beber, y emborracharse [...]" (F., Cal.: 435);"Cahuin, compotatio, epulum, convivium, ludi, spectacula Indorum [...]”"(H., Chil. II: 615 - 616), “CAHUIN Junta por casa nueva: malalcahuiñ - bebida o tomadura por cercar" (F.-Hern. I: 5); "kawiñ, s., "cualquiera fiesta o más bien borrachera que hacen con ocasión del yillatun, de certámenes, carreras, trillas, inauguraciones de casas o canoas, entierros, etc.” (Aug. I: 79); kawiñ , fiesta(s) (Coñ.: 76 et pássim). “kawiñ [...] fiesta reunión de una comunidad" (Alon., 1989: 130).

En J. I. Molina: "Estos convites, que suelen durar dos o tres días, se llaman cahuin, o círculos, porque al rededor de un gran ramo de canela se sienten en círculo a comer y beber" (II: 122).

Los cahuines o juntas, durante las cuales se ingería vino, solían terminar en desórdenes. Esta parte del significado ha permanecido.

"calcha. (Del mapuche calcha, pelos interiores) f. Arg. Manta del apero de montar. // 2. Chile. Pelusa o pluma que tienen algunas aves en los tarsos" (DRAE: 269).

Vid. supra calchacura (Fitonimia).

“calchona. (De calchón). f. Chile. En la tradición popular, ser fantástico y maléfico que atemoriza a los caminantes solitarios. // 2. Chile. bruja (//mujer que tiene pacto con el diablo). // 3. (// mujer vieja y fea)"(DRAE: 269). Vid. supra calchacura (Fitonimia).

"Calchona. Ser fabuloso de la mitología popular, parecido a una cabra u oveja "linuda", es decir, de lana o pelo largo; se dice que espanta i daña de noche a los que andan solos. Parece que tiene cierta semejanza con el Werwolf del alemán, Loup garou del francés. Del mapuche calcha, pelos interiores" (L., DE.:162); "La CALCHONA se parece a una oveja de grandes lanas. Les sale al paso a los que viajan solos por el campo y les pide de comer. $\mathrm{Si}$ no le dan, los embiste hasta derribarlos y los revuelve y pisotea [...]" (Vic.: 21-22). Es también una bruja, un alma en pena. ${ }^{12}$

12 El autor consigna otras versiones de la Calchona. 
"cancato. m. Pescado asado a las brasas, relleno con queso y otros ingredientes, típico de Chiloé, en Chile" (DRAE: 284).

De kankan /kankan/, kankatun/kankatun/ 'asar', 'el asado'. "Cancan, asar en asador" (Vald., Voc.); "Cancan: Caro tosta [...], assa [...] Roast meat [...] gebrahtenes Fleisch [...] carne asada" (Herck., en Schul.: 10, 27, 38, 55) 13. "Cancan - asado, y asar [...]" (F., Cal.: 438); "Assa, tosta, assa, cancan [...]" (H., Chil. I: 302), "Cancan, assum, torridum" (H., Chil. II: 617); “CANCAN. Asado, y asar" (F.-Hern. I: 6); "Cancatun, v. La acción de cocer o asar el cancato" (Cañ.: 257); "kaykan, tr., asar, adj. asado. s., el asado [...]” (Aug. I: 73); “kangkang asar, asado, el asado" (Alon., 1989:129); "kangkan [kay'kan]: Carne asada a las brasas" (Catr.: 74).

"chalcha. (De or. mapuche). f. Chile. Papada de los animales, especialmente de los vacunos. U. m. c. pl." (DRAE: 348); "charcha. f. Chile. chalcha. // 2. coloq. Chile. Acumulación de grasa, especialmente en el vientre. // coloq. Chile. En lenguaje juvenil, cosa de mala calidad. U. t. c. adj." (DRAE: 352). De chalcha /čalča/ "papada'. "Chalcha - papada" (F., Cal.: 442). El autor no especifica si es propia de los animales. La voz no está consignada en otros léxicos coloniales.

"chamanto. m. Chile. Manto de lana fina con muchas listas de colores, que usan los campesinos" (DRAE: 348).

Según Lenz, podría pensarse en una fusión de chamall con manto (DE.: 244 - 245).

"chapalele. m. Especie de pan hecho con harina y papa rallada que, en Chiloé, Chile, suele acompañar al curanto" (DRAE: 351).

¿De chapüdkülen /čapïðkïlen/ 'estar aplastado'? "Chapùd - cosa chata, ò aplastada: chapùdlonco - cabeza aplastada, mal amassada: chapùdgen serlo" (F., Cal.: 444), "[...] chapùdcovquen - es puñetear, ò hacer los panes amasando" (F., Cal.: 462); "Chapúd [Chapùd] depressus. chapúd [chapùd] lonco, caput depressum" (H., Chil. II: 622); "Trapalele (s. m.) Pedazo de masa sobada y recortada y que se hierve solo en agua y sal" (Cav., 1914: 410, 1921: 112); "chapəd, adj., aplastado, chato; v. gr. - kəlen estar tableado. -kofke la tortilla, las hostias; - kofken, n., hacer tortillas. - logko cabeza achatada [...]" (Aug. I: 18); "chapüd aplastado, chato, atortillado" (Alon., 1989:27). Es típico de Chiloé. No está consignado en Lenz.

13 El nombre aparece también como caucan, pero debe ser errata. 
"chape. m. Chile. Trenza de pelo [...]" (DRAE: 351).

De chape/čape/ 'trenza'. "Chape - las trenzas del cabello: chapen, chapecan - hacerlas" (F., Cal.: 444); "Chape, chapen, crinium post tergum collectio. Chapecan, capillos ita colligere, ligare" (H., Chil. II: 621); "CHAPE, CHAPECAN. Las trenzas del cabello, y hacerlas" (F.-Hern. I: 8); "chape, s., la trenza. // - kan, tr., trenzar, colchar" (Aug. I: 17); loyko chape, trenzas del cabello (Coñ.: 186, 187,211, 217).

"charchazo. m. coloq. Chile. Bofetada en la mejilla" (DRAE: 352). De chalcha. Vid. supra.

"charquicán. m. NO Arg., Chile y Perú. Guiso hecho a base de charqui, ají, zapallo y otros ingredientes" (DRAE: 353$)$.

Del quechua ch'arki/č́ arki/ 'cecina, carne salada y seca', y los morfemas del mapuche $\{-\mathbf{k a} \mathbf{a}-\}$ y $\{-\mathbf{n}\}$, con los cuales se forman verbos: 'hacer una comida con charqui'. "Charqui, cezina, Charquin, hazer cezina" (Vald., Voc.); "Charqui-el charqui, ò cezina: charquin -hacerla" (F., Cal.: 444); "Caro salita, condita sale, charqui" (H., Chil. I: 302); "Charqui, caro salita, sale condita" (H., Chil. II: 622); "CHARQUI. Charqui o cecina chanquin [charquin] hacerlo: charquitun comerlo" (F.-Hern. I: 9); "charki, s., carne cortada en fajas y secada al sol o ahumada (cecina) //. - n, - tun, tr., charquear (la carne)" (Aug. I: 18). La palabra debe haber sido adoptada por el mapuche en época prehispánica. Por ello, seguramente nadie sospecha que es de origen quechua (Chharqui. Tassajo o cecina o cuerpo seco o el flaquísimo) GH.: 98, “ch'arqui, s. carne salada y secada al sol” (Midd.: 381). Vid. L., DE.: (261 - 263).

"chilenismo. m. Vocablo, giro o modo de hablar propio de los chilenos" (DRAE: 357).

De Chile. Este provendría del nombre de un ave. Es solo una hipótesis. Vid. supra trile (Zoónimos).

"chopazo. m. Chile. Golpe dado con el chope. // 2. Bol. y Chile. puñetazo" (DRAE: 365).

De chope. Vid. supra (Cultura mapuche).

"chuica. f. coloq. Chile. garrafa (// vasija esférica)" (DRAE: ibíd.).

De chuyko /čuiko/'tinajita', "Chuyco - tinajita” (F., Cal.: 453). La voz no está consignada en otros léxicos mapuches.

"chuico. (Del mapuche chuyco, tinajita). Bol. y Chile. Damajuana de cierta capacidad" (DRAE: 367). 
“coironal. m. O. Arg. y Chile. Terreno en que abunda el coirón" (DRAE: 394).

De coirón. Vid. supra (Fitonimia).

"colihual. m. Arg. Terreno poblado de colihue" (DRAE: 398).

"coligual. m. Arg. y Chile. colihual " (DRAE: ibíd.).

De coligüe, colihue. Vid. supra (Fitónimos).

“contre. m. Chile. molleja (//estómago de las aves)" (DRAE: 436).

"contri. (Del mapuche conthi o conthùl). m. Chile. Molleja (//estómago de las aves)" (DRAE: ibíd.).

De kontrü /kont'î/, kontrül /kont'ïl/'molleja de ave'. "Conthi, conthùl - molleja de las aves" (F., Cal.: 460); "CONTHI, o Rùcùl. Mollejas de las aves" (F.-Hern. I: 13).

“copucha. (De copa). f. Bol. y Chile. mentira (// expresión contraria a lo que se sabe) //2. Chile. Vejiga que sirve para varios usos domésticos [...]" (DRAE: 441).

De pukuchu /pukuču/, la copucha. "Pucuchu, bejiga" [sic] (Vald., Voc.); "Pucuchu -la vejiga con que echan ayuda" (F., Cal.: 603); "pucuchu, clyster" (H., Chil. II: 757); PUCUCHU. "Bejiga con que hechan ayudas" (F.-Hern. I: 60). La palabra es un préstamo del quechua, adoptado tempranamente por el mapuche ("Puccuchu [...] bexiga" (GH.: 294). Vid. L., DE.: 211.

“curanto. M. SO Arg. y Chile. Comida a base de legumbres, mariscos o carne, cocida sobre piedras muy calientes en un hoyo que se recubre con hojas" (DRAE: 485).

De kurantu /ku.santu/ 'colectivo de piedras'. "Cura - piedra [...] curantu - pedregal [...]" (F., Cal.: 466); "Cura, lapis, saxum, petra. curantu, saxetum [...]" (H., Chil. II: 638); “CURANTU. Pedregal, cascajo" (F.-Hern. I: 15, II: 73); "Curanto, s.- El cocido que se hace de varias cosas, en especial de pescados y mariscos en un hoyo preparado al efecto en la tierra [...]" (Cañ.: 263-264); "kurantu, s., el pedregal [...]" (Aug. I: 100); "kurantu [ku'rantu]: Pedregal" (Catr.: 98).

"curiche. m. //. Chile. Persona de color oscuro o negro" (DRAE: 486).

De kurü//kuıï/ 'negro' y che/če/ 'gente', 'persona'. "Curúche, negro (Vald., Voc.); "Curiche, curùche - los negros" (F., Cal.: 467). "Niger, curùche" (H., Chil. I: 383). "NEGRA jente. Curùche" (F.-Hern. II: 65). "negro, m., (raza humana) tapayu, kurüche" (Aug. II: 253). 
"gualve. (Del mapuche walwe, maizal). m. Chile. Terreno pantanoso" (DRAE: 789).

De wal(ün)/wal(ïn)/ 'producir un murmullo el agua' y we/we/. "Hualhualn, ò hualhualùn, ò hualgaln - hacer un murmullo el agua, ò sonar, gruñir las tripas, hacer gargarismo, ò zangolotear lo líquido, ò hacer ruido semejante: hualn - idem: hualihueyco -sonò el ciènego, ò el charco [...]" (F., Cal.: 504): "Hualhualun, strepitus aquae, intestinorum, \& c. item.gargarizatio, gargarizatus, gargarizo" (H., Chil. II: 669). No es verosímil el significado 'maizal', pues se trata de un terreno cenagoso o pantanoso, no apto para el cultivo (Cañ.: 278); "walwálïn, n., murmullar las corrientes de agua, las cascadas, los remolinos, sonar las tripas" (Aug. I: 244).

"guata2. (Del mapuche huata) f. coloq. NO Arg., Bol., Chile, Ecuad. y Perú. Barriga, vientre, panza" (DRAE: 794).

De wat'a /watra/, wata/wata/ "panza'. "Huatha - la panza" (F., Cal.: 505); "Ventriculus, stomacus, huata, pùta (H., Chil. I: 286); "HUATHA. Panza de animales" (F.-Hern. I: 27). La palabra cayó en desuso en mapudungun; actualmente se emplea pütra /pïtra/, con el mismo significado.

"guatazo. m. coloq. Chile. Caída de bruces. // 2. Chile. Golpe dado con el vientre al caer en el agua. // 3. Chile. Frustración producida por una desilusión inesperada" (DRAE: íbíd.).

De guata. Vid. supra.

"laque. (Voz mapuche). m. // 2. Especie de porra de fierro o de madera recubierta" (DRAE: 914).

De lake /lake/, lükay /lïkai/ 'las Tres Marías'. "Laque - dos, ò tres bolas, ò piedras amarradas para tirar, y coger" (F., Cal.: 530); "Duo lapides rotundi corio involuti, \& utrique funis extremitati fortiter \& fideliter alligati, laque" (H., Chil. I: 436); "LAQUEE.Dos o tres piedras o bolas amarradas para tirar i agarrar" (F.-Hern. I: 37); “lakai, s., el boleador [...]” (Aug. I: 114); lëkai, las boleadoras (Coñ.: 36, 299, 300); “lïkay el boleador" (Alon., 1989: 140). En verdad, significaba originalmente las ‘boleadoras' o 'Tres Marías'.

"linao. m. Especie de juego de pelota, muy usado en la isla de Chiloé, provincia de Chile" (DRAE: 936).

¿De lli / $\mathbf{K i} /$ 'principio de cualquier cosa' y nagü(n)/nayï(n)/ antü /antï/ 'bajar (el sol): 'cuando principia a bajar el sol'? Los jugadores rivales se 
reunían, en una pampa, en la tarde, al caer, al entrarse el sol ${ }^{14}$. La evolución del nombre pudo ser la siguiente://ina $>$ linau $>$ linao/. "Lli- [...] tomase por principio de cualquier cosa [...]" (F., Cal.: 540); "Lli, principium, initium, primordium, caput, fons, origo [...]" (H., Chil. II: 702); "Nagh - abajo, bajada, hacia abajo [...]" (F., Cal.: 574); "Nâu, infra: descensus, descensio [...]" (H., Chil. II: 720); “naqn, n., bajar (n.) (hacia allá)" (Aug. I: 146), "Haberse inclinado mucho naqn (n.) antü [el sol]; naqantün [bajar el sol] [...]”' (Aug. II: 358). El juego se llamaría en español 'el vespertino', denominación que sería correcta y usual.

"macal1" m. Chile. Terreno poblado de plantas de maqui" (DRAE: 954).

De maqui. Vid. supra (Fitonimia).

"mallín. (Del mapuche malliñ, lago). m. Arg. Pradera cenagosa propia de la región semidesértica de la Patagonia" (DRAE: 966).

De malliñ /maKìn/ 'laguna'. "Laguna-mallin" (F., Voc.: 362); “Mallin, lacuna, palus udis" (H., Chil. II: 709, también en H., Chil. I: 262); “Mallin, s. Vega húmeda, pantanosa, con pajonal" (Cañ.: 298); "malliñ (kó) el aguazal [...]" (Aug. I: 130); "malliñ [ma'kïn]: Aguazal; agua detenida en sitios bajos u hondos" (Catr.: 103). Los mallines existen en diferentes puntos del territorio mapuche.

En J. I. Molina: “La Laguna Mallin"( I: 410).

"natral. m. Chile. Terreno poblado de natris" (DRAE: 1063).

De natri. Vid. supra (Fitonimia).

"pangal. (de pangue). m. Chile. Terreno poblado de pangues" (DRAE: 1130).

De pangue. Vid. supra (Fitonimia).

"percán (Del mapuche percan). m. Chile. Moho que, por la humedad, se forma en diversas sustancias vegetales y animales" (DRAE: 1172).

De perkan /pe.skan/ 'moho'. "Percan, orin o moho" (Vald., Voc.); "Percan el moho, y criarse, ò tomarse de èl: también se dice de la carne, pescado, etc.

14 "El Linao es un juego de pelota y al mismo tiempo un pugilato, que suele tener por contendientes a individuos de distintas capillas y subelegaciones.

Se reunen los partidos [bandos] desafiados, a la caída del sol, en una pampa escogida para el objeto de antemano, y se elige a los individuos más diestros y fuertes en ambos partidos [...]" (Cav., 1914: 178. El juego le fue narrado por N. N.). 
quando se corrompe [...]" (F., Cal.: 586); "Caries, mucor, muscus, rubigo, percan" (H., Chil. I: 306), "Percan, muscus, mucor [...]" (H., Chil. II: 742); "PERCAN. Moho, i criarse o tomarse de moho; i se dice de la carne o pescado cuando se corrompe" (F.-Hern. I: 54); "perkan, s., el moho (p. e. en el pan [...])" (Aug. I: 171); "perkan [per'kan]: Cubierto de moho gris" (Catr.: 141).

En J. I. Molina: "Percan enmohecer” (II: 371).

“pichintún. m. coloq. pizca" (DRAE: 1188).

De pichintun 'un poco', 'un poquito'. "Pichintun - (de pichin =ser poco, pequeño). Niño pequeño. F. de A. dice pichitun =volverse chico, corto". En dialecto chileno pichitun y pichintun significan cosa pequeña" (Cav., 1921: 94). "pichi - tun, n., volverse corto, chico, poco" (Aug. I: 179).

"pilcha. (Del mapuche pulcha, arruga). f. rur. Arg. Bol. y Par. Prenda de vestir pobre o en mal estado. U. m. en pl. [...]" (DRAE: 1194).

De pülcha /pïlča/, o pültta /pïlta/ 'arruga'. "Pùlcha, ò pùlta - arruga [...]" (F., Cal.: 607), "Arruga - pùlcha" (F., Voc.: 311); "Ruga, plcha [pùlcha] [...]" (H., Chil. I: 291, 299), "Púlcha [pùlcha] plcha [pùlcha], ruga. pùlchan, plchalen [pùlchalen], rugosum esse [...]" (H., Chil. II: 750); “ARRUGA, del cuerpo. Pùlta, Pùltha [...]" (F.-Hern. II: 10). La voz se usa en Chile.

"piñén. m. coloq. Chile. Mugre adherida al cuerpo por desaseo prolongado" (DRAE: 1198).

De pingen /pinen/ 'una enfermedad'. "Pigen - it: una enfermedad, como engranujada" (F., Cal.: 590); "PIGE $\tilde{N}$. Rajaduras en pies, cara o manos cuando corre viento frío i seco: una enfermedad como engranujado. Pigeñn. Padecerlas" (F.-Hern. I: 56); "pingeñ [pi'yen]: Suciedad y partidura en los pies" (Catr.: 181).

"pirco. (Del mapuche pidcu). m. Guiso chileno de judías, maíz y calabaza" (DRAE: 1201).

De pidku /piðku/, pidko/piðko/. "Pilcu, maçamorra para cauallos" (Vald., Voc.): "Pidco - un mote de frijoles cocidos, con maíz" (F., Cal.: 590); "Puls ex phaseolis \& maicio, pidcu" (H., Chil. I: 302), "Pidcu, phaseoli \& maicium simul cocta" (H., Chil. II: 744); "PIDCU. Mote, comida de grano, sea maiz, frijol o habas" (F.-Hern. I: 56); "pishku, pidku, adj., cocido en olla sin sal. Aplícase comúnmente a las habas, arvejas y maíz, y al trigo que se cuece en agua para hacerlo mote" (Aug. I: 184).

"pirquén. (del mapuche pilquén, trapos). Dar a, o trabajar al $\sim$, frs. Chile. En el lenguaje de las minas, trabajar sin condiciones ni sistema determinados, 
sino en la forma que el operario quiera, pagando lo convenido al dueño de la mina" (DRAE: 1202).

De pilken /pilken/, pilkeñ /pilkep/ 'trapos'. "Pilquen - trapos, trapillos" (F., Cal.: 592), "Trapos, trapillos- pilquen" (F., Voc.: 408); "Reliquiae, pilquen" (H., Chil. I: 299); "pillkeñ, s., (ekull) cualquier vestuario de mujer; cualquier trapo, bueno o malo [...]" (Aug. I: 181).

"pirquinero. m. Hombre mezquino a ruin" (DRAE: ibíd.).

De pirquén. Vid. supra.

"pololo". (De or.mapuche). m. Bol. y Chile. Hombre que pretende a una mujer [...]" (DRAE: 1220).

¿De püldu /pïlðu/, pül-lü /pïl-lï/ 'mosca'? Vid. supra pololo (Zoónimos)

"poncho". Prenda de abrigo que consiste en una manta, cuadrada o rectangular, de lana de oveja, alpaca, vicuña, o de otro tejido, que tiene en el centro una abertura para pasar la cabeza, y cuelga de los hombros generalmente hasta más abajo de la cintura [...]" (DRAE: 1222).

De pontro /pont $\mathbf{t}^{\mathrm{r}} \mathbf{0} /$, poncho/pončo/ 'la manta', 'la frazada'. "Pontho, poncho dizen ellos sus ponchos, mantas o fressadas gruesas y burdas" (F., Cal.: 600); "Alia [vestis stragula] similis notae, sed ejusdem unius coloris \& sine figuris, ponchu, poncho" (H., Chil. I: 295), "Poncho, vestis stragula" (H., Chil. II: 754); "pontro, s., la frazada de lana del país" (Aug. I: 187); pontro, frazada(s) (Coñ.: 28 et pássim); "Pontro = la frazada" (Alon., 1985: 127); "pontro [pon't'o]: Frazada" (Catr.: 69). Actualmente posee este significado en mapuche.

"poto". (Del mochica potos, partes pudendas). m. NO Arg., Bol., Chile, Ecuad., Par. y Perú. nalgas (//porciones carnosas y redondeadas)" (DRAE: 1231).

De poto /poto/ 'asentaderas', 'nalgas', 'ano'. "Poto - el siesso" (F., Cal.: 600), "Siesso - poto, cuchiu [cùchiu]" (F., Voc.: 399); "Anus, podex, poto" (H., Chil. I: 280), "Poto, sedes, anus" (H., Chil. II: 754); "POTO. Trasero sieso" (F.-Hern. I.: 59). Podría provenir de otra lengua amerindia, pero no está documentado. Lenz consideró la voz de origen mapuche (DE.: 635). En J. I. Molina: “El ano Poto (I: 414).

“quiltro. Vid. supra (Zoónimos).

"rulo². (Del mapuche rulu). m. Chile. Tierra de labor sin riego" (DRAE: 1355).

De rulu /aulu/ 'vega', 'campo húmedo'. "Rulu - las vegas, ò llanos 
húmedos" (F., Cal.: 625), "Vega-rulu" (F., Voc. 410); "Rulu, campus, locus madidus, humidus" (H., Chil. II: 774); “vega, f. rulu+" (Aug. II: 400); rulu, vega (Coñ.: 38 et pássim); "rulu [ru'lu]: Tierras planas en donde los cultivos crecen mejor sin necesidad de muchas lluvias" (Catr.: 97).

En J. I. Molina: “El Valle Rulu” (I: 410).

"trumao. m. Chile. Tierra arenisca muy fina de rocas volcánicas" (DRAE: $1520)$.

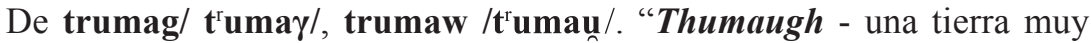
delgada, ò arenisca" (F., Cal.: 649), "Arenisca tierra - thumaugh [...]" (F., Voc.: 311); "THUMAUTUE. Tierra arenisca" (F.-Hern. I: 76); trumaq, polvo suelto (Coñ.: 77); "trumag [t'u'mar]. Tierra; polvo suelto" (Catr.: 97).

"trutro. (De or. mapuche). m. Chile. Muslo de las aves. // 2. coloq. Chile. Muslo de las personas" (DRAE: 1521).

De tute /tute/, trutre /t'trt $\mathbf{r}$ / "caderas'. "Tute - el quadril" (F., Cal.: 632); "Ilia, tute" (H., Chil. I: 280); "THUTHE. Caderas de animal" (F.-Hern. I: 76); "trutre, s., las caderas" (Aug. I: 237). "trutre las caderas" (Alon., 1989: 194). /-o/ de trutro se debe sin duda a influencia del español.

"ulpo. m. Chile. Especie de mazamorra hecha con harina tostada y agua fría" (DRAE: 1528).

De ulpud /ulpuð/, ullpüd /uKpïð/, ulpu /ulpu/, ülpu /ïlpu/ 'harina tostada con agua (fría)'. "Ulpu, ulpud, ò ullpùd - bebida simple de harina tostada con agua: ulpudn, ulpudtun -tomar este ulpo" (F., Cal.: 669); "Farina ex grano tosto cum aqua calida, chedcan .cum frigida, ùlpu, ùllpud' (H., Chil. I: 308), "Ullpud [ùllpud], ulpu [ùlpu], potus ex aqua et farina tosta. ùllpúdn, hunc

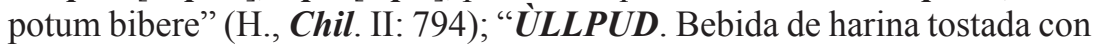
agua. ùllpudn. Hacer el ulpo: ùllpudtun tomarlo, o beberlo" (F.-Hern. I: 86); "ullpad (mürke) harina tostada bien revuelta con agua" (Aug. I: 241).

En cronistas y J. I. Molina: ullpo (Ov.: 110); "[...] y a falta de chicha le dan al marido ulpo, que es arina [sic] de zebada, o de maiz tostado con agua, bebida y sustento de los caminantes y de los que van a la guerra" (Ros. I: 155); Ulpo: harina disuelta en agua fresca (Mol. I: 135); ulpo: bebida de soldados mapuches (Trib. de T.: 84); ullpo: harina tostada con agua (si es clara) (JPG.: 49). 


\section{ADJETIVOS}

Calchón, na; calchudo, da; cari; copuchento, ta; guatón, na; lauchero, ra; piltriento, ta; pilucho, cha; potoco, ca.

"calchón, na. (De calcha). adj. Chile. Dicho de un ave: que tiene calchas. // 2. Chile. Dicho de una caballería. Que tiene muchas: Que tiene muchas cernejas" (DRAE: 269).

De calcha. Vid supra calchacura (Fitonimia).

"calchudo, da. adj. Chile. calchón" (DRAE: 269).

De calcha. Vid.supra calchacura (Fitonimia).

"cari. (Del mapuche cari, verde). adj. rur. Arg. De color pardo o plomizo. Manta cari" (DRAE: 308).

De karü /ka.ıi//, kadü /kaðï/, kari /ka.ıi/ 'verde', 'crudo', pero también 'tordillo', 'rosillo'. "Carù, cari - verde color, y cosa verde, no cocida [...] cari cahuellu - cavallo tordillo [...]" (F., Cal.: 439); "Carù, crudus. Item. color viridis. Item nigror albicans [...]" (H., Chil. II: 618); "CADÜ. Color ceniciento. Cadù macuñ, poncho cadi" (F.-Hern. I: 5). "karü, adj., verde, crudo, no maduro [...] - kawellu caballo rosillo blanco [...]" (Aug. I: 77); "Cadi (a. inv.) - Se aplica al ganado ovejuno de lana mezclada de blanco y negro. Es una variante del chileno cadi" (Cav., 1914: 359).

"copuchento, ta. adj. Bol. y Chile. Mentiroso, que propala noticias exageradas, que abulta las cosas" (DRAE: 441).

De copucha. Vid. supra (Otros sustantivos).

"guatón, na. NO Arg., Bol., Chile, Ecuad. y Perú. barrigudo. U. t. c. s. (DRAE: 794).

De guata. Vid. supra (Otros sustantivos).

"lauchero, ra. adj. coloq. Chile. Dicho de un jugador: Que habitualmente espera la ocasión de marcar un tanto sin incorporarse de lleno al juego. U. t. c. s." $(\boldsymbol{D} \boldsymbol{R} \boldsymbol{A E}$ : 917)

De laucha. Vid. supra (Zoónimos).

"piltriento, ta. adj. despect. coloq. Chile. andrajoso" (DRAE:1195).

De pilcha. Vid. supra (Otros sustantivos). 
"pilucho, cha. adj. coloq. Chile. desnudo (// sin vestido) // 2. Chile. pelele (// traje de una pieza para niños) (DRAE: 1195).

Según el Dr. Lenz, "Probablemente es una formación híbrida de pelo ("estar en pelo", cp. 'peluquecho') con terminación mapuche de adjetivos [-chi /-či/ ]: peluchi>piluchi >pilluchi, de nuevo asimilado al cast. $\boldsymbol{o}$ a en la terminación. Como el indio cuando niño, i en casa también cuando adulto, a menudo anda casi desnudo, es mui posible que los españoles i en particular las mujeres criollas a menudo los hayan retado "no andes en pelo, no estés en pelo, etc." (DE.: 596). Es posible; no se encuentra un adjetivo mapuche en los léxicos con tal significado.

“potoco, ca. adj. Bol. y Chile. rechoncho. U. t. c. s."(DRAE: 1231). De poto. Vid. supra (Otros sustantivos).

\section{ADJETIVOS GENTILICIOS}

Aconcagüino, na; angolino, na; araucano, na; cachapoalino, na; cauquenino, na; chacabucano, na; chaitenino, na; chileno, na; chillanense; chilote, ta; choapino, na; colchagüino, na; curicano, na; elquino, na; huilliche; illapelino, na; liguano,na; llanquihuano, na; maipino, na; mallequino, na; mapuche; maulino, na; melipillano, na, neuquino, na; ñublino ñublense; pehuenche; penquista; picunche; puelche; rancaguino, na; ranquel, ranquelino, na; talquino, na; temucano, na.

"aconcagüino, na. adj. Natural de Aconcagua. U. t. c. s. // 2. Perteneciente o relativo a esta provincia de Chile" (DRAE: 23$)$.

De konka /konka/ 'atados de paja para techar' y wa /wa/ 'lugar donde hay algo'. "Conca - manojitos, o ataditos de paja, o carrizo para techar: concan - hazerlos" (F., Cal.: 459), "Atados [...] de paja - conca" (F., Voc.: 312 - 313); "Palearum ad tegendam domum manipulus, concan" (H., Chil. I: 407), "Concan, paleae manipuli ad domum tegendam; tectum illi stramineum imponendum" (H., Chil. II: 633); "CONCA. Manojos o atados de paja o carrizo para techar" (F.-Hern. I: 12); "koyka, s., el atado de yerbas; v. gr. $\boldsymbol{k} \ddot{u} \boldsymbol{n} \boldsymbol{a}$ atado de $\boldsymbol{k u ̈ n a}$ [una paja para techar]" (Aug. I: 91); koyka, atados [de paja küna] (Coñ.: 176). La a antepuesta puede provenir del español, como en el caso de Arauco. El nombre aparece tempranamente documentado con las formas Canconcagua, Anconcagua, un valle. Vid. Cartas de Pedro de Valdivia, la Crónica de Vivar. 
"angolino, na. adj. Natural de Angol. U. t. c. s. // 2. Perteneciente o relativo a esta ciudad de Chile" (DRAE: 105).

De Angol y esta de engkolün /enkolïn/ 'subir a gatas, subir trepando, y agarrándose con manos, y pies'. El nombre se debe a un cerro que era necesario subir para acceder a la ciudad. Fue llamada por los españoles Los Confines. "Encoln, encolpran, ò encon, econ, econpran, todos son lo mismo, esto es, subir a gatas, subir trepando, y agarrandose con manos y pies". Encolmapu - la tierra de Angol, que le dio el nombre un cerro llamado assi [....] (F., Cal.: 486); "Encon, encopran, encolpran, econ, scandere, ascendere, conscendere, subire uno salto. item. quadrupedis in modum sursum repere; in altum prorepere; scandere in subrectum \& manuum \& pedum beneficio, subsidio, auxilio" (H., Chil. II: 656).

Angol es comuna y ciudad de la VIII ${ }^{a}$ Región.

"araucano", na. adj. Se dice del individuo de alguno de los pueblos amerindios que, en la época de la conquista española, habitaban en la zona central de Chile y que después de extendieron por la pampa argentina. U. t. c. s. // 2. m. mapuche (idioma de los araucanos)" (DRAE: 131).

De rag /..say/'greda' y ko /ko/ 'agua'(s): 'agua(s) gredosa(s)', con la preposición a del español, antepuesta. Nombre de una provincia de la VIII ${ }^{\mathrm{a}}$ Región de Chile. El nombre Arauco fue difundido por Alonso de Ercilla y Zúñiga.

"cachapoalino, na. adj. Natural de Cachapoal. U. t. c. s. // 2. Perteneciente o relativo a esta provincia de Chile" (DRAE: 259).

¿De kachu /kaču/ 'pasto', 'yerba' y pual 'loco', 'delirio', es decir, 'pasto o yerba que hace delirar, volverse loco'? "cachu - el pasto del campo" (F., Cal.: 434), "Pual - loco, que desvaría por enfermedad: pualgen - serlo, estarlo: Pualn - desvariar assi" (F., Cal.: 602); "Pual, deliramentum, delirium. Pualn, pualgen, deliro, desipio. Pualgeimi cam" ¿Quae te dementia cepit? ¿Quis te tantus furor invasit? ¿Quo furore correptus, oestrove insaniae percitus es?" (H., Chil. II: 757). Según Vivar (68), un cacique se llamaba Cachapoal, y este habría dado origen al nombre del río que tiene tal nombre (en la $\mathrm{VI}^{\mathrm{a}}$ Región). Cachapoal ocurre también en otras regiones: Quebrada Cachapoal ( $V^{a}$ Región); Cachapoal, pueblo en la provincia de Ñuble (VIII ${ }^{a}$ Región); cerro Cachapoal, en la comuna de San Carlos (VIII Región); Cachapoal, pueblo en la VIII ${ }^{a}$ Región. El nombre no es exclusivo de un río; por ello es dable pensar que puede haber significado una planta, cuyo nombre no quedó documentado en vocabularios del mapuche.

Cachapoal es provincia de la VI ${ }^{\mathrm{a}}$ Región. 
"cauquenino, na. adj. Natural de Cauquenes. U. t. c. s. Perteneciente o relativo a esta ciudad de Chile" (DRAE: 328$)$.

De canquén. Vid. supra (Zoónimos).

Cauquenes es ciudad y comuna de la provincia de Linares, VII ${ }^{a}$ Región.

"chacabucano, na. adj. Natural de Chacabuco. // 2. Perteneciente o relativo a esta provincia de Chile" (DRAE: 346$)$.

¿De chakay/čakai/ ' 'un arbusto (Discarya serratifolia, Fam. Rhamnaceae)', pu /pu/ 'dentro' y ko /ko/: 'chacay(es) dentro del agua'?

"Chacay - un arbol conocido" (F., Cal.: 441); "CH $\boldsymbol{A C A}$. El espino negro de esta tierra" (F.-Hern. I:7); "chakai, s., arbusto conocido con tal nombre o con el de espino negro" (Aug. I: 16).

Chacabuco es provincia de la Región Metropolitana.

"chaitenino, na. adj. Natural de Chaitén. U. t. c. s. // 2. Perteneciente o relativo a esta ciudad, capital de la provincia de Palena, en Chile" (DRAE: 347).

¿De chaytun /čaitun/ 'colar, pasar líquidos por un chaihue /čainwe/, un canasto'? "Chayhue - un canastito para colar chicha, y cernir harina, y miden con ella sal, y otras cosas: es como medio almud", "Chayhuetun chaytun - colar" (F., Cal.: 442); "Chaihue, calathus, quasillus, quo metiuntur res solidas; \& duo modium efficiunt, per eundem \& liquores purgantur. Chaihuetun, chaitun, liquores purgare" (H., Chil. II: 620); "CHAIHUE. Canastillo de boquisitos para colar chicha y sernir arina [sic]", "CHAITUN. Colar” (F.-Hern. I: 8); “chaitun, tr., colar, pasar líquidos por el chaiwe (colador)", "chaiwe, s., canastita ordinariamente de pallpollfoki, que sirve de cernidor o colador" (Aug. I: 16); “- Chaihue (s.m.) - Canastito para pisar y lavar mote (en Chiloé "trigo pelado") y también para mariscar [...]" (Cav., 1914: 322). Si la etimología es verdadera, el lugar se habrá caracterizado por la confección de chaihues, probablemente más para mariscar.

Chaitén es provincia, comuna y ciudad de la XI Región.

"chileno, na. adj. Natural de Chile. // 2. Perteneciente o relativo a este país de América" (DRAE: 358).

De Chile. Vid. supra trile (Zoónimos). (Tb.L., DE.: 279-284).

“chillanense. adj. Natural de Chillán.U. t. c. s. // 2. Perteneciente o relativo a esta ciudad, capital de la provincia de Nuble, en Chile (DRAE: 358).

De chilla /čiKa/ 'zorro chilla'. La forma básica mapuche chillan /či $\mathbf{a n} /$ indica una característica del lugar, en este caso, la de haber zorros, los cuales seguramente ya no hay en el presente. Otros topónimos contienen chilla, 
como Chillamávida ('montaña donde hay zorros chilla'), un mineral Chillán, Nevados de Chillán, una Quebrada de Chillán, etc. Cerca de la ciudad de Chillán pasa un río con ese nombre ${ }^{15}$. El nombre del río dio origen, sin duda, al de la ciudad ${ }^{16}$.

El adjetivo más usual es chillanejo/a.

Chillán es comuna y ciudad de la VIII ${ }^{a}$ Región.

"chilotes ${ }^{3}$ ta. adj. Natural del archipiélago de Chiloé. U. t. c. s. // 2. Perteneciente o relativo a este archipiélago de Chile" (DRAE: 358).

De chülle 'una gaviota' (Larus spp.) y we 'lugar donde hay algo': 'lugar donde hay gaviotas chülle'. Chiloé es archipiélago y provincia de la $\mathrm{X}^{\mathrm{a}}$ Región Sur.

"choapino, na. adj. Natural d Choapa. U. t. c. s. // 2. Perteneciente o relativo a esta provincia de Chile. //3. Chile. Alfombra tejida a mano" (DRAE: 364).

¿De trowün /t' direccional cislocativo: 'hacia acá', 'aquí': ¿(el río) que rasga (la tierra) hacía acá'? "ṫoun, hender, touún [touùn], rajar (Vald., Voc.); "Thoun, o thiun - rajarse, henderse" (F., Cal.: 649); "Toùn, hio, dehisco. Toú [toù] hiatos, scissura: terra hiat aestu" (H., Chil. II: 790); "trown, n., agrietarse, rajarse la tierra por la sequía o los temblores, los platos de palo o las piedras: Trowi ti lil Se ha agrietado la tierra" (Aug. I: 236); “Choapa, Chuapa, río que divide la provincia de Coquimbo de la de Aconcagua, de troun, rajar, hender y de la partícula pa, venir, troupay = viene hendiendo la tierra, como el Maipo la rompe" (Val. I: 257).

Choapa es provincia de la IV ${ }^{a}$ Región.

"colchagüino, na. adj. Natural de Colchagua. U. t. c. s. // 2. Perteneciente o relativo a esta provincia de Chile" (DRAE: 396).

De koltraw /kolt'au/'renacuajo' y wa/wa/ 'lugar donde hay algo'. "colchau,

15 "Las ciudades de Chile tienen otros nombres fuera de los que les pusieron sus fundadores que son los que en lengua de los indios tenían los ríos que por ellas pasan, o el de la provincia o valle donde tienen su asiento; y digo esto, porque por tales nombres nombran a muchas de las ciudades los españoles, más que por los que les pusieron sus fundadores” (G. de Náj.: 10).

16 La etimología 'silla del sol' que, por ejemplo, se encuentra en el Google, es inverosímil, y contradice el patrón de los topónimos mapuches. En verdad, se trata de la palabra española silla (de montar) adoptada por el mapuche, la cual ha dado origen al verbo chillan 'yo ensillé', 'yo ensillo'. ("chilla - [...] la silla, ò avio de montar à cavallo [sic]: chillan - ensillar "(F., Cal.: 448); "sternere equum, ephippium equo imponere, chillan, fillan [shillan]" (H., Chil. I: 213); "chilla, s., la silla de montar [...] - n., ensillar [...]" (Aug. I: 23). 
renaquajos" (Vald., Voc.); Colchau, ò colthau - renaquajos" (F., Cal.: 458); "ranunculus, coltau [koltraw]" (H., Chil. I: 222), "Colchau, coltau, insecta aquatica [....]" (H., Chil. II: 632); "COLTHAU. Renacuajo, colthauhue liugar donde los hai" (F.-Hern. I: 13); "kolchau*, s., [...] renacuajo" (Aug. I: 92); colchau, poloikiñ, renacuajos (Coñ.: 119); "koltraw [kol't'au]: Renacuajo" (Catr.: 166].

Colchagua es provincia de la VI Región.

"curicano, na. adj. Natural de Curicó. U. t. c. s. // 2. Perteneciente o relativo a esta ciudad y provincia de Chile" (DRAE: 486).

Del map. kurü /ku.ıі// 'negro' y ko: 'aguas negras'. Curicó es provincia, comuna y ciudad de la VII ${ }^{a}$ Región.

"huilliche. adj. Se dice de un individuo de un pueblo amerindio originario del centro de Chile. U. t. c. s. // 2. Perteneciente o relativo a los huilliches" (DRAE: 838).

De willi /wißi/, willü /wißï/ 'sur' y che /če/, 'persona', 'gente': 'gente del sur'. "Huylli, tierra de arriba hazia el sur" (Vald., Voc.); "Ghùylli - el sur: ghùylliche, ò ghùylli mapu - llaman la gente, ò la tierra de azia [sic] el Sur, desde Tholten ò Quepe adelante [...]" (F., Cal.: 489); "Regio meridiem versus, Hillù [sic], huilù mapu [...] Incolae, Huillúche" (H., Chil. I: 365), "Huillù, huilù, Regni Chilensis pars Australis quam vocant Huillù mapu: \& incolae vocantur Huillùche, Huiliche [...]" (H., Chil. II: 680); "HUYLLIMAPU. Tierra hacia el sud respecto donde se está" (F.-Hern. I: 32); "willi, s., el sur [...] - mapu, s. c., la tierra del sur, el sur" (Aug. I: 263); willimapu, el sur (Coñ.: 38); "willi el sur, willimapu la tierra del sur" (Alon., 1989: 227); "huilliche [wi'Giče]: Gente del sur" (Catr.: 18).

"illapelino, na. adj. Natural de Illapel. U. t. c. s. // 2. Perteneciente o relativo a esta ciudad, capital de la provincia de Choapa, en Chile" (DRAE: 846). ¿De illav /iKav/ 'plano', 'llano' y pele /pele/ 'barro': '(lugar) llano con barro'? "Illav - llano, llana cosa" (F., Cal.: 521), "Pele, ò pel le, pelde, pede-barro, lodo [...]" (F., Cal.: 582); "Illaf, planus, aequus" (H., Chil. II: 688), "Pelle, pel-le, pede, lutum" (H., Chil. II: 740); "pel·e,s., [ ...] el barro, lodo" (Aug. I: 168).

Illapel es comuna y ciudad de la IV Región.

"liguano, na. adj. Natural de la Ligua.U. t. c. s. // 2. Perteneciente o relativo a esta ciudad, capital de la provincia de Petorca, en Chile" (DRAE: 934).

De lliwa / Kiwa/ 'el adivino'. "Llihua - el adivino, à quien consultan" (F., Cal.: 541); "Divinus, vates, Hariolus, Auspex, augur, auctor, principium, 
inventor rei novae, llihua" (H., Chil. I: 524), "llihua, inventor, auctor, vates, divinus" (H., Chil. II: 703).Seguramente en ese lugar había un adivino renombrado.

La Ligua es comuna y ciudad de la V Región.

"Ilanquihuano, na. adj. Natural de Llanquihue. U. t.c.s. // 2. Perteneciente o relativo a esta provincia de Chile" (DRAE: 942$)$.

De llangkün / Kạkïn/ 'perderse, esconderse, ocultarse' y we 'lugar': 'lugar escondido'; 'lugar para zambullirse'. Antes, el lago que lleva ese nombre estaba rodeado de selvas impenetrables que seguramente impedían verlo. "Llancùn, ò llann - perderse algo o escurrirse, como cayendosele; tomase por caerse las hojas de los arboles, o zambullirse dentro del agua" (F., Cal.: 519).

Llanquihue es provincia, comuna y ciudad (lacustre) de la Xa Región.

"maipino, na. adj. Natural de Maipo. U. t. c. s. // 2. Perteneciente o relativo a esta provincia de Chile" (DRAE: 962).

De maipu(we) '(lugar de) tierra arable'. "Maypun-romper la tierra" (F., Cal.: 545); "Maipun, terram subigere, proscindere, arare" (H., Chil. II: 707); “MAYPUN. Rastrear la tierra para sembrar” (F.-Hern. I: 42); “maypün moler, rastrear la tierra, preparar la tierra", "maipu tierra escarbada, molida, trumao, tierra blanda para echar la semilla" (Alon., 1989: 92).

Maipú es comuna de la Región Metropolitana.

"mallequino, na. adj. Natural de Malleco. // 2. Perteneciente o relativo a esta provincia de Chile" (DRAE: 966).

De malle /maKe/, mallo /mako/ 'greda blanca' y ko 'agua(s)': 'agua(s) de greda blanca'. "Mallo cal, o tierra blãca" (Vald., Voc.); "Malle, ò mallo, ò malo - una tierra blanquisca, y pintada, o cosa de este color: Malleco - agua de esta tierra, y el rio de Angol, y una Reducción algo mas arriba [...]" (F., Cal.: 546 - 547); "Mallo, terra alba, candida" (H., Chil. I: 247); "MALLO. Tierra blanquisca: mallo co, agua de dicha tierra" (F.-Hern. I: 42).

Malleco es provincia de la IX ${ }^{\text {a }}$ Región.

"mapuche. (Del mapuche mapu, tierra, país y che, gente). adj. Se dice del individuo de un pueblo amerindio que, en la época de la conquista española, habitaba en la región central y centro-sur de Chile. U. t. c. s. // 2. Perteneciente o relativo a los mapuches //3. m. Lengua de los mapuches" (DRAE: 981). De mapu 'tierra, país, patria' y che 'gentede la tierra': 'gente de la tierra, del país'. Мapu Che: Indio (F., Arte, Diálogo: 112-113 et pássim); Мapu che: Indus (H., Chil. I: 332, 365, 393, 386), H., Chil. II: 556, 567, 698), “mapuche+, s. c. el indígena. / adj. lo de los indígenas //- ché, habitante de algún país [...]" 
(Aug. I: 131); "mapuche [ma'puče]: Persona o gente de la tierra. El nombre de un pueblo indígena que vive en el centro-sur de Chile" (Catr.: 12).

"maulino, na. Adj. Natural de Maule. // 2. Perteneciente o relativo a esta provincia de Chile" (DRAE: 996).

De maw-le-n /maun-le-n/ 'estar lloviendo': '(lugar) donde llueve'. "Maun - llover, y la lluvia: mau - lluvia [...]" (F., Cal.: 550); "Maun, maunn, pluvia imber copiosus, largus, densissimus.item.pluo" (H., Chil. II: 713); "MAHÙN. Llover y la lluvia [...]" (F.-Hern. I: 43); "mawan, s., la lluvia, - $\boldsymbol{n}$, impers. llover" (Aug. I: 133).

Maule es comuna de la VII Región.

"melipillano, na. adj. Natural de Melipilla. U. t. c. s. // 2. Perteneciente o relativo a esta ciudad de Chile o a su provincia" (DRAE: 1005).

De meli /meli/ 'cuatro' y pillan/piKan/, pillañ /piKaj/. Vid. pillán (Cultura mapuche).

Melipilla es provincia, comuna y ciudad de la Región Metropolitana.

"neuquino, na. adj. Natural de Neuquén. U. t. c. s. // 2. Perteneciente o relativo a esta provincia de la Argentina o a su capital (DRAE: 1070).

¿De nagken /na $\mathbf{y k e n / , ~ n a w k e n ~ / n a u k e n / ~ ' ( v e n i r ~ d e ) ~ b a j a d a ~ ( e l ~ r i ́ o ) ' ? ~}$ "Naghn-baxar, descendere [...]" (F., Cal.:574); "Nâ̂, nau, infra: descensus, descensio [...] nâun, descendo [...]" (H., Chil. II: 726); "naqn, n., bajar (n.) (hacia allá)" Aug. I: 146).

Neuquén es ciudad capital de la provincia del mismo nombre, en la Patagonia Argentina.

“ñublense. adj. ñublino. apl. a pers., U. t. c. s." (DRAE: 1085).

"ñublino, na. adj. Natural de Ñuble. U. t. c. s. // 2. Perteneciente o relativo a esta provincia de Chile" (DRAE: ibíd.).

¿De ngüvlen / jïv-le-n/ 'estar tapado', 'oculto'; 'ser estrecho'? “Gùvn desparecerse, ò taparse, ocultarse [...] (F., Cal.: 502-503), "taparse, cerrarse - gvùn" (F., Voc.: 403); "Nuble. Río caudaloso y rápido que atraviesa de E. a O. la provincia a que presta su nombre [...] Sus márgenes son en su primera parte algo quebradas, montuosas y estrechas; después se abren y se extienden en terrenos de más o menos cultivo hasta su término [...]" (Sol - A.: 483); "Ñuble, río de la provincia del mismo nombre, que nace en las vertientes del noreste del Nevado, de Chillán, y un fundo de Chillán Viejo, de gùvlu, participio presente de gvìn, desaparecer, ocultarse $=$ el que se oculta" (Val. II: 116).

Ñuble es provincia de la VIII ${ }^{a}$ Región. 
"pehuenche. (Del mapuche pewen, pino, y che, gente). adj. Se dice del individuo del pueblo amerindio que habitó la zona cordillerana de la actual provincia argentina de Neuquén. Fue el primero en sufrir la influencia lingüística y cultural de los araucanos. U. t. c. s. y m. en pl. // 2. Perteneciente o relativo a los pehuenches. // 3. Chile. Se dice de una parte de los habitantes de la cordillera de los Andes. U. t. c. s. U. m. en sent. despect." (DRAE: 1162). De pewen /pewen/ 'el pino Araucaria araucana' y che /če/. "Pehuen - los pinos de esta tierra, y los pinales: pehuen mapu - la cordillera, ò tierra de los Pehuenches" (F., Cal.: 582-583); "Montes Andes, Pire mapu, pire mahuida. Horum montium incolae, PehuenChe" (H., Chil. I: 365), "Pehuen, pinus. Pehuenche, Indi qui montes Andes incolunt" (H., Chil. II: 740); "pewen, s., el pino (Araucaria imbricata). //- che, s.c., los indios pehuenches, los que viven al pie de la Cordillera, cerca de la región de los pinares" (Aug. I: 172); pewenche, pehuenche, (mapuche) argentino (Coñ.: 83 et pássim); "pewenche [pe'wenče]: Gente que vive en los lugares de la cordillera donde hay pinos araucarias y sus frutos (piñones) (Catr.: 17).

En cronista: "Peguenches [Pegüenches], quiere dezir indio de los Pinares" (Ros.: 197).

"penquista.adj. Natural de Concepción. U. t. c. s. // 2. Natural o relativo a esta ciudad de Chile o a su provincia" (DRAE: 1169).

De Penco, y este de pengu /penu/ 'el árbol peumo'. Vid. peumo (Fitónimos). "Penguco mo casarapuy, lapuy cay - à Penco fue a casarse, y morirse" (F., Arte: 73).

Penco es actualmente comuna y ciudad de la provincia de Concepción, VIII Región.

"picunche. adj. Se dice del individuo de un pueblo amerindio que vivía en el valle central de Chile. U.t. c. s. // 2. Perteneciente o relativo a los picunches. //3. Lengua hablada por los picunches" (DRAE: 1190).

De piku/piku/, pikum/pikum/'norte' y che/če/ : 'gente del norte'. "Picun, el norte" (Vald., Voc.); "Picu,picum-el norte, ò la parte, ò tierra acia [sic] el norte" (F., Cal.: 590); "Norte-picu" (F., Voc.: 375); "Versus Septentrionem, Picu mapu" (H., Chil. I: 365), "Boreas, Aquilo, picu" (H., Chil. I: 507), "Picu, polus arcticus, septentrio, Borealis pars. picun, ad septentrionem vergere: ventum septentrionalem esse" (H., Chil. II: 744); "PICU. El norte, la parte o tierra hacia el norte" (F.-Hern. I: 56); "piku, el norte [...] pikum che, s. c., gente del norte" (Aug. I: 180); "pikumche [pi'kumče]: Gente del norte" (Catr.:17).

"puelche. (Del mapuche puel, oriente). adj. Se dice del individuo de un pueblo amerindio del grupo tehuelche septentrional. U. t. c. s. y en pl. // 
2. Perteneciente o relativo a los puelches. // 3. Chile. Indígena que vive en la parte oriental de la cordillera de los Andes. // 4. Chile. Viento que sopla desde la cordillera de los Andes hacia el poniente" (DRAE: 1260).

De puelche/punelče/ 'gente del Oriente'. "Puelche-nación que está al Oriente de la cordillera [...], Puelcrùv - viento Leste, u oriental" (F., Cal.: 603), "Oriente - puel ple, ò mapu" (F., Voc.: 378); "Indus trasmontanus, puelche" (H., Chil., I: 365), "Solanus, subsolanus, puelche, puelcrùf" (H., Chil. I: 507), "Puelches, qui trans Andes Chilenses habitant [...]" (H., Chil. II: 757); "PUELCHE. Indios pehuenches, nación al oriente de la cordillera nevada" (F.-Hern. I: 60); "pue-lche, s. c. los argentinos" (Aug. I: 188).

En cronistas y J. I. Molina: "[...] los puelches - que son indios serranos, de diferente lengua y traje -[...] (Nuñ. de P. : 635); "Los indios puelches que viven en la otra banda de la sierra nevada [...]" (Ros. I: 212); Puelches: habitantes del cuarto Uthanmapu: hombres orientales (Mol. II: 127, 227).

"rancagüino, na. adj. Natural de Rancagua. U. t. c. s. Perteneciente o relativo a esta ciudad, capital de la provincia de O'Higgins, en Chile" (DRAE: 1287).

De rangka /.sanka/ 'una flor' (Lasthenia obtusifolia, Fam. Compositae [Gu.: 282] ) y wa /wa/: 'lugar donde hay ranca(s)'.

Rancagua es comuna y ciudad capital de la $\mathrm{VI}^{\mathrm{a}}$ Región.

"ranquel. (Del mapuche ranquelche, gente del cañaveral, de ranquel, carrizo de las pampas, y che, gente). adj. Se dice del individuo de un pueblo amerindio del grupo tehuelche fusionado con los araucanos que, entre los siglos XVIII y XIX habitó las llanuras del noroeste de la pampa, el sudeste de San Luis y el sur de Córdoba, en la Argentina. U. t. c. s. // 2. Perteneciente o relativo a los ranqueles. $/ / 3 \mathrm{~m}$. Lengua de los ranqueles, que es un dialecto el araucano o mapuche" (DRAE: 1287).

De rangkül /.sajkïl/ 'carrizo'. "Ranql, carrizo, o caña" (Vald., Voc.); "Rancùl - el carrizo, ò caña" (F., Cal.: 618); "Ranql, carex" (H., Chil. II:

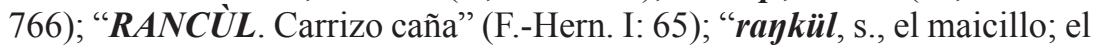
carrizo [...]" (Aug. I: 193); raykül pilko, el maicillo (Coñ.: 95); "rankül el carrizo" (Alon., 1989: 101).

"ranquelino, na. adj. Relativo o perteneciente a los indios ranqueles. U. t. c. s." (DRAE: ibíd).

De ranquel. Vid. supra.

"talquino, na. adj. Natural de Talca. U. t. c. s. // 2. Perteneciente o relativo a esta ciudad y provincia de Chile" (DRAE: 1445). 
De tralka / $\mathbf{t}^{\mathrm{r}}$ alka/, talka /talka/ 'el trueno'; 'el disparo de arma de fuego'. Debe entenderse 'lugar donde truena'. "Talca, el trueno y el arcabuz" (Vald., Voc.); "Thalca, ò talca- proprie el trueno, tomanlo por el arcabuz, escopeta, ò boca de fuego, por el trueno que hacen [...]" (F., Cal.: 635); "Talca, sclopus, sclopetum, item. tonitru [...]" (H., Chil. II: 776); "THALCA pillañ. El trueno" (F.-Hern. I: 71); "Tralka, s., el trueno, la escopeta" (Aug. I: 224); "tralkan tronar, el trueno" (Alon., 1989: 178); "tralkan [t'al'kan]: Trueno" (Catr.: 108).

Talca es provincia, comuna y ciudad capital de la VII ${ }^{\mathrm{a}}$ Región.

"temucano, na. adj. Natural de Temuco. U. t. c. s. // 2. Perteneciente o relativo a esta ciudad de la provincia de Cautín, en Chile" (DRAE: 1462). De temu Vid supra (Fitonimia) y ko/ko 'agua'(s): 'agua(s) de temu'. Temuco es comuna y ciudad capital de la IX ${ }^{\text {a }}$ Región.

\section{VERBOS DERIVADOS}

Achunchar, apercancar, apirgüinarse, aquintralarse, chapecar, copuchar, empiluchar, empotarse, lauchear, maloquear, pirquinear, pololear, trapicarse.

achunchar. (De chuncho). tr. Bol. y Chile. Avergonzar, turbar. U. m. c. prnl. En Perú, u. solo c. prnl" (DRAE: 19).

De chuchu, chuncho. Vid. supra (Zoónimos). Tb. chucho en L., DE.: 318-320.

"apercancar. tr. Chile. Dicho de la humedad: Llenar la ropa de hongos. U. m. c. prnl." (DRAE: 121).

De percán. Vid. supra (otros sustantivos).

“apirgüinarse. prnl. Chile. Dicho del ganado: Padecer pirgüín” (DRAE: 122).

De pirgüín, pirhuín. Vid. supra (Zoónimos).

"aquintralarse. prnl. Chile. Dicho de un árbol o de un arbusto: Cubrirse de quintral. // 2. Chile. Dicho de un melón o de otra planta: Contraer quintral (// enfermedad)" (DRAE: 129).

De quintral. Vid. supra (Fitónimos). 
"chapecar. tr. Chile. trenzar" (DRAE: 351).

De chape. Vid. supra (Otros sustantivos).

"copuchar. intr. Chile. Propalar noticias alarmantes, exagerando los hechos" (DRAE: 441).

“copuchear. intr. Chile. copuchar" (DRAE: ibíd).

De copucha. Vid. supra (Otros sustantivos).

"empiluchar. tr. fest. coloq. Chile. desnudar (// quitar el vestido). U. t. c. prnl." (DRAE: 601).

De pilucho. Vid. supra (Adjetivos).

"empotarse. prnl. coloq. Chile. Dicho de una persona: Sentir atracción sexual por otra" (DRAE: 602).

De poto. Vid. supra (Otros sustantivos).

"lauchear. intr. coloq. Chile. En algunos deportes, jugar limitándose a esperar la oportunidad de marcar un tanto // 2. coloq. Chile. En algunos deportes, robar la pelota al contrario a espaldas de los defensas" (DRAE: 917).

De laucha. Vid. supra (Zoónimos).

"maloquear. (De maloca). intr. Dicho de los indios: Hacer correrías" (DRAE: 967).

De malón, maloca. Vid. supra (Cultura mapuche).

"pirquinear. intr. Chile. dar a pirquén” (DRAE: 1202).

De pirquén. Vid. supra (Otros sustantivos).

"pololear. (De pololo $)$. tr. Bol. y Chile. Mantener relaciones amorosas de cierto nivel de formalidad. // 2. prnl. coloq. Chile. Tratar gentilmente a alguien con el fin de conseguir algo" (DRAE: 1220).

De pololo. Vid. supra (Zoónimos).

"trapicarse. prnl. Chile. Atragantarse con un líquido o con trozos de alimento" (DRAE: 1504).

De trapi /t'api/ 'ají'. trapikan/t'apikan/, trapilkan/trapilkan/ 'guisar con ají'. "'tapi, el agi [sic]” (Vald., Voc.); "Thapi - el agì [sic], thapican, agiaco, o guisado con agì, o guisar [...], Trapilcan, thapiln - guisar con agì, o comerlo solo con sal" (F., Cal.:617); "Tapi, piper rubrum, hispanum. Tapican, hoc pipere aliquid aspergere, condire" (H., Chil. II: 783); "trapi, s., el ají [...]" (Aug. I: 226); "trapi el aj'”" (Alon., 1985: 181). El primer significado en español debe haber sido 'atragantarse con ají'. 


\section{INTERJECCIÓN}

"huichó, interj. Chile. U. para espantar a algunos animales" (DRAE: 838).

Probablemente de wichu /wiču/, /wichü/wiči// 'aparte'. "Huichun, seorsum, separatim. Huichuntun, seligo, sepono" (H., Chil. II: 678); "HUYCHU. Aparte" (F.-Hern. I: 31); "wichu, adv. y adj., aparte [...]" (Aug. I: 259). "Huichi, ó huichó. Interjecciones que se usan para alejar de la presencia las aves domésticas [...]" (Rom., T.3:155); Hemos oído en el Alto Bío-Bío ¡wichü!, ¡wich! para espantar, alejar, aves que intentan entrar a una ruka, o un huerto. Seguramente es usual en el campo, donde las personas suelen tener aves domésticas.

\section{CONCLUSIONES}

- Dado que el mapudungu(n) no ha tenido la importancia de otras lenguas amerindias, como el quechua, el nahuatl, o el maya (quiché), el $\boldsymbol{D} \boldsymbol{R} \boldsymbol{A} \boldsymbol{E}$ incluye un número significativo de voces mapuches.

- Algunas voces no señalan su procedencia y, por lo tanto, solo pueden reconocer su origen quienes conocen el mapudungu(n).

- Algunas voces son de uso general en Chile, pero otras solo son empleadas regionalmente.

- Algunas voces mapuches de uso general en Chile no están incluidas en el $\boldsymbol{D} \boldsymbol{R} \boldsymbol{A} \boldsymbol{E}$ (por ejemplo, bailahuén (planta medicinal), pino (contenido de la empanada chilena), ulmo (un árbol), y otras.

- Sería necesario corregir - en algunos casos- las formas originales consignadas, pues no son del todo exactas.

- $\quad$ No es posible determinar con seguridad, en algunos casos, la forma original de las voces mapuches, por no haber quedado documentadas, o transcritas, de manera correcta. 


\section{REFERENCIAS BIBLIOGRÁFICAS}

Academia Chilena de la Lengua. 2010. Diccionario de uso del español de Chile (DUECh). Santiago, Chile: MN Editorial Ltda.

Alongueo, Martín. 1985. Mapuche Ayer - Hoy. Padre Las Casas, Chile: Imprenta y Editorial "San Francisco".

1989. El habla de mi tierra. Mapudungun. P. Las Casas, Temuco: Ediciones Kolping.

Araya M., Braulio y Guillermo Millie H. 2005. Guía de campo de las aves de Chile. Santiago de Chile: Editorial Universitaria.

Armesto, JuAn Et AL. (eds.). 1995. Ecología de los bosques nativos de Chile. Vicerrectoría Académica y Estudiantil. Universidad de Chile. Santiago: Editorial Universitaria.

Augusta, Félix José DE. 1916. Diccionario Araucano-Español Español-Araucano. Santiago: Imprenta Universitaria.

Cañas Pinochet, Alejandro. 1911. "Estudios de la lengua veliche". En Volumen XI de los Trabajos del Cuarto Congreso Científico ( $1^{\circ}$ Pan-Americano) celebrado en Santiago de Chile del 25 de Diciembre de 1908 al 5 de Enero de 1909. Trabajos de la III Sección Ciencias Naturales, Antropológicas y Etnológicas publicados bajo la dirección del Prof. Carlos Porter [...]. Santiago de Chile: Imprenta, Litografía y Encuadernación "Barcelona". Tomo I: 143 - 330.

Carvallo y Goyeneche, Vicente. 1875. Descripción histórico - geográfica del Reino de Chile. Colección de Historiadores de Chile y documentos relativos a la Historia Nacional. Tomo VIII. Santiago de Chile: Imprenta de la Librería del Mercurio.

Catrileo, María. 1995. Diccionario lingüístico-etnológico de la lengua mapuche. Mapudungun-Español-English. Santiago, Chile: Editorial Andrés Bello.

Cavada, Francisco J. 1914. Chiloé y los Chilotes. Estudios de folklore y lingüistica de la provincia de Chiloé (República de Chile) acompañados de un vocabulario de chilotismos y precedidos de una breve reseña histórica del archipiélago [...] Santiago: Imprenta Universitaria.

1921. Diccionario manual isleño. Provincialismos de Chiloé (Chile). Santiago de Chile: Imp. Yolanda.

Coña, Pascual, 1973. Memorias de un cacique mapuche. Copia facsimilar de "Vida y costumbres de los indígenas araucanos en la segunda mitad del siglo XIX”, con prólogo de Rodolfo Lenz. Santiago: ICIRA.

Febrés, Andrés, 1765. Arte de la Lengua General del Reyno de Chile, con un diálogo ChilenoHispano muy curioso: a que se añade la Doctrina Cristiana, esto es, Rezo, Catecismo, Coplas, Confesionario, y Pláticas; lo más en lengua Chilena y Castellana: y por fin un vocabulario Hispano-Chileno y un Calepino Chileno - Hispano más copioso. Compuesto por el P. Andrés Febrés Misionero de la Comp. de Jesús. Año de 1764. Lima.

- 1846. Diccionario Chileno Hispano, compuesto por el R.P. Andrés Febrés De la C. de J. Enriquecido de voces i mejorado por el R.P. Misionero Fr. Antonio Hernández i Calzada de la órden de la Regular Observancia de N.P.S. Francisco [...] Santiago: Imprenta de los Tribunales.

Gómez de Vidaurre, Felipe. 1889. Historia geográfica, natural y civil del Reino de Chile por el jesuita Felipe Gómez de Vidaurre. Con una introducción biográfica y notas por J. T. Medina. Colección de historiadores de Chile y de documentos relativos a la historia nacional. Tomo XIV. Santiago de Chile: Imprenta Ercilla.

González de NÁjera, Alonso, 1889. Desengaño y reparo de la guerra del Reino de Chile donde se manifiestan las principales ventajas que en ella tienen los indios á nuestros españoles, y los engaños que de nuestra parte han sido causa de la dilación de su conquista, con un 
medio que permite brevedad para acabarla [...] Publicado con una introducción biográfica por J.T. Medina. Santiago de Chile: Imprenta Ercilla.

González Holguín, Diego. 1952. Vocabvlario de la Lengva General de todo el Perv llamada LENGUA QQUICHUA o del Inca [...]. Nueva edición, con un prólogo de Raúl Porras Berrenechea [...]. Universidad Nacional mayor de san Marcos. Publicaciones del Cuarto Centenario. Edición del Instituto de Historia. Lima: Imprenta Santa María.

Gunckel, Hugo, 1959. "Nombres indígenas relacionados con la flora chilena". En BFUCh Tomo XI (1959): 192-327.

Havestadt, Bernardo. [1777] 1883. Chilidúǵu sive Tractatus Linguae Chilensis opera Bernardi Havestadt. Editionem novam immutatam curavit Dr. Julius Platzmann. Vols. I y II. Lipsiae: in Aedibus B.G. Teubneri.

Hoffmann J., Adriana. 1982. Flora silvestre de Chile zona austral árboles, arbustos y enredaderas leñosas. Santiago de Chile: Ediciones Fundación Claudio Gay.

1998. Flora silvestre de Chile zona central. Cuarta edición. Santiago de Chile: Ediciones Fundación Claudio Gay.

(ed.). 2001. Enciclopedia de los bosques chilenos. Conservación Biodiversidad Sustentabilidad. Colección Voces del Bosque. Santiago de Chile: Gráfica Andes.

Lazo, Waldo, 2002. Insectos de Chile. Atlas entomológico. Santiago de Chile: Facultad de Ciencias de la Universidad de Chile.

Lenz, Rodolfo. 1905-1910. Diccionario etimolójico de las voces derivadas de lenguas indíjenas americanas. 2 vols. Santiago de Chile: Imprenta Cervantes.

Mann F., Guillermo. 1954. Vida de los peces en aguas chilenas. Santiago de Chile: Ministerio de Agricultura, Universidad de Chile.

Medina, J. T. 1917. Voces Chilenas de los Reinos Animal y Vegetal que pudieran incluirse en el Diccionario de la Lengua Castellana y propone para su examen a la Academia Chilena. Santiago de Chile: Imprenta Universitaria.

1928. Chilenismos. Apuntes lexicográficos. Santiago: Soc. Imp. y Lit. Universo.

Middendorf, E. W. 1890. Wörterbuch des Runa Simi oder der Keshua Sprache. Leipzig: F. A. Brockhaus.

Molina, Juan Ignacio. 2000. Compendio de la historia geográfica, natural y civil del Reyno de Chile. Primera parte. Libro I, Tomo 1. Colección Biblioteca del Bicentenario. Ex Libris. Santiago: Pehuén Editores.

Molina, Juan Ignacio. 2000. Compendio de la historia civil del Reyno de Chile. Segunda Parte Libro I, Tomo 2. Colección Biblioteca Bicentenario. Santiago: Pehuén Editores.

Morales Pettorino, Félix. 2006. Nuevo diccionario ejemplificado de chilenismos y de otros usos diferenciales del español de Chile. Tomos I-III. Valparaíso: Editorial Puntángeles, Universidad de Playa Ancha.

Muñoz Pizarro, Carlos. 1966. Sinopsis de la flora chilena. Claves para la identificación de familias y géneros. $2^{\mathrm{a}}$ edición. Santiago: Ediciones de la Universidad de Chile.

Muñoz, Orlando; Montes, Marco; Wilkomirsky, Tatiana. 2001. Plantas medicinales de uso en Chile. Química y farmacología. Santiago: Vicerrectoría de Asuntos Académicos, Universidad de Chile.

Nuñez de Pineda y Bascuñán, Francisco. 2001. Cautiverio Feliz. Edición crítica de Mario Ferreccio Podestá y Raïssa Kordić Riquelme. Estudio preliminar de Cedomil Goić. Tomos I y II. Santiago de Chile, Seminario de Filología Hispánica, Facultad de Filosofía y Humanidades, Universidad de Chile.

Olivares, Miguel De. 1863. Historia militar, civil y sagrada de Chile. Colección de Historiadores de Chile y documentos relativos a la Historia Nacional IV. Santiago: Imprenta del Ferrocarril. 
Oroz, Rodolfo. 1966. La lengua castellana en Chile. Facultad de Filosofía y Educación, Universidad de Chile.

OrtúZAR, CAMILO. 1893. Diccionario Manual de locuciones viciosas y correcciones de lenguaje con indicación del valor de algunas palabras y ciertas nociones gramaticales. Santiago: $\mathrm{S}$. Benigno Canavese Imprenta Salesiana.

Osorio, Cecilia. 2002. Moluscos marinos en Chile de importancia económica. Guía para su identificación. Santiago-Chile: Facultad de Ciencias, Universidad de Chile.

Ovalle, Alonso De. 1969. Histórica Relación del Reyno de Chile. Universidad de Chile. Facultad de Filosofía y Educación. Instituto de Literatura Chilena. Santiago de Chile: Editorial Universitaria.

Pérez García, José. 1900. Historia de Chile. Colección de Historiadores de Chile y documentos relativos a la Historia Nacional. Tomo XXII. Santiago de Chile: Imprenta Elzeviriana.

Pérez Matus, Alejandro A. et al. 2004. Guía de peces de Chile. [Santiago de Chile]: OCEANA. Oficina para el Sur y Antártica, $\mathrm{N}^{\circ} 5$.

Real Academia Española. 2001. Diccionario de la Lengua Española. Vigésima segunda edición. Madrid: Espasa - Calpe.

Riso-Patrón, Luis. 1924. Diccionario jeográfico de Chile. Santiago: Imprenta Universitaria.

Rodríguez, Zorobabel. 1875. Diccionario de chilenismos. Santiago: Imprenta de "El Independiente".

Román, Manuel Antonio. 1901-1918. Diccionario de Chilenismos y de otras locuciones viciosas. 5 tomos. Santiago: Impr. de la Revista Católica.

Rosales, Diego De. 1877. Historia General de el Reyno de Chile Flandes Indiano [...] Publicada, anotada i precedida de la vida del autor i de una estensa noticia de sus obras por Benjamín Vicuña Mackennas. T.I.Valparaíso: Imprenta del Mercurio.

SÁnchez, Gilberto. 2005. "La contribución léxica del mapudungu al español de Chile". En UniverSOS 2, 2005: 169-184.

Santelices, Bernabé. 1989. Algas marinas de Chile. Distribución. Ecología.Utilización. Diversidad. Santiago: Ediciones Universidad Católica.

Schuller, R. R. 1907. El Vocabulario Araucano (de 1642-1643). Bibliografía de la Lengua Mapuche o Araucana. Santiago de Chile: Imprenta Cervantes.

Simonetti, Javier A. et al. (eds.), 1995. Diversidad biológica de Chile. Santiago: CONICYT.

Solano Asta-Buruaga y Cienfuegos, Francisco. 1899. Diccionario Geográfico de la República de Chile. Segunda edición corregida y aumentada. Santiago de Chile.

TRIBAldos DE Toledo, Luis. 1863. Vista general de las continuadas guerras: dificil conquista del Gran Reino, Provincias de Chile; desde su descubrimiento por la nación española en el orbe antártico hasta la era presente [...]. Colección de Historiadores de Chile y documentos relativos a la Historia Naciona. IV. Santiago: Imprenta del Ferrocarril.

VAldivia, LuIs DE. 1606. Arte y Gramatica General de la Lengva Que corre en todo el Reyno de Chile, con vn Vocabulario, y Confessonario. Compuestos por el Padre Luys de Valdiuia de la Compañia de Iesus en la Prouincia del Piru [...] En Lima por Francisco del Canto. Año.1606.

[1621]. 1897. Nueve sermones en lengua de Chile por el P.Luis de Valdivia de la Compañía de Jesús. Reimpresos a plana y renglón del único ejemplar conocido y precedidos de una bibliografía por José Toribio Medina. Santiago de Chile: Imprenta Elseviriana.

VAldivia, Pedro DE. 1955. Cartas. Introducción por Jaime Eyzaguirre. Santiago de Chile: Editorial del Pacífico, S. A.

Valenzuela, Pedro Armengol. 1918. Glosario Etimológico De Nombres de Hombres, Animales, Plantas, Río y Lugares, y de Vocablos incorporados en el Lenguaje vulgar, 
aborígenes de Chile y de algún otro país americano. Vols. I y II. Santiago de Chile. Imprenta Universitaria.

Vicuña Cifuentes, Julio. 1915. Mitos y supersticiones recogidos de la tradición oral chilena. Estudios de Folk-Lore Chileno. Santiago de Chile: Imprenta Universitaria.

Vivar, Gerónimo De. 1979. Crónica y relación copiosa y verdadera de los Reinos de Chile (1558). Edición de Leopoldo Sáez - Godoy. Bibliotheca Ibero-Americana. Veröffentlichungen des Ibero-Amerikanischen Instituts Preussischer Kulturbesitz. Herausgegeben von Wilhelm Stegmann. Band 27. Berlin: Colloquium Verlag.

Wilhelm de Moesbach, Ernesto. 1999. Botánica indígena de Chile. Prólogo y edición Carlos Aldunate, Carolina Villagrán. Santiago: Editorial Andrés Bello.

Yrarrázaval Larraín, José Miguel. 1945. Chilenismos. Santiago de Chile. 